STUDIES ON THE HAEMATOLOGY OF SHERP.

Being a Thesis submitted

for the Degree of D.Sc. of Edinburgh University.

$$
\text { by }
$$

Howard Henry Holman, Ph.D., M.R.C.V.S.

$$
\text { D. Sc., } 1946 \text {. }
$$

October, I945. 
FORFWORD.

THESIS.

\section{STUDIES ON THE HAEMATOIOGY OF SHIHEP.}

I. The BIood Picture of HeaIthy Sheep.

2. IndividuaI Daily Variation.

3. Leucocytic Reaction.

4. Erythrocytic and Thrombocytic Pictures and Variation in Physical Attributes.

5. A Survey of BIood Pictures in Sheep Diseases.

SUPPIFMENTARY PAPERS.

In these papers the author was responsible for the haematology and pathology.

BIood Picture of Pining Conditions in Sheep. Stewart and HoIman. (I94X). J. Comp. Path. \& Ther. 54, 4 I.

Blood Changes and Post-Mortem Findings following Intravenous Inoculation of Sheep with CuIture FiItrate of CI. WeIchil, Types A.? C. and D. Gordon, Stewart, HoIman and TayIor. (I94:7). J. Bact. \& Path. 50, 25I.

Observations on the BIood-Picture of Sheep Treated with Phenothiazine. HoIman and Pattison. (I942). Vet. Rec. 54, 215.

A study of the Blood Picture of Lambs Suffering from Parasitic Gastritis. Holman and Pattison. (I94I). Vet. Rec. 53, 49I.

Attempts to Reproduce the Pyaemia associated with Tick-Bite. TayIor, HoIman and Gordon. (I94I). Vet. Rec. 53 , 337. 
The following thesis consists of five papers dealing with the blood-picture of the sheep in health and disease. Four of the papers have aIready been published in the JournaI of Comparative Pathology and Therapeutics and the fifth paper has been accepted for publication by the same journaI.

The work was carried out under the aegis of the Animal Diseases Research Association, Moredun Institute, Gilmerton, Midlothian, and I would Iike to express my thanks to the director, Dr. J. RusseII Greig, M.R.C.V.S., Ph.D., F.R.S.E., for facilities and for his kind encouragement, to Dr. W. S. Gordon, M.R.C.V.S., Ph.D., F.R.S.E. for having taught me how an investigation should be carried out, and to CoI. W. F. Harvey, M.A., M.B., F.R.C.P.Ed., Superintendent of the RoyaI College of Physician's Laboratory, Edinburgh, for his generous heIp and advice on numerous occasions. 
Reprinted from "The Journal of Comparative Pathology and Therapeutics," January, 1944, Vol. 54, No. 1.

Studies on the Haematology of Sheep

I.-The Blood-picture of Healthy Sheep 


\section{STUDIES ON THE HAEMATOLOGY OF SHEEP}

\section{I.-THE BLOOD-PICTURE OF HEALTHY SHEEP \\ BY}

H. H. Holman,

Animal Diseases Research Association, Moredun Institute, Edinburgh.

\section{INTRODUCTION}

THIS work was undertaken to discover the clinical merit of blood examinations in sheep, and to ascertain whether or not any standards could be laid down that would add to the value of the sheep as an experimental animal. This article is limited to the blood-picture of healthy sheep. Some standards for sheep in the United Kingdom have already been set by Fraser (1930). Both Fraser-and Wirth (1931) have summarised the results of workers in other countries.

The sheep used in our investigation were Scottish hill sheepCheviots and Blackfaces - and their crosses with the Border Leicester breed-Half-breds and Grey faces respectively. In addition, five sheep of the Suffolk breed were included. No special test for health was carried out, the sheep being assumed healthy in the absence of obvious signs of disease. With the exception of new-born lambs, it is probable that all sheep were to some extent infested with helminths. The work is based on samples obtained from 171 sheep, of which 22 were bled on several occasions. In Fig. 1 and Table I not more than one sample from any individual has been employed.

\section{TECHNIQUE}

Three criteria were used in selecting a suitable technique, viz. that the methods (1) should be applicable under field conditions; (2) should not be too tedious, if found practicable, to be repeated by other workers; (3) should be sufficiently accurate to indicate the distribution of the normal range.

Procuring Blood Samples.-All sheep were bled from the jugular vein. Fresh blood was used to make blood films and to fill coagulation tubes; oxalated blood was used for the remaining estimations.

Leucocytes.-For the leucocyte count blood was diluted to $1: 20$ with 4 per cent. acetic acid by means of a Piney pipette; cells lying in 2 sq. $\mathrm{mm}$. in both chambers of a haemocytometer were counted; where the difference between the two sides exceeded 10 per cent. a further dilution was counted. For the differential count, films were stained by Leishman's stain and examined by Schilling's four field meander method. The frequent use of the classification of the cellular elements of blood as material for statistical analysis has created a desire for mathematical accuracy to an extent unheard of in the histological examination of other tissues and it has become quite common for pathologists responsible for routine differential counts to look askance at counts which they know to be under 400 or 500 cells, while in some veterinary investigations even 800 cells have been classified. As in this investigation only 200 cells have been classified, it is felt that this requires some justification. The advantage of counting a large number of 
cells is the reduction of the sampling error. Thus where cells represent about 50 per cent. of the total present, the sampling error when 200 cells are counted exceeds seven cells per hundred only once in twenty times; where 400 cells are classified this error is reduced to five cells. To classify 200 cells may take from 20 to 60 minutes, depending on the film; to double this time by classifying another 200 cells on the chance of reducing a large error by two cells would be justified if there existed some condition in which this increased accuracy was vital; no such condition is revealed in textbooks on haematology. In the view of the writer the extra time spent on the examination of the film is out of all proportion to the additional clinical help derived from it, and the more extensive examination is akin to observing the respiration rate for 30 minutes and recording it correct to $0 \cdot 1$ of a respiration. The full error in the technique used will be referred to in a later article when dealing with the variation in individuals.

Leucocytes have been classified according - to Schilling's haemogram. Most cells are easily recognised after reference to a textbook on histology or haematology, and no special description appears necessary. Difficulty may occur, however, in differentiating between atypical monocytes and atypical lymphocytes; points of distinction are given in textbooks but it is more important to have a clear mental impression of the typical cells. A point of discrimination used by the writer is that in lymphocytes the nucleus appears as a flat pancake-like body in which the chromatin is so disposed that it gives an impression of a wrinkled surface, while in the monocyte the nucleus appears lobular with an undulating surface, somewhat resembling an island with hills and valleys. In the few cases where cells have defied classification they have been classified as lymphocytes.

Neutrophils have been classified by Schilling's index, using the following criteria. Nuclei varying in appearance from a shape resembling a biscuit with a piece bitten out to a shape resembling a thick horseshoe with the heels parallel (see Osgood and Ashworth, 1937, cell No. 76) were classified as "Young forms"; nuclei varying from a thick horseshoe shape with the heels opened out to a simple ribbon-like nucleus shaped variously as a U, C, S or W (see Osgood and Ashworth, cell No. 77) were classified as "band forms"; and nuclei 'showing commencing lobulation (see Osgood and Ashworth, cells No. 78 and 79), or ragged in structure (Schilling's "Degenerative band forms") were classified together with all the segmented cells as adult neutrophils or polymorphs.

Erythrocytes.-For the red count, blood was diluted to $1: 200$ with saline by means of a Piney pipette ; at least 250 cells were counted on both sides of the haemocytometer, and where the difference between the two sides exceeded 10 per cent. a further dilution was counted. The packed cell volume was obtained by spinning duplicate small haematocrit tubes for an hour. Haemoglobin content was estimated by a Zeiss Ikon haemometer, a modification of the Sahli method; with this instrument 30 estimations duplicated by the Biochemical Department using a Newcomer disc, showed that in 29 cases the Zeiss Ikon gave the higher reading, the increase averaging at $1.5 \mathrm{~g}$. per $100 \mathrm{ml}$. Where Price-Jones curves were drawn up a modification of.Martin and Hynes method was used and the class intervals varied by 0.5 micron. "Fragility was tested by salt solutions varying by 0.05 per cent. $\mathrm{NaCl}$ and results were read after standing overnight, only the maximum haemolysis was noted. In view of the fact that the erythrocytes fell into only six classes by this method it would appear that a variation of 0.02 per cent. between solutions would be more suitable. 
Thrombocytes.-These were counted unstained in the same preparation as the red count after this had been completed.

Properties of Whole Blood.-Coagulation time was estimated by a capillary tube method in which the tubes were immersed in water at $39^{\circ} \mathrm{C}$. and tested each 30 secs. Viscosity was measured by Denning Watson viscosity tubes and the mean of two readings recorded. Specific gravity was estimated by using mixtures of benzol and chloroform of known densities; the method has been more fully described elsewhere (Stewart and Holman, 1940). Sedimentation was measured by using the apparatus described by Shufflebottom (1935), recording the fall in tubes roughly $7 \mathrm{~mm}$. in external diameter after 24 hours.

\section{GENERAL RESULTS}

For simplicity in treatment the results have been divided into General Results and Variations from the general results. The general results are restricted to sheep sampled between the months of June and December inclusive; lambs born in March or April are therefore excluded and the lowest age represented is approximately three months. These general results are summarised in Fig. 1 and Table I.

For the results to be statistically valid it was necessary to include the variation due to error, and therefore even when complementary measurements or a subsequent estimation indicated that a large error had been made, the original estimation was included when calculating both the mean and the standard deviation. Marked abnormalities, either due to error or to a supposed abnormality in a sheep, have not, however, always been included in the diagram of the distribution, and in a few places single variates lying more than three standard deviations from the mean have been removed and the number of sheep and the maximum or minimum adjusted accordingly.

Léucocytic Picture.-The average leucocyte count, as seen in Fig. 1, was $9 \cdot 2$ thousand with a S.D. of $3 \cdot 1$. This is very similar to Fraser's figures of 8 thousand with a S.D, of 1.9 for ten sheep; in fact, it will be seen from Fig. 1 that the figure of 8 thousand represents the mid-point for the mode of our distribution, but that in our results the curve is somewhat skewed to the left, with two counts of 17 thousand (and one count of 28 thousand omitted from diagram) helping to increase the value of the average.

With regard to the different types of leucocytes, our ratio of neutrophils to lymphocytes average at $24: 67$ is compared with Fraser's ratio of $39: 52$. This shows a considerable difference and, although with one exception Fraser's figures for neutrophils fall within the distribution shown in Fig. 1, a statistical comparison shows a significant difference of the means with $t=5.64$ and $\mathrm{P}=$ less than 0.001 where $\mathrm{n}=121$, and this will be referred to in the discussion. Fraser's mean figure of 3.2 for monocytes falls within our modal class, and his figures for eosinophils with a mean of 4.9 and a S.D. of 6.1 is in close agreement with our results. 
Fourie (1931), working in South Africa on Haemonchus infestation in young sheep (exact age and breed not recorded), gives the results of blood examinations on eleven young sheep believed to be free from worms. Taking the first samples for each of his sheep, the following figures were obtained for leucocytes. The total leucocyte count showed an average of $8 \cdot 4$ thousand and a S.D. of 3.4 ; here the mean is again almost identical with the mid-point of the modal class, with the standard deviation in close agreement with our figure. The ratio of neutrophils to lymphocytes averages $33: 62$; this average for the neutrophils has a S.D. of 18.2 and therefore does not disagree with our result, while the range of 5 per cent. to 71 per cent. for eleven sheep gives a wider distribution than our range for 113 sheep, suggesting our range is not excessive for healthy animals. Fourie's proportion of monocytes, $2 \mp 2$, is close to ours and his proportion of eosinophils $2 \mp 2 \cdot 6$, well within one standard deviation of our results.

The nuclear index has been found to show variation with age, and this is dealt with under the appropriate heading. The point has been made in discussing technique that neutrophil cells with nuclei of mature appearance were classified as polymorphs even when the nucleus was not segmented. In Table I we show the distribution of these cells among 15 four-month-old sheep and it can be seen that the variation in their distribution renders them useless as a sensitive clinical guide, particularly as 15 per cent. of the differential count may represent more than two-thirds of the total neutrophil proportion.

Erythrocytic Picture.-The erythrocyte count, with an average of 11.5 million per c.mm., is higher than Fraser's figure of 10.3 for ten sheep and lower than Fourie's figure of 12.4 for eleven young sheep. The standard deviations are $1.8,1.4$ and 1.6 respectively. This is a fairly close agreement, with the arithmetical mean of these two workers scarcely more than standard deviation from our own.

Our mean figure for haemoglobin was $12 \cdot 4$, with a standard deviation of $1 \cdot 4$, and in the section on technique it was noted that the instrument gave higher readings than a Newcomer disc used in the Biochemical Department. Unfortunately, both Fraser and Fourie give their results in percentages and no comparison is possible. Allcroft (1941), working in England and Wales, gives a mean of 11.5 for ewes and his figures give a standard deviation of 1.5. Wintrobe (1942), using four sheep in America, gives a mean of 12.9, and Wirth, quoting Welsch, records, a range of $11 \cdot 3$ to $12 \cdot 7$. The fact that our haemometer gives a somewhat higher reading than another instrument and the close similarity between our standard deviation and that of Allcroft, suggests that there is little difference in the haemoglobin readings between sheep in Scotland and England or Wales. The mean corpuscular volume in our investigation averaged $27 \cdot 4$ cubic microns, compared with Fourie's figure which works out at $29 \cdot 4$, and Wintrobe's figure of 35 for four sheep; there 
is thus a close agreement between our figures and those of Fourie,

- but Wintrobe's figure falls on the extremity of our distribution curve. Our mean figure for the mean corpuscular haemoglobin concentration is higher than Wintrobe's figure of 35 per cent.; in view of the absence of any information about the sheep he used, this has little importance.

Price-Jones curves were made for only three, sheep, with the following results :-

$\begin{array}{ccccc} & \text { Mean } & \text { Standard } & \text { Minimum } & \text { Maximum } \\ \text { No. } & \text { Diameter } & \text { Deviation } & \text { Diameter } & \text { Diameter } \\ 1 & 4 \cdot 7 & 0 \cdot 38 & 4 \cdot 0 & 6 \cdot 0 \\ 2 & 4 \cdot 9 & 0 \cdot 29 & 4 \cdot 0 & 6 \cdot 0 \\ 3 & 4 \cdot 5 & 0 \cdot 35 & 3 \cdot 5 & 5 \cdot 5\end{array}$

This is in close agreement with Chamberlin (1933), who gives the corpuscular diameter for Australian sheep as lying between 4 and 6 microns, and with Innes and Shearer (1940), who examined a smear from a pregnant ewe in England and found a mean diameter of 4.2 microns and a standard deviation of 0.48 . The present tendency is to rely upon the packed cell volume for an estimation of corpuscular size, for, although the actual classification takes a pair of workers only about 25 minutes once the apparatus is set up, in laboratories where the microscope is continually required for other purposes, the process of fixing and calibrating the microscope in addition to the estimation makes the method tedious. 'Thus, as the Price-Jones curve offers little or no advantage over the estimation of the corpuscular volume, the method was not included in our routine examination.

Few workers have examined the erythrocytic fragility, and our results (Fig. 1) can be compared only to those of Kohanawa and Kadono, quoted by Wirth. These workers found a range of 0.45 to 0.57 per cent. $\mathrm{NaCl}$ for maximum haemolysis with the mean at 0.5 . These results show the cells to be more resistant, but it is possible that this was due to their using young animals.

Thrombocytes.-Platelet counts on 29 sheep gave no indication of a normal curve (see Table I) and as diseases affecting the numbers of these bodies are of little clinical importance in farm animals, other than the dog and the horse, the technique was discontinued. Fraser, counting platelets in stained blood smears, gives a range of 250,000 to 750,000 per c.mm. (number of sheep and S.D. not stated) and a mean of 490,000 . Wirth shows a wide difference among various workers.

Properties of Whole-Blood.-The figures for coagulation time in sheep are shown in Fig. 1. Owing to variations of method they cannot be compared directly with the results of other workers. Wirth quotes the following results. Marek, using a glass-tube method (method of Lee and White) at room temperature, gives a range of 4 to 8 minutes; Haag, using the same method in farm buildings during winter, gives a range of 3 to 5 minutes; Schubert, 
testing blood at intervals with a needle, found traces of fibrin at between 1.25 and 1.5 minutes. When Burker's apparatus at $25^{\circ}$ was used, Kuhar recorded $5 \cdot 1$ to 5.5 minutes and Amendt, 2.5 minutes.

Our results for the sedimentation rate, as assessed by the Shufflebottom apparatus, are shown in Table I.

TABLE I

SUPPLEMENTARY Distributions

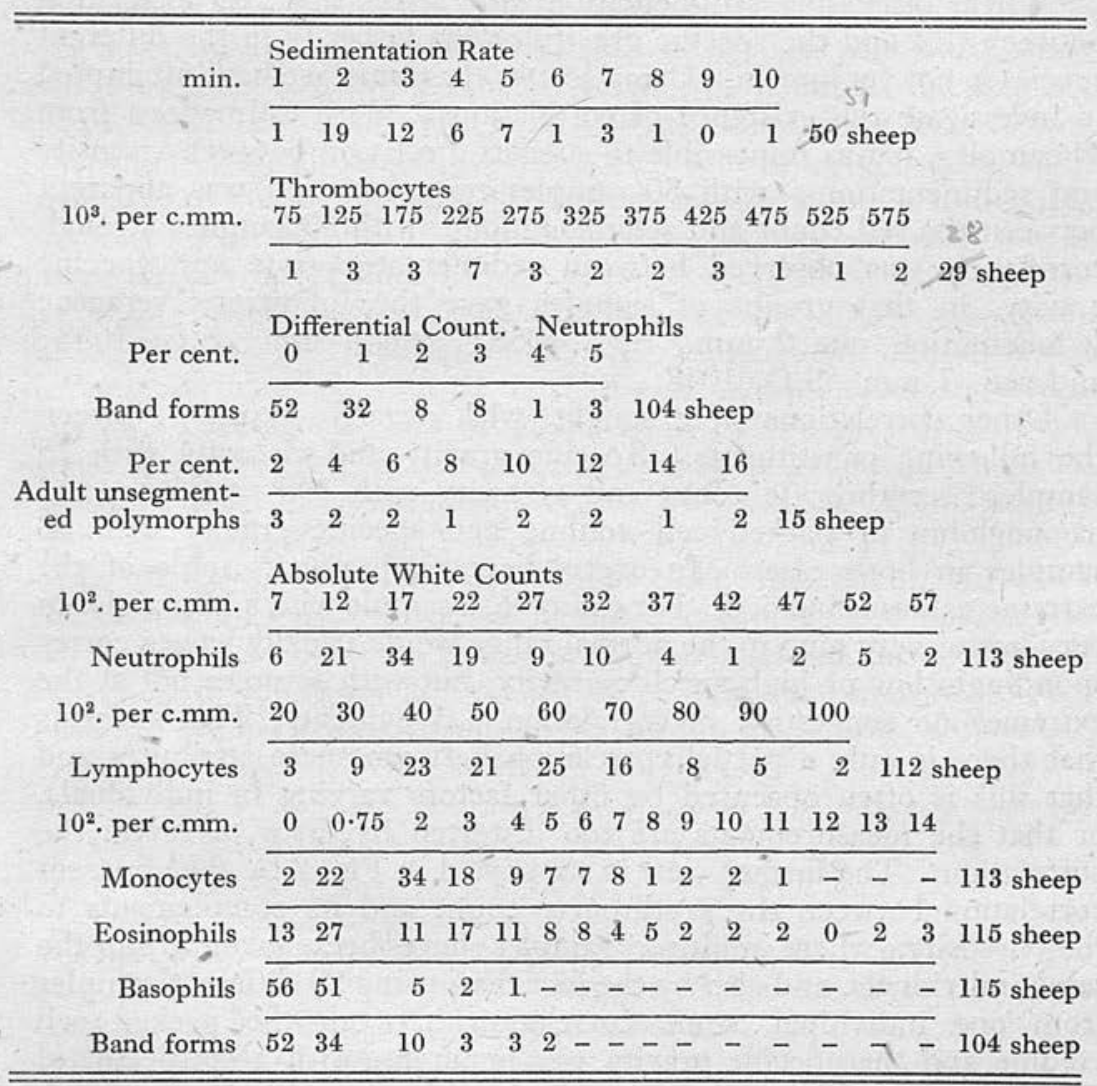

Wirth quotes the results of an investigation by Zott, using undiluted blood in a capillary tube, recording a fall of $1 \mathrm{~mm}$. in 2 hours and $6 \mathrm{~mm}$. in 24 hours. Our experience with this test suggested that it was rather haphazard and that duplicate readings occasionally showed a big difference ; further, where changes were marked, they were concomitant with a change in the erythrocyte count and hence more reliably interpreted by that method. The test appeared to be of little clinical value and was discontinued after preliminary observations.

The specific gravity of sheep's blood (Fig. 1) averaged 1052, 
where water equals 1000 ; Bonard (Wirth) gives a range of 1040 to 1046, figures on the low side of our distribution curve, and Krugers a range of 1026 to 1027 , figures well outside our normal range. The viscosity averaged $5 \cdot 8$ times that of water (Fig. 1). The only other figures we have for viscosity are from Fraser, who gives several estimations made with a Hess viscometer on three sheep; these figures range from $2 \cdot 2$ to $4 \cdot 0$, averaging around $3 \cdot 0$, the majority of his estimations thus being outside our distribution.

Wirth, discussing sedimentation rate, states that the correlation between this and the specific gravity or the viscosity in the different species is not yet known. Using scatter diagrams, we have attempted to investigate the existence of correlations: With estimations from 24 samples, it was impossible to suggest a relation between viscosity and sedimentation; with 50 samples no correlation was apparent between the red count and sedimentation; with 33 samples a rough correlation was observed between sedimentation rate and specific gravity, in that groups of samples gave the following averages: sedimentation rate 2 mm., S.G. 1056 ; sed. 4 mm., S.G. 1053 ; and sed. 7 mm., S.G. 1048.

Other correlations were sought, with negative results, between the following constituents. Specific gravity and viscosity with 75 samples; erythrocyte count and viscosity with 108 samples; and haemoglobin or packed cell volume and specific gravity with 88 samples in both cases. In every diagram, however, some of the extreme values coincided. For example, a sample with a haemoglobin very low or very high in the normal range would usually have a correspondingly low or high specific gravity, but with samples not at the extremes no suggestion of correlation was evident. This suggests that there is only a partial correlation between these attributes and that this is often obscured by other factors varying in individuals, or that the measurements are too distorted by error to reveal the correlation. The former view is supported in Fig. 2 by the apparent correlation between the erythrocyte count and its complements to the viscosity, where multiple samples have been taken from the same individuals, and also by the fact that, using 20 different samples from one individual, some correlation between the packed cell volume and the specific gravity was apparent, with a coefficient of correlation of 0.55 , which is significant where $\mathrm{n}=18$ (Fisher, 1938. Table V.A.).

Thus, summing up, it can be seen that while correlations are apparent when multiple samples are taken from one individual, or a small group of individuals, these correlations are obscured when single samples from a number of individuals are used, and therefore the correlation between these attributes has little practical importance.

VARIATIONS

To give some indication of the variation due to " age or season," a group of four sheep was bled each month for two years. When 
the first samples were taken the sheep were two or four weeks old. Variations Due to Age

Erythrocytes.-From Fig. 2 it can be seen that the red count commenced with a low average of c. $9 \cdot 2$ million in May and again descended to this level during the following April; the highest level was reached during December of the second year. These changes are not believed to be due to age and will be considered under the heading of seasonal variations. The haemoglobin did not agree with the primary low values obtained for the red count for the first few months but thereafter was in close agreement. The packed cell volume showed a big contrast to the red count in the primary samples with the result that the M.C.V. showed a high level for the first month; after this the packed cell volume agreed fairly well with the red count, the M.C.V. varying only by three or four cubic microns. The M.C.H.C. showed surprisingly little variation and is practically a straight line.

These results suggest that although the red count was lower during the first two months of life, the haemoglobin concentration in the blood was kept normal by the larger size of the erythrocytes. The larger average cell size of yoang lambs where growth is rapid, would appear feasible in that macrocytes may be produced whenever haempoiesis is stimulated above a certain rate, but this point calls for confirmation.

By increasing the number of lambs under one month old to 15 (the maximum available) it was found that average cell volume for this group was 35.5 cubic microns as compared to the average of 27.4 given in Fig. 1 for sheep and lambs over three months. From these two groups it was possible to build a four-fold table, as follows :

Lambs under one month ... ... Cell Size Cell Size $\begin{array}{cc}\text { Above } 30 \text { c. } \mu & \text { Below } 31 \text { c. } \mu \\ 12 & 3 \\ 11 & 88\end{array}$

From this, using Yates modification, $X^{2}=34 \cdot 3$ and $\mathrm{P}=$ less than 0.001 . Hence the apparent larger average size of corpuscle in young lambs is unlikely to be due to chance.

The remaining attribute shown in Fig. 2 is the erythrocytic fragility, and this can be seen steadily increasing over a period of ten monthly points. This increase in fragility can also be supported by taking the larger group of lambs, where the average maximum fragility is 0.48 per cent. salt, compared to an average of 0.55 for 37 adult sheep. From these groups significance can be tested by a four-fold table with the following cells :-

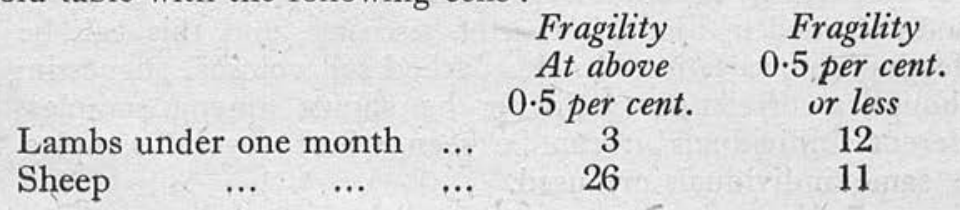


Here, with Yates modification, $X^{2}=6 \cdot 2$, and $\mathrm{P}$ is between 0.02 and 0.01 . Thus the increased resistance of the erythrocytes in young lambs is shown to be significant.

Leucocytes.-Examining the absolute leucocyte counts given in Fig. 2, it can be seen that the neutrophilic "band forms " are present in greater numbers during the first few months of life. This sign of myeloid activity is not unexpected in actively growing lambs, and it was supported by the examination of other groups of sheep as shown in Table II. Inspection of Fig. 2 also suggested a lower proportion of eosinophil cells in young lambs, and this hypothesis was again supported by the group of 15 lambs which gave an average of 1.1 per cent. eosinophils (S.D. \pm 1.9 ) in the differential count compared to 4.2 in Fig. 1. This agrees with Fraser, who recorded a lower percentage of eosinophils in lambs. Both the above variations are significant when tested by the " $t$ " test. Further inspection shows an increase in lymphocytes when the lambs were three or four months old, but this change is not supported by the findings in other lambs of that age and individual records for the four lambs on which the figure was based suggests that this result was due to a chance increase in the leucocyte count of only one or two of the individuals from which samples were taken over the four months

TABLE II

BAND FORMS

\begin{tabular}{ccc}
\hline \hline Age & No. of Lambs & Mean. \\
\hline Under 3 months... & 20 & 1.54 \\
3-8 months ... & 79 & 0.94 \\
9 months and over & 65 & 0.51 \\
\hline \hline
\end{tabular}

Percentage of Band Forms in Differential Count for Various Ages.

involved, different individuals showing this change on different occasions. The decrease in the total count during November has also been attributed to chance, for recourse to larger groups showed that 37 lambs of this age group gave an average of 9.5 thousand compared to an average of 9.4 for lambs bled in July or August. Fraser gives figures for lambs at birth and shows that a reversal in the ratios between neutrophils and lymphocytes occurs between birth and the first week, the first samples showing roughly 80 neutrophils to 30 lymphocytes and the second 50 neutrophils to 60 lymphocytes. We have not had an opportunity to confirm this.

Properties of Whole Blood. - The only property of the whole blood recorded in Fig. 2 is that of viscosity, and this can be seen reflecting the variations in the packed cell volume, suggesting that although a correlation could not be shown among samples from different individuals it can be seen where several samples from the same individuals are used. 


\section{Seasonal Variation}

For the purpose of finding the distribution of the various constituents, histograms were built using coloured cards, marked and cut to denote various attributes. In building histograms of the erythrocytes and their complements, haemoglobin and packed cell volume, it was observed that the lowest values were from sheep sampled in February and March. To avoid this bias, due to this seasonal factor, sheep sampled during the spring, and the month immediately preceding or succeeding it, were not included among the population of Fig. 1 or Table I.

The mean figures for haemoglobin for the four seasons were as follows : Spring, $9 \cdot 6 \mathrm{~g}$. (26 sheep); summer, $11.7 \mathrm{~g}$. (38 sheep); autumn, $10 \cdot 6 \mathrm{~g}$. (34 sheep); and winter, $11 \cdot 7 \mathrm{~g}$. (60 sheep). That the lower figures for February and March were unlikely to be dependent on chance alone can be shown by a chi squared test, with the following cells :-

Haemoglobin

Values above $11.0 \mathrm{~g}$.

Sheep samples in February and March Sheep shown in Fig. 1

$$
2
$$

99

\section{Haemoglobin Values below $11 \cdot 0 \mathrm{~g}$.}

Using Yates modification, $X^{2}=52 \cdot 3$ and $\mathrm{P}$ is less than 0.001 . No other indications of seasonal variation are indicated by Fig. 2, but it will be noticed that the decline in the erythrocytic values in autumn coincides with the lower average of 10.6 for 34 sheep, as compared to 11.7 for the remaining two seasons. This change was not apparent in the first year when the animals were lambs. The group containing sheep bled in February and March consisted of animals kept at Moredun Institute and bled in 1938, 1940 and 1942. The group bled in the autumn consisted of animals bled in 1941 and 1942. This variation is referred to in the discussion.

\section{Variations Due to Sex.}

Wirth states that male animals show a higher erythrocyte count and haemoglobin values than females, and that castrated males lie between the two. In building histograms no difference due to sex was noticed and, in addition, we were able to select from our samples 18 pairs of castrated and female sheep, comparable in that they were running in the same flock and were of the same age and breed. Our results, which were obtained in this way from selected sheep, are summarised in Table III, in which the averages for the different constituents in the two groups are given. Comparison shows that the differences between the two groups, if existent, are not of practical importance and that Fig. 1 can be used for either females or castrated males without introducing any great error. 
TABLE III

18 Pairs of Comparable Castrated Male and Female Animals

\begin{tabular}{|c|c|c|c|c|c|c|c|c|}
\hline & M. & F. & & M. & F. & & M. & F. \\
\hline $\begin{array}{l}\text { R.C. ... } \\
\text { W.C.... } \\
\text { Band .... } \\
\text { Poly. ... } \\
\text { Lymph. } \\
\text { Mono. }\end{array}$ & $\begin{array}{c}11 \cdot 3 \\
12 \cdot 3 \\
0 \cdot 75 \\
21 \\
71 \\
2 \cdot 75\end{array}$ & $\begin{array}{c}10 \cdot 5 \\
9 \cdot 7 \\
0 \cdot 33 \\
22 \\
70 \\
2.85\end{array}$ & $\begin{array}{l}\text { Eosin. } \\
\text { Bass. ... } \\
\text { Coag.... } \\
\text { Frag. ... } \\
\text { S.G. ... }\end{array}$ & $\begin{array}{l}3 \cdot 5 \\
0 \cdot 7 \\
2 \cdot 2 \\
0 \cdot 55 \\
1052\end{array}$ & $\begin{array}{l}4 \cdot 0 \\
0 \cdot 53 \\
2 \cdot 3 \\
0 \cdot 6 \\
1052\end{array}$ & $\begin{array}{l}\text { P.C.V. . } \\
\text { Visc. } \quad \ldots \\
\text { Hb } \quad \ldots \\
\text { M.C.V. } \ldots \\
\text { M.C.H.C. }\end{array}$ & $\begin{array}{c}30 \\
5 \cdot 4 \\
12 \cdot 1 \\
27 \\
40\end{array}$ & $\begin{array}{c}30 \\
5 \cdot 8 \\
11 \cdot 7 \\
29 \\
39\end{array}$ \\
\hline
\end{tabular}

\section{Variation Due to State of Exertion.}

It was thought desirable to find out whether sheep caught quietly in a small pen showed any variation in haematological values from those driven in from near-by fields and excited to some extent by the efforts of a sheep dog. Three sheep were therefore bled with the minimum of excitement, and then chased round a field by an active sheep dog for three minutes. The panting sheep were bled as soon as they returned to the pen, and re-bled an hour later. There was little or no change in any of the constituents shown in Fig. 1 nor was the number of band forms increased.

\section{Variation Due to Breed}

In building histograms for the various attributes of sheep's blood no difference due to breed was observed.

\section{DISCUSSION}

The only definite disagreement between our results and those of Fraser is the ratio of neutrophils to lymphocytes, for he recorded that neutrophil cells averaged 39 per cent. of the differential count compared to our figure of 24 per cent. The possibility exists that his sheep were suffering from a heavier worm infestation than ours; the complementary explanation that our sheep were suffering from a neutropenia due to some chronic debilitating condition is unlikely in view of the various ages and environments of the sheep used in our investigation. Fraser's method of examining smears is not given, but our own occasional observations confirm those of Hay (1942) that an uneven distribution is unlikely to cause marked error. The possibility that neutropenia is an effect of the colder environment is not substantiated by any definite seasonal variation in Fig. 2. Fraser does not state the breed of his sheep, but it seems unlikely from our experience that this would be responsible for the difference.

Lambs on the day of birth have not been used in this investigation, but Fraser shows a decrease in erythrocytes from 12 million at birth to 10.5 after one week, and quotes other authors who record a higher count for lambs. Owing to the seasonal variation shown 
by our sheep in February, March and April, we were unable to add any useful evidence to this contention, except to say that while the adult sheep showed unexpectedly low haemoglobin figures for these months, the figures for lambs born during March and April were much higher (due, as has been explained, to the fewer but largersized erythrocytes). Thus, if no seasonal variation existed, presumably the figures for lambs would exceed those found in the adult during summer.

The seasonal variation that has been pointed out has not been investigated and our attempt to explain it is pure speculation. It has been noticed in two instances that pining sheep at Moredun did not commence to thrive until the growth of fresh grass at the end of May or in the beginning of June even although the factor causing their poor condition was removed some months previously. June or July therefore appears to be the time of nutritional abundance when the haemoglobin content of the blood reaches its highest absolute level. With autumn the optimum period terminates and a slight decline in the haemoglobin value commences. In winter the autumnal fall is followed by a slight rise but this is not sustained, a much greater fall in haemoglobin being observed in spring. Climatic conditions during these months make it impossible to keep the feeding at an optimum level and the fall in spring is most probably due to inanition since the rise in haemoglobin commences with the flush of early summer grass. Some proof of this is vouchsafed by the higher levels of haemoglobin shown in Fig. 2 during the spring of 1943, which was mild, and followed an exceptionally mild winter.

\section{SUMMARY}

To set standards for healthy sheep so as to facilitate the interpretation of alterations due to disease, samples from 171 sheep were examined. The distributions for animals sampled during the summer, winter and autumn seasons were recorded and are shown in Fig. 1 and Table I.

After a short trial the following estimations were discarded as having little practical value: sedimentation rate; counting of platelets ; and the estimation of Price-Jones curves. It was noted that the fragility test used was open to criticism as the variation of 0.05 per cent. $\mathrm{NaCl}$ between tubes limited healthy sheep to only six variates. The desirability of placing Schilling's "Degenerative band forms," and other lobular but unsegmented neutrophils, among the adult group when making a nuclear index, is pointed out.

Lambs under one month old were shown to have erythrocytes more resistant to haemolysis with salt solution and of a larger mean corpuscular volume; the probability of lambs having a higher erythrocyte count is discussed. Lambs showed a higher percentage of band form neutrophils and a lower percentage of eosinophils.

A seasonal variation was observed in that during the spring of some years a significant decrease in haemoglobin occurred. No 
difference in the blood picture was proved between females and castrated males, resting animals and those just previously exerted, or among the different breeds used in the investigation.

The results showed no disagreement of a practical nature with those of Allcroft for the haemoglobin values of ewes in England and Wales, or with Fraser's blood-picture for English sheep, with the exception of the neutrophil-lymphocyte ratio, which it is speculated, may perhaps have been due to a larger worm burden among Fraser's sheep.

\section{REFERENCES}

Allcroft, W. M. (1941). F. agric. Sci., 31, 320.

Chamberlin, W. E. (1933). Aus. vet. F., 9, 2.

Fisher, R. A. (1938). Statistical Methods for Research Workers. 7th Edit. Oliver and Boyds Edinburgh.

Fourie, P. J. J. (1931). Rep. Director vet. Research, Dept. Agric., Onderstep., S. Africa, 17, 495.

Fraser, A. C. (1930). Rep. Inst. anim. Path., Univ. Camb., 1, 114.

Hay, S. (1942). Edin. med. F., 49, 200.

Innes, J. R. M., and Shearer, G. D. (1940). F. comp. Path., 53, 1.

Osgood, E. E., and Ashworth, C. M. (1937). Atlas of Haematology. Stacey Inc: San Francisco, U.S.A.

Shufflebottom, G. (1935). Lab. F., 7, 433.

Stewart, J., and Holman, H. H. (1940). Vet. Rec., 52, 157.

Wintrobe, M. M. (1942). Clinical Haematology. Kimpton : London.

Wirth, D. (1931). Grundlagen einer Klinischen Hämatologie der Haustiere. Urban \& Schwarenberg: Berlin.

\section{Works Consulted}

Schilling, V. Trans. by Gradwohl, R. B. H. (1929). The Blood Picture Kimpton: London.

Whitby, L. E. H., and Britton, J. C. (1937). Disorders of the Blood. 2nd ed. Churchill: London.

Mainland, D. (1938). The Treatment of Laboratory and Clinical Data. Oliver \& Boyd: London.

Goldner, F. M., and Mann, W. N. (1938). The Statistical Error of the Differential White Count. Guy's Hospital Reports, 88, 54.

[Received for publication fune 2nd, 1943] 

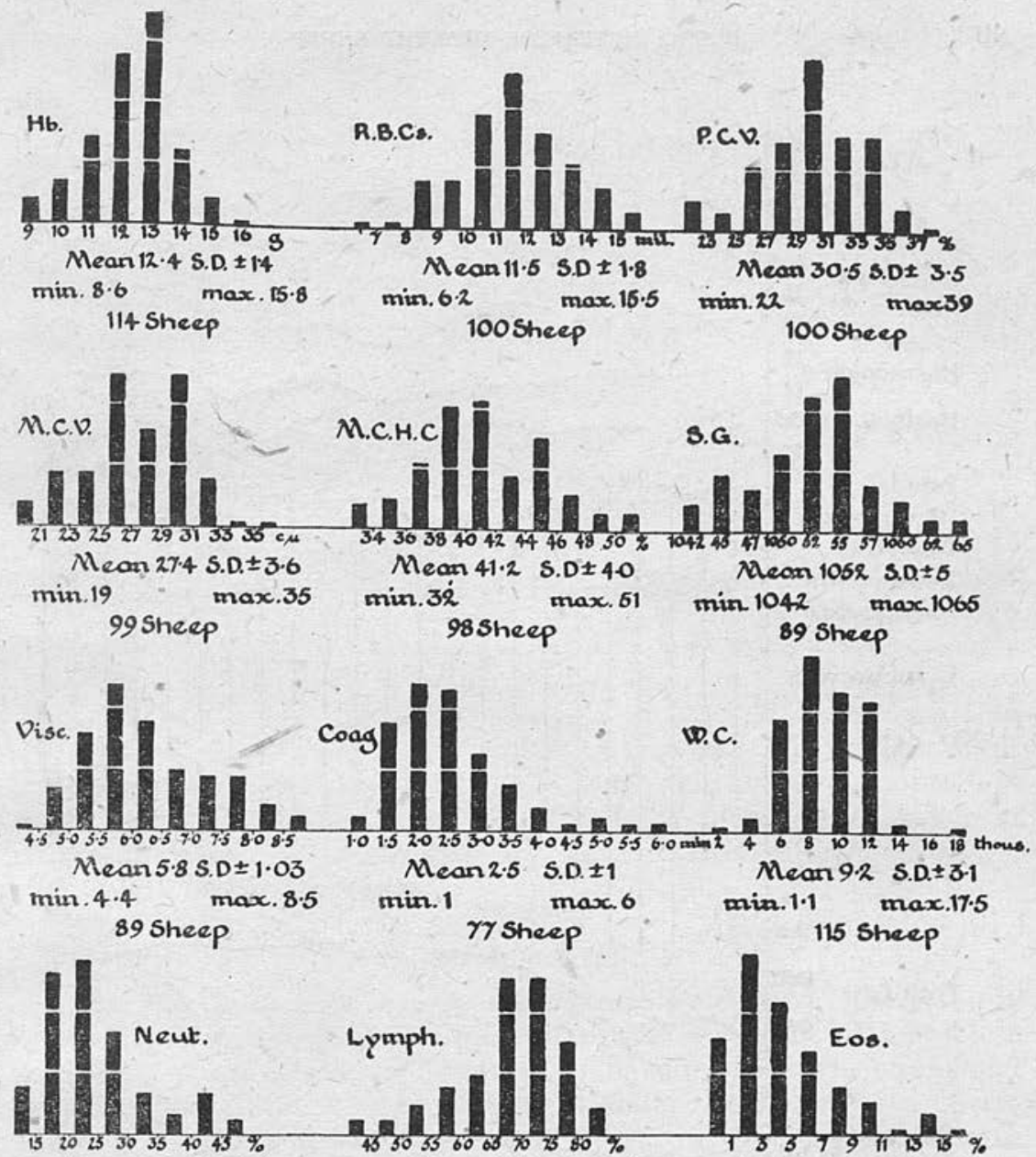

Mean 24 S.D. 8.7

mix $11 \quad \max .47$

113 Sheep

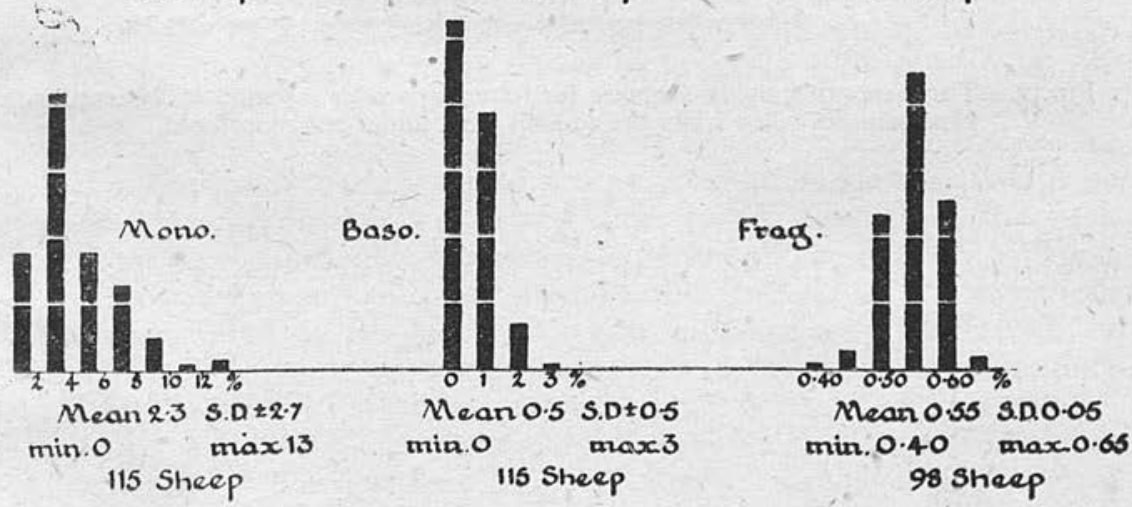

Fig. 1.-Distribution of the principal constituents of the blood of sheep between the months of June and December. White lines mark levels of 10 per cent. 


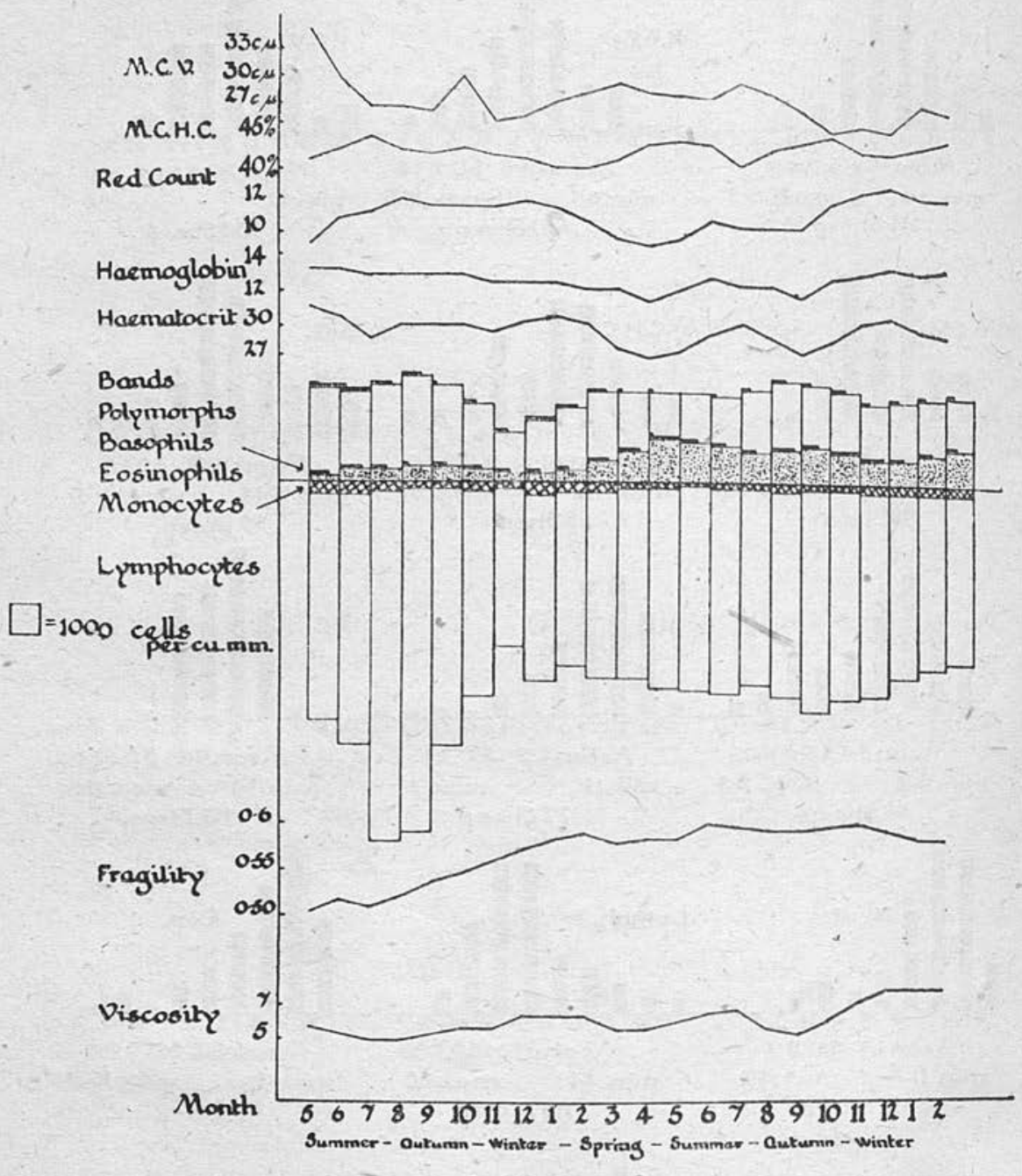

Fig. 2.-Three-month moving averages for four sheep over a period of 24 months. First samples taken when the animals were under one month old. 
Vol. 54. No. 3. July, 1944.

\title{
STUDIES ON THE HAEMATOLOGY OF SHEEP
}

\author{
II. INDIVIDUAL DAILY VARIATION \\ $\mathrm{By}$ \\ H. H. Holman, \\ Animal Diseases Research Association, Moredun Institute, Edinburgh
}

\section{INTRODUCTION}

THE normal ranges for the various attributes of the blood of healthy sheep, as given in the first article (Holman, 1944), are all very wide. Hence it is necessary to point out that variations occurring in serial observations on individual sheep may be significant even though they fall well within the range derived from a considerable number of animals. For example, although the normal range for haemoglobin extends from 8.6 to $15.8 \mathrm{~g}$. per $100 \mathrm{ml}$., it is exceedingly unlikely for the same sheep to show a figure as high as $15 \mathrm{~g}$. one day and a figure as low as $9 \mathrm{~g}$. the next day. In view of this it is desirable to form some estimate of the range to be expected when observations are made on successive days on the same animal and the object of this paper is to obtain such an estimate of the expected range of the differences of such pairs of consecutive readings when no abnormal factor intervenes.

\section{EXPERIMENTAL}

To determine such a range some suitable standard of probability must be adopted - as in all similar statistical problems. No absolute upper limit can in general be set to the uncontrollable variations that may be found in one animal within 24 hours ; it is necessary, therefore, to be content to find a value which, in the absence of some interfering factor, on the average will be exceeded only in some small fraction of all observations; the smaller the fraction chosen the greater this value will be. For this paper the value so calculated has been termed the "Maximum Admissible Difference," or M.A.D., with the implied probability added in brackets. Thus M.A.D. (99 per cent.) would represent the maximum difference between two readings on the same animal that is likely to occur when no interfering factor has intervened, or, more precisely, a difference that would be exceeded only once in a-hundred times in the absence of any such interfering factor. In biological experiments it has been found advisable for many purposes to take the fraction as one-twentieth (corresponding to 95 per cent.) and to consider a difference or deviation as significant when it lies beyond the limit corresponding to this fraction. This means that the limit is exceeded in untreated animals only about once in twenty observations. Any effect of less magnitude is dismissed as probably due to the normal biological variation and experimental error, whilst any greater effect is con- 
sidered more or less significant according to the extent the limit is exceeded and the circumstances of the experiment.

The problem, then, is to calculate a value that is likely to be exceeded once in twenty times, at the most, by the difference between two observations made at an interval of 24 hours. There will be such a value for each blood constituent examined, and it will be dependent largely on the experimental technique used, the skill of the operator, and probably such factors as the condition and environment of the sheep. The M.A.D.s given in Table I, therefore, apply only when the technique described in the previous paper is carried out and the general conditions applying in that work are satisfied.

To calculate these M.A.D.s the method given by Mainland (1938) has been employed. In Table I (part 1), column 1 denotes the item, column 2 the number of sheep from which data are obtained, column 3 the standard deviation of the 24-hour differences in individual sheep, and column 4 the M.A.D. (95 per cent.) calculated by multiplying the standard deviation given in column 3 by the appropriate value in the table of " $t$ " (Fisher and Yates, 1943), corresponding to a probability of one-twentieth ; the use of the tableof " $t$ " for this purpose is suggested by Mainland (1938) and for this $n$ is taken as the number of sheep given in column 2 .

TABLE I

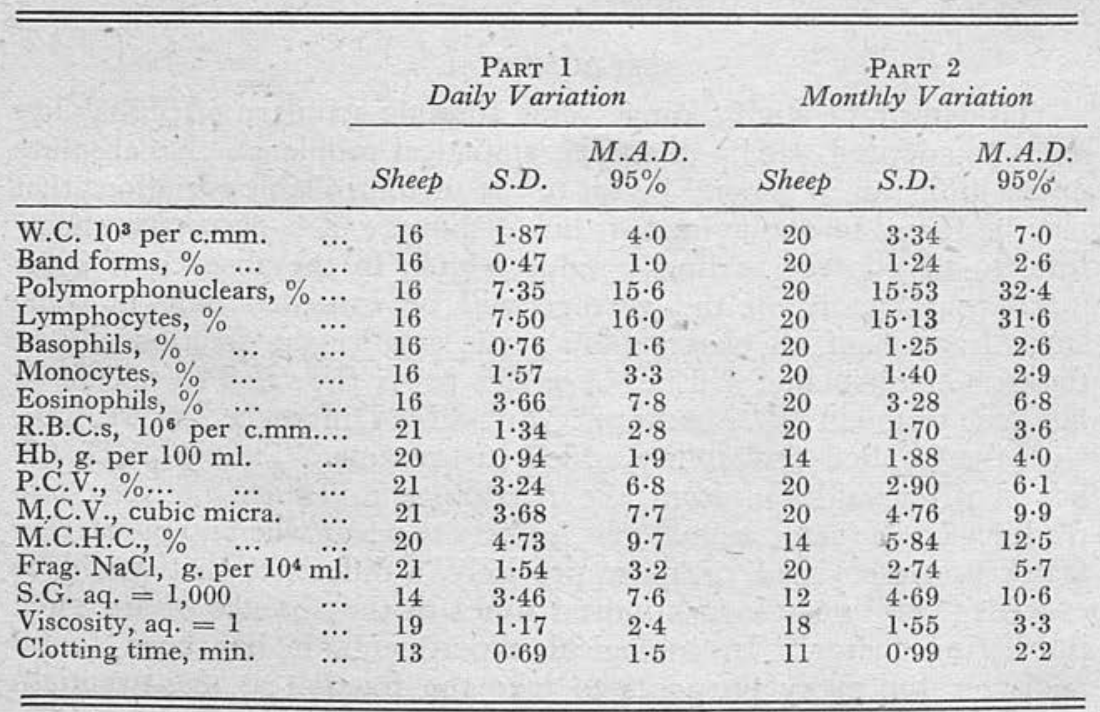

Table I (part 2) refers to pairs of observations made at an interval of not 24 hours, but one month. As would be expected, for most items the M.A.D.s are, here, somewhat greater but there are three exceptions, namely, eosinophils, monocytes, and the packed cell volume. It must, however, be remembered that these M.A.D.s 
themselves are subject to considerable errors of sampling and of experiment, and such accidental errors may account for the monthly range being somewhat less than the daily range for these three items. In other words, the results are consistent with the monthly M.A.D. being at least equal to the daily one. It should be stated that for some of the items in Table I (part 1) the results were calculated from data that included a few sheep bled at an interval of 48 hours, but inspection showed that these figures were statistically homogeneous with the 24 -hour data, and did not significantly alter the results.

Among the items in Table I the experimental error in estimation is highest in the classification of leucocytes by the differential count, and as the leucocytic picture is most important from the clinical point of view, an estimation of the experimental error alone has been made for comparison. It can be seen from the results given in Table II that while the total leucocyte count and the estimation of eosinophils differ significantly from those of the daily estimation, the M.A.D. (95 per cent.) for the monocytes is by chance larger than that for the daily variation, showing that in the case of this type of cell the technique is quite inadequate for the detection of small variations due to biological rhythm.

TABLE II

EXPERIMENTAL ERror in Estimation of Leucocytes

Based on 20 Duplicates

\begin{tabular}{lllllr}
\hline \hline & & & S.D. & M.A.D. $95 \%$ \\
\hline W.C., $10^{3}$ per c.mm. & $\ldots$ & $1 \cdot 13$ & $2 \cdot 3$ \\
Neutrophils* & $\ldots$ & $\ldots$ & $5 \cdot 74$ & $11 \cdot 9$ \\
Lymphocytes & $\ldots$ & $\ldots$ & $6 \cdot 49$ & $13 \cdot 6$ \\
Basophils & $\ldots$ & $\ldots$ & $\ldots$ & $0 \cdot 74$ & $1 \cdot 5$ \\
Monocytes & $\ldots$ & $\ldots$ & $\ldots$ & $2 \cdot 40$ & $5 \cdot 0$ \\
Eosinophils & $\ldots$ & $\ldots$ & $\ldots$ & $2 \cdot 00$ & $4 \cdot 2$ \\
& & \\
\hline \hline
\end{tabular}

SUMMARY

A table is given as a guide to the daily (and monthly) variation in various haematological constituents of the blood of individual sheep. These tables give the "Maximum Admissible Difference" for the various constituents; the M.A.D. (95 per cent.) being such that the difference of two readings made on the same sheep at an interval of 24 hours (Part 1, Table I) or one month (Part 2, Table I) should not exceed this value in more than 5 per cent. of the $\mathrm{c}$.ses in the absence of some interfering factor. When the M.A.D. is exceeded, the existence of some effect other than sampling and experimental errors becomes probable, provided that the technique described by Holman (1944) is strictly adhered to. 


\section{ACKNOWLEDGMENT}

I am indebted to Dr. W. O. Kermack, of the Royal College of Physicians Laboratory, Edinburgh, for considerable help in the presentation of this paper and for the use of the term "Maximum Admissible Difference."

\section{REFERENCES}

Fisher, R. A., and Yates, F. (1943). Statistical Tables for Biological, Agricultural and Medical Research. 2nd edit. Edinburgh: Oliver and Boyd.

Holman, H. H. (1944). F. comp. Path., 54, 26.

Mainland, D. (1938). The Treatment of Laboratory and Clinical Data. Edinburgh: Oliver and Boyd.

\section{Consulted}

Goldner, F. M., and Mann, W. N. (1938). The Ståtistical Error of the Differential White Count. Guy's Hospital Reports, 88, 54.

[Received for publication February 26th, 1944] 
Reprinted from "The Journal of Comparative Pathology and Therapeutics." Vol. LIV. No. 4. October, 1944.

\title{
STUDIES ON THE HAEMATOLOGY OF SHEEP
}

\author{
3. LEUCOCYTIC REACTIONS \\ B By \\ H. H. HOLMAN \\ Animal Diseases Research Association, Moredun Institute, Edinburgh
}

\section{INTRODUCTION}

THE leucocytic picture has become established as an aid to diagnosis and prognosis, but the degree of its value - as Harvey (Harvey and Hamilton 1932) pointed out-is still a matter of controversy. This article is confined to a description of various types of reaction and to setting arbitrary standards where these appear to be practical.

The technique used in this investigation and the results obtained from healthy sheep were given in the first article (Holman, I944a), but for convenience the results for leatcocytes are repeated as percentiles, in which the figure limiting each Io per cent. is given; the limit excluding the first 5 per cent. at each end has also been indicated, the respective figures being given in brackets (Table I).

In the second article (Holman, I944b), it was pointed out that the wide distribution of the normal range allowed small reactions to be overlooked and a Maximum Admissible Difference was calculated for each type of cell. M.A.D.s for daily variation were included and it was accepted that a variation greater than this coefficient was to be taken as evidence that the normal biological variation over 24 hours had been disturbed. These coefficients and the ones for error have been appended to Table $\mathrm{I}$.

TABLE I.

Distribution and Variation of LeUCOCytes.

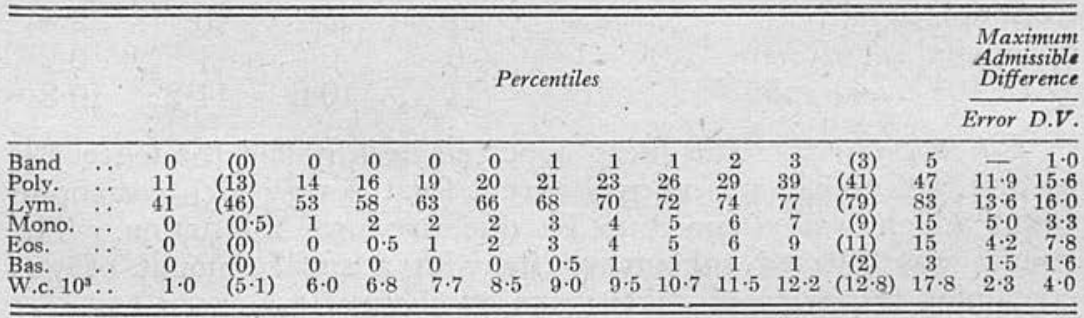

Additional figures, limiting the first 5 per cent. at each end, are given in brackets. D.V. rofers to daily variations.

\section{TYPICAL REACTIONS}

Schilling (1929) formulates the fundamental leucocytic reaction to infections or other irritations, as consisting of three phases. The first phase is the neutrophilic invasion phase (or battle phase) in whieh there is an increase in the number of neutrophil cells, their numbers including an increased proportion of metamyelocytes (band forms and possibly young forms) a change known as a "shift to the left," while the eosinophils tend to disappear. The second 
phase is termed the phase of monocytic defence; here the neutrophil cells recede in numbers and show a smaller proportion of immature forms, a small number of eosinophils return and the monocytes increase in numbers to above the normal level. The third phase is the phase of lymphocytic recovery; here with the-decrease in neutrophils there is a relative lymphocytosis accompanied by an eosinophilia.

Working on sheep it has been found that these phases are similar to, but not identical with, those described by Schilling. The invasion phase is precisely similar but the defence phase is better classified by the decrease in the neutrophil reaction rather than by an increase in monocytes, for this is irregular in its appearance, and similar increases may occur in the invasion phase or in the recovery phase. In contrast to man, the recovery phase is different for sheep, the stage of relative lymphocytosis is not apparent and a small increased proportion of neutrophil cells may persist for days or even weeks after the recovery of the animal. This phase is therefore better classified by the appearance of eosinophils in numbers above the average or by an eosinophilia, often accompanied by the appearance of one or two basophils. Examples of different degrees of reaction caused by experimental injections of Staphylococcus aureus are depicted in Fig. 1, and these will now be discussed.

\section{Mild Transient Reaction}

\begin{tabular}{lllrrrrc}
\multicolumn{1}{l}{ Types of Experiment } & $\ldots$ & 1 1st & 2nd & 3rd & 4 th & 5 th \\
Band forms & $\ldots$ & $\ldots$ & 0 & 6 & 2 & 1 & 1 \\
Polymorphs & $\ldots$ & $\ldots$ & 31 & 74 & 59 & 56 & 47 \\
Lymphocytes & $\ldots$ & $\ldots$ & 43 & 26 & 26 & 27 & 33 \\
Monocytes & $\ldots$ & $\ldots$ & 3 & 3 & 8 & 5 & 9 \\
Eosinophils & $\ldots$ & $\ldots$ & 22 & 1 & 5 & 10 & 9 \\
Basophils $\ldots$ & $\ldots$ & $\ldots$ & 1 & 0 & 0 & 1 & 0 \\
W.C. $10^{3} \ldots$ & $\ldots$ & $\ldots$ & $6 \cdot 3$ & $14 \cdot 0$ & $10 \cdot 6$ & $11 \cdot 2$ & $10 \cdot 8$
\end{tabular}

Pre-inoculation. The sheep appeared healthy and the leucocytic picture (see above) was normal except for the very high eosinophil count which was assumed to be due to worm infestation. The animal was injected subcutaneously with a small amount of pus containing staphylococci taken from an abscess in a sheep.

Invasion Phase. On the second day the sheep was dull and showed a temperature of $104 \cdot 8^{\circ}$ but retained its appetite. The total leucocyte count remained just within the range shown in Table I, but had increased by over two M.A.D.s for daily variation, a circumstance considered to be highly significant. Both polymorphs and band forms had increased to figures outside the limits in Table I, indicating a relative neutrophilia with a shift to the left. The monocytes showed no change, but the eosinophils had decreased to only 1 per cent., a change exceeding twice the M.A.D. and therefore highly significant. (Fig. 1, example 1.) 
Defence Phase. On the third day the sheep appeared healthy but its temperature was $104^{\circ}$. The total count had fallen to well within the normal range and the neutrophilia was receding with a decrease in metamyelocytes; the monocytes showed an increase - considered just significant-and there was a slight increase in eosinophils.

Fig. 1

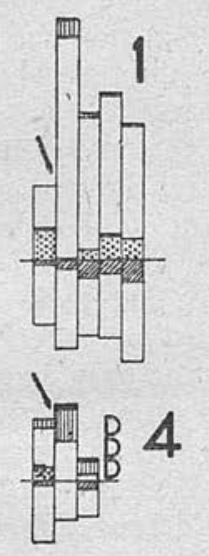

\section{TYPICAL.}
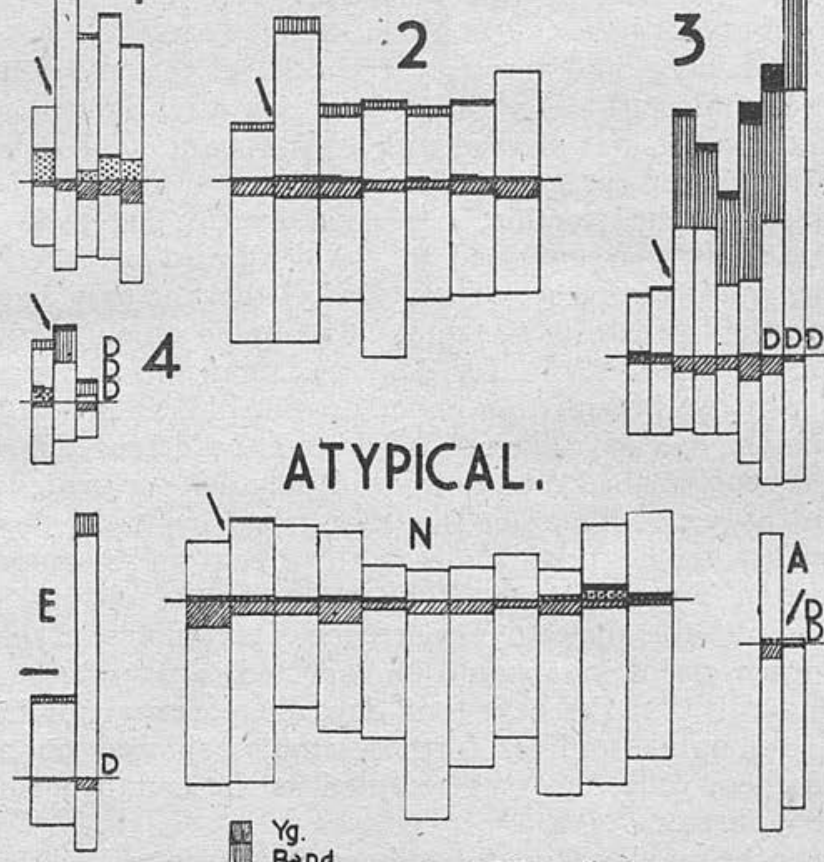

Granular

Non-granular

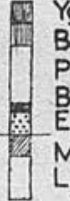

Yg.

Band. $\quad-1000$ Cells per c.mm.

It is regretted that owing to technical difficulties in reproduction low eosinophile counts have appeared as a black line.

Recovery Phase. On the fourth day the sheep appeared normal with a temperature of $103 \cdot 6^{\circ}$. The total count was roughly the same but there was an insignificant decrease in the neutrophilia and in the proportion of monocytes. The recovery phase was denoted at this time by the increase in eosinophils which returned to a high figure. On the fifth day there was little change but the neutrophils had now decreased to a point just within the highest limit of the normal range and the eosinophils remained at a high level. 


\section{Mild Prolonged Reaction}

The figures for this reaction were published in detail as differential counts (Taylor, Holman and Gordon, 1941). They are given here as a composite diagram consisting of the averaged absolute counts for three sheep. (Fig. 1, example 2.) The sheep were injected subcutaneously with $1 \mathrm{ml}$. of a culture of Staph. aureus matched to No. 2 tube of Brown's scale.

The pre-experimental blood picture was normal, having a total count of 11.0 thousand with 33 per cent. neutrophils of which 1.6 per cent. were band forms. No blood sample was taken on the day following inoculation and therefore the peak of the invasion phase may have been lost, but on the second day after inoculation the neutrophilic reaction was marked with a total count of 14.7 thousand and a neutrophil percentage of 48 , of which seven were band forms. The mildness of the reaction, suggested by the smallness of the "shift to the left," is confirmed by the continued presence of the eosinophils, and it can be seen from Table I that the only significant changes are the increase in the total count by an amount exceeding the limit set by the M.A.D. for daily variation and an increase in the number of band forms to a point just outside the normal range.

The sample two days after this showed the defence phase, for neutrophilic reaction had died down and only 4.7 per cent. of band forms were present. Thus on this day, taken by itself, there was no abnormality, for eosinophils were still present and no monocytic defence period was apparent. The only definite change in the next two samples was the tardy occurrence of a complete eosinopenia at a time when eosinophils would bè expected to reappear. In the two samples covering the next four days there was an undramatic return of eosinophils and, as further samples showed no marked increase in these cells, this was accepted as the commencement of the recovery phase.

Although the samples from three sheep have been treated together, in order to show that the different phases are a general rule rather than the spectacular exception, this treatment suffers from two defects. Firstly, samples were taken on alternate days only, and secondly, small changes in individual sheep are obliterated. Thus at the third sample two sheep showed 10 per cent. monocytes which could be accepted as a monocytic defence period and it could be argued that, had the sheep been bled daily, the third animal would have shown this reaction either the day before or after the others. Records from other sheep, however, suggest that the appearance of this monocytic increase is irregular and unreliable. The picture for this reaction makes it clear that although a reaction may be obvious when serial samples are examined, the abnormality would not be evident if samples had been taken at certain periods within the reaction.

\section{Severe Neutrophilic Reaction with Unfavourable Course}

The data for both this and the following example have been 
taken from unpublished work on lambs that was carried out in cooperation with Dr. A. McDiarmid. All lambs were injected intravenously with thick suspensions of Staph. aureus. In each case the figures for three lambs have been averaged.

Two preliminary bleedings have been depicted (see Fig. 1, example 3), as, by chance, no eosinophils were apparent in the pre-inoculation samples. On the day following injection a severe neutrophilic reaction was apparent with a large proportion of metamyelocytes which included a small percentage of young forms. There was also a complete eosinopenia. For the next two days the neutrophil count decreased both relatively and absolutely, but the blood picture remained at the invasion phase in that the proportion of immature forms was increasing, and had even reached a point at which they represented more than half the total neutrophilic cells. It is interesting to note that at this point-when the large proportion of metamyelocytes predicted an unfavourable termination to the infection - all three sheep were still able to stand and retained some appetite. From this day onward there was an increase in the total count but the unfavourable course was quite obvious from the high proportion of immature neutrophils and the steady increase of the young forms. On the next day one lamb was dead but the intense reaction was still obvious in the remaining lambs; the second sheep died the next day and the third lamb died the day after that, with a final sample showing an agonal leucocytosis in which the neutrophilic reaction was still pronounced. Thus, from first to last the reaction remained within the neutrophilic battle stage as shown by the intense "shift to the left" and the complete absence of eosinophils.

\section{Severe Reaction Leading to Fatal Leucopenia}

This sample is typical of an overwhelming infection in which the neutrophilia, expected to appear in the peripheral blood, is obliterated, and the only evidence of neutrophilic reaction is that given by the marked "shift to the left." (Fig. 1, example 4.) The pre-inoculation sample shows a fairly high percentage of band forms - not abnormal for young lambs-but after injection there was a pronounced shift and this, together with the complete absence of eosinophils, suggested an unfavourable prognosis. The following day, despite the shift to the left, both neutrophils and lymphocytes had decreased in absolute numbers, and this was accepted as the beginning of a fatal leucopenia. The three lambs were found dead on the following morning.

\section{Neutropenia}

ATYPICAL REACTIONS

This reaction results from an infection with tick-borne fever, described elsewhere (Taylor et al., 1941), and is a composite picture of the figures obtained from three sheep. It c.n be seen that in 
the sample taken two days after infection there was a slight increase in neutrophil cells, but that this increase did not amount to a neutrophilia, nor could the appearance of 1 per cent. band forms that accompanied it be termed a shift to the left. (Fig. 1, example N.) Over the next six days there was a steady fall in neutrophil cells but eosinophil cells were still present and the monocytes did not exceed the figures for the pre-inoculation sample. At the next sample the reaction was more marked, with only 13 per cent. polymorphs and a complete absence of eosinophil cells: this phase lasted over the next four days, after which eosinophils were again apparent and polymorphs increased in numbers.

The above example, like example 2 , loses some individual reactions owing to the averaging of the figures for three sheep, and by its restriction to samples made on alternate days. Thus it could be suggested that a true neutrophilia was present on the day following inoculation, and this in fact is sometimes the case, but it is an exception to the rule. Again it could be claimed that there was no neutropenia for the neutrophils did not fall below 13 per cent., a point within the normal range, but individual records show that two sheep fell to 5 per cent. and 6 per cent. neutrophils respectively, although the figures for the third sheep merely receded to below the normal average. . If, however, the example represented the reaction in a single sheep-as it might well do - the only points of significance would be the fall in neutrophils between the fourth and fifth sample which is in excess of the M.A.D. for daily variation in neutrophils, and the complete absence of eosinophils for three consecutive samples which is unlikely to have occurred by chance.

\section{Agranulocytosis}

The production of an agranulocytosis by the toxin of $\mathrm{Cl}$. welchii, type A, has been described elsewhere (Gordon, Stewart, Holman and Taylor, 1940). Such an agranulocytosis is depicted in Fig. 1, example A, which consists of the averaged figures for two sheep. It shows that after the injection of toxin the granular cells are almost obliterated and there is a decrease in the number of monocytes, although the lymphocytes remain comparatively unchanged. Comparing this picture and the neutropenia of tick-borne fever with the leucopenia produced by massive doses of staphyloccoci in example 4, it can be seen that in the atypical example there is neither a marked "shift to the left" nor a decrease in lymphocytes.

\section{Reaction Limited to a Terminal Eosinopenia.}

Some infections, including amongst others, scrapie, produce no change in the blood-picture except during a brief period before death. The terminal counts of a sheep that had been affected with scrapie for some months are depicted in Fig. 1, example E. The sample, taken three days before death, showed no abnormality other 
than the absence of eosinophils (a factor that is not significant if limited to a single sample), and the last sample showed, in addition to the eosinopenia, the beginning of an agonal leucocytosis.

\section{ABNORMAL VARIATIONS IN LEUCOCYTES}

\section{Neutrophilic Reactions}

Neutrophilic reactions are by far the most important from the diagnostic point of view and they will be dealt with in detail.

A mild, transient reaction has been described (Example 1) and proved significant, but for the purpose of setting standards it is desirable to know the absolute minimum that can be regarded as a neutrophilic reaction. The difficulty of setting such a limit for daily samples is seen in Table II, where the results of unpublished work on skin reactions in Johne's disease carried out in collaboration with Dr. A. Wilson Taylor, are summarised. It can be seen

TABLE II

RESUlts 24 Hours after INTRADERMAL INJECTION OF JOHNIN

\begin{tabular}{lccccccr}
\hline & \multicolumn{2}{c}{$\begin{array}{c}\text { Neutrophilic } \\
\text { Bands. }\end{array}$} & \multicolumn{2}{c}{$\begin{array}{c}\text { Reaction } \\
\text { Polys. }\end{array}$} & \multicolumn{2}{c}{ Eosinophils } \\
\cline { 2 - 8 } & Sig. & $V$. & Sig. & $V$. & D. & $I$. \\
\hline Positive skin reactions & $9 \dagger$ & 7 & $11^{*}$ & 5 & 16 & 0 \\
Negative " & 1 & 4 & 0 & 5 & 3 & 2 \\
Uninjected controls ... & 0 & 4 & 0 & 4 & 3 & 1 \\
\hline
\end{tabular}

Sig.- Indicates an increase exceeding the M.A.D. (95 per cent.) for daily variation. V.-Indicates a variation either upward or downward, but within the limit of the M.A.D. D.-Indicates a decrease in the numbers of eosinophils. I.-An increase in the number of eosinophils.

* Four of these were outside the normal limit and therefore could also have been classified as a relative neutrophilia.

+ None of these were outside the normal range, the highest being 3 per cent. band forms.

from the table that the standard denoting a reaction must be an arbitrary one and open to error, but that unless it is placed to cover all increases exceeding the M.A.D., some slight reactions will be lost. Thus, with daily sampling it is advisable to take any increase above 15.6 polymorphs in the differential count as a neutrophilic reaction.

Both Schilling (1929) and Wirth (1931), depicting the fundamental curve of neutrophilic reaction in man and the horse respectively, show a small primary decrease in the number of neutrophils just after the time of infection and preceding the much more obvious neutrophilic increase. Further, Wallbach (1935) records a transient decrease in neutrophil cells in rabbits following the injection of toxic material to a susceptible animal, but claims an immediate increase in these cells where the rabbit has been immunised against the antigen, 
Using $C l$. welchii type D toxin, an attempt was made to confirm these points. After injection of the toxin sheep were bled at frequent intervals, 5,15 and 60 minutes after commencing. The results are summarised in Table III. It can be seen that a small fall in neutrophil cells is common during the first 5 to 15 minutes but that the only occasions when the change was large enough to be considered significant was where the toxin was given subcutaneously. No correlation was noted between the amount of toxin and the extent of the decrease, nor did the decrease distinguish between susceptible animals and those previously immunised.

This experiment showed further that a neutrophilic reaction was often present at the end of the first hour, either as a relative neutrophilia or as a "shift to the left," and that at three hours a combination of these two reactions could be present. Thus reactions can occur very quickly, and for such reactions as anaphylactic shock

TABLE III

Decrease in Neutrophil Cells following Injections

\begin{tabular}{|c|c|c|c|c|c|}
\hline & \multicolumn{2}{|c|}{ Decrease } & \multirow{2}{*}{$\begin{array}{l}\text { No. } \\
\text { Change }\end{array}$} & \multicolumn{2}{|c|}{ Increase } \\
\hline & Sig. & $V$. & & Sig. & $V$. \\
\hline $\begin{array}{l}\text { Subcutaneous injection of solution of } \mathrm{Cl} \text {. welchii } \\
\text { type } \mathrm{D} \text { toxin } \ldots \\
\text { Intravenous injection of solution of } \mathrm{Cl} \text {. welchii }\end{array}$ & 5 & 4 & 1 & 4 & 0 \\
\hline type D toxin $\quad \cdots \quad \ldots \quad \ldots \quad \ldots$ & 0 & 7 & 0 & 2 & 0 \\
\hline Subcutaneous injection of $100 \mathrm{ml}$. innocuous fluid & 0 & 2 & 0 & 0 & 0 \\
\hline Totals & 5 & 13 & 1 & 6 & 0 \\
\hline
\end{tabular}

Sig.-Indicates an increase or decrease greater than the M.A.D. (95 per cent.) for error alone, that is, an alteration of 12 or more cells. V.- Indicates that the alteration was within one M.A.D. All changes measured 5 or 15 minutes after injection.

when the assaulting dose is given intravenously, it would be necessary to take several samples on the first day, for if left till the next day the leucopenia would be overlooked and only the succeeding leucocytosis would be recorded.

The exact borderline between health and disease cannot be drawn but it is advisable for practical purposes, and even at the expense of an occasional error, to try to set standards for the limits of normality, particularly as failure to strike the exact limit would merely establish an unusually high normal value for neutrophils (for example), as a "slight neutrophilia," a wrong diagnosis that would lead to no grave error in prognosis. Therefore, when the technique described in the first article is earried out, the following standards are offered as a guide.

Neutrophilic Reaction.-This can be assumed if there is a rise of at least 16 polymorphs or at least two band forms between the differential counts of two daily samples. It should be noted that 
although the M.A.D. for daily variation in band forms is one, the M.A.D. for error alone in basophils is 1.5 . The distribution of these two cell types is very similar, and hence it is safer to raise the limit to two cells, as above.

Relative Neutrophilia and Relative Neutropenia.-The limits set for polymorphs in Table I, namely, above 47 and below 11 per cent., are suitable, in that at both extremes the polymorphs represented the total neutrophil count.

Absolute Neutrophilia and Absolute Neutropenia.-As in the above the absolute limits for polymorphs are suitable for this range; for 113 sheep these were $5 \cdot 6$ and $0 \cdot 7$ thousand per c.mm.

For general purposes the relative counts are more sensitive. Both for lambs and sheep, 6 per cent. band forms may be taken as a slight "shift to the left." In moderate reactions about one-third of the neutrophil cells may be band forms, and perhaps 0.5 per cent. young forms may be present. In severe reactions the immature forms constitute more than half the total neutrophil cells and here, as in man, the prognosis is unfavourable. An exception to this rule exists in the case of sheep suffering from a concomitant infection of tick-borne fever, which can be diagnosed by seeing the specific bodies lying within the neutrophil cells during the febrile part of the disease; in this case the band forms easily outnumber the few polymorphs that are present without connoting an unfavourable prognosis.

Toxic changes are sometimes seen in neutrophil cells but they are not as common or as obvious as in the horse. They have not been studied in this investigation.

\section{Lymphocytes}

The numbers of lymphocytes are an essential requirement for the estimation of the proportion of other cell types, but they appear of little importance in themselves. In parts of this investigation the proportion of large to small lymphocytes, the lymphocyticmonocytic ratio, the appearance of cells with two nuclei and the proportion of cells showing azure granules were recorded, but the significance of the results could not be interpreted.

The rarity of lymphatic leukaemia in sheep makes the definition of an absolute lymphocytosis of little value and the fall of both neutrophils and lymphocytes in severe infections or anaphylactoid shock can be estimated as easily from the total leucocyte count. In view of this the definition of standards limiting normality appears redundant.

\section{Monocytes}

In sheep, these cells are sometimes difficult to distinguish from large lymphocytes but, in contrast to the horse, they are easily distinguished from band forms that have undergone toxic changes. They may show the presence of tick-borne fever bodies during an 
infection, and occasionally what appears to be a typical monocyte may contain the remains of an erythrocyte within its cytoplasm.

Monocytes fluctuate during infections, showing increased numbers. over short periods (monocytic defence periods), but the significance of these waves is not understood, nor would the error in estimating the number of monocytes permit them to be used as a sensitive diagnostic agent.

\section{Eosinophils}

Schilling places great reliance on the absence of eosinophils as a sensitive indication of ill health, and takes the precaution of also examining a thick blood film for the presence of these cells as an additional guide to their numbers. In sheep the significance of the eosinophil count is always complicated by the possibility of worm infestation, and before discussing the standards to be adopted it is advisable to discuss the reaction that usually occurs under the influence of eosinotactic substances. Weinberg and Seguin (1914, 1915) and Biggart (1932) have shown that the production of a local eosinophilia is carried out at the expense of blood eosinophils causing a temporary eosinopenia. The stimulus also leads to an increased production of eosinophil cells, creating a period of eosinophilia. Finally, when the stimulus is neutralised, the eosinophilia dies away, in many cases leaving the eosinophils infiltrated in the lesion.

Thus only certain stages in worm infestation produce an eosinophilia; other stages (particularly in severe infestations) produce eosinopenia, but marked eosinophilic infiltrations can be present in the lungs of sheep concomitant with a normal eosinophil blood count.

Again, in the case of allergy an eosinophilia is expected, although an allergic reaction accompanied by a decrease in blood eosinophils followed by a return to common numbers with no eosinophilia has been seen. (Table II.) Here, presumably, the blood eosinophils infiltrated into the lesion but the stimulus was not strong enough to increase their production.

Relative Eosinophilia.-In Table I it can be seen that the distribution of eosinophils is skewed to the right. This is probably due to some apparently healthy sheep showing an increased eosinophil count due to worm infestation. Whatever the reason may be, the practical value of the term eosinophilia is lost if such counts as 13,15 and 17 per cent. eosinophils are included as normal in the healthy sheep. Hence the records for six sheep bled each month for two years (see first article) were examined for information on this point, and after comparing them with other records it was considered practical to regard all counts of over 9 per cent. eosinophil cells as connoting a relative eosinophilia.

Eosinopenia.-A smear taken from an apparently healthy sheep may reveal no eosinophils. It could be argued that this was due to a certain stage in a slight worm infestation in which an eosinopenia 
was produced, but even if this argument was accepted it would have little value in helping to set up a criterion of eosinopenia for the diagnosis of ill health in the sheep, as for practical purposes sheep slightly infested with worms cannot be excluded from among heallthy sheep.

As the absence of eosinophils in one daily sample cannot be accepted as an eosinopenia, the records for healthy sheep from which two samples had been obtained were examined and the results given in Table IV. It can be seen that out of 68 sheep sampled twice, eosinophils were in no case absent on both occasions. Thus the complete absence of eosinophils from two smears taken on different days is unlikely to occur by chance, and can be accepted as defining an eosinopenia, thus giving a useful, and sometimes the only, indication of ill health. It should be noted, however, that for lambs under one month old-where the eosinophils average only 1.1 per cent. (Holman, 1944) - this definition is not reliable.

TABLE IV

Presence of Eosinophils in Smears from Healthy Sheep, Sampled on Two Occasions

\begin{tabular}{cccc}
\hline & & \multicolumn{2}{c}{ Eosinophils Absent } \\
\cline { 3 - 4 } Number of & Approx. Interval & On One Occasion & On Both Occasions \\
\cline { 3 - 4 } & Between Samples & On & 0 \\
16 & 1 day & 2 & 0 \\
11 & 2 days & 2 & 0 \\
15 & 3 & 3 & 0 \\
6 & Week & 1 & 0 \\
20 & Month & 5 & 0 \\
\hline 68 & & 13 & 0 \\
\hline
\end{tabular}

Eosinophils possess some phagocytic powers (Weinberg and Seguin). It should be noted, however, that during an infection with tick-borne fever the bodies which may be found within the cytoplasm of an eosinophil are not necessarily phagocytosed.

\section{Basophils}

The occurrence of these cells corresponds-to some extent with the eosinophils : they are usually absent during eosinopenia and often present during eosinophilia. An odd basophil may, however, appear at any time, including periods of eosinopenia, and even in some cases a few hours before death. Hence they have little clinical value.

Basophilia.--In a pining lamb a count of 16 per cent. basophils was recorded; post-mortem examination did not reveal the cause of ill health. No other cases have been seen but the possibility of their appearance makes it advisable to define the term basophilia. From the data furnished in Table I, this definition would be the presence of more than 3 per cent, basophils, 


\section{Total Leucocytes}

Leucocytosis. - In man the existence of a physiological leucocytosis is accepted and hence the term does not necessarily connote ill health. In view of this a more arbitrary attitude can be adopted in fixing a useful limit in sheep so that the largest proportion of animals reacting to stimuli can be diagnosed as abnormal. The figure of 13 thousand per c.mm. excludes only three out of 113 apparently healthy animals and would seem from general experience to be a useful standard for leucocytosis.

Leucopenia.-In low leucocyte counts the sampling error is much bigger than in high counts, and it is advisable to scan a larger area. Had this precaution been permissible it is unlikely that the figure of the lowest count, viz., 1.1 thousand, would have appeared. However, by allowing the same latitude as was done in the case of leucocytosis, and excluding the three extreme counts, the figure for leucopenia is set at four thousand, and this is acceptable as a practical standard.

\section{SUMMARY AND CONCLUSIONS}

In this article an attempt has been made to set for the sheep certain standards similar to those already well established for man; no new conceptions have been introduced other than the use of the Maximum Admissible Difference.

Typical reactions of different degrees of severity as produced in sheep by pyogenic organisms, are described. They consist of three stages, viz., the neutrophilic invasion phase, the defence, phase in which the neutrophilic reaction subsides and the recovery phase indicated by the appearance of numbers of eosinophils. Usually there is a temporary decrease in neutrophils immediately after an injection. The period required for the complete reaction varies and may take three days or three weeks. The neutrophilic reaction can commence as soon as one hour after injection.

Examples of atypical reactions are given: they are neutropenia, agranulocytosis, and ill health indicated by eosinopenia alone.

The following standards are set: Leucocytosis - Slight, $13.0 \times 10^{3}$ per c.mm. ; marked $20.0 \times 10^{3}$. Leucopenia-4.0 $010^{3}$. Neutrophilic Reaction -Slight, an increase of 16 per cent. neutrophil cells or of 2 per cent. band forms, between counts on two successive days. Marked, and severe, as for " shift to the left." Shift to the leftSlight, 6 per cent. band forms. Marked, metamyelocytes constituting one-third of the neutrophil cells. Severe, metamyelocytes forming one-half of the neutrophil cells. (An exception to the last two definitions occurs when an infection with tick-borne fever is also present.) Neutrophilia-Relative, 47 per cent. neutrophil cells : absolute, $5.6 \times 10^{3}$ per c.mm. Neutropenia-Relative, 11 per cent. : absolute, $0.7 \times 10^{3}$. Eosinophilia-Relative, 8 per cent. eosinophils. Eosinopenia-Relative and absolute, absence of eosinophils in 200 cell counts on two smears made on different days. 
It is concluded that neutrophils and eosinophils are the two celltypes most helpful as a guide to diagnosis and prognosis, but that many slight reactions will be overlooked unless samples are taken daily.

\section{REFERENCES}

Biggart, J. H. (1932). J. Palh. Bact., 35, 799.

Gordon, W. S., Stewart, J., Holman, H. H., and Taylor, A. W. (1940). Ibid., 50, 251.

Harvey, W. F., and Hamilton, T. D. (1932). Edinb. med. J., 39, 297.

Holman, H. H. (1944a). J. comp. Path., 54, 26: (1944b). Ibid., 179.

Schilling, V. (Trans. by Gradwohl, R. B. H.) (1929). The Blood Picture. Kimpton: London.

Taylor, A. W., Holman, H. H., and Gordon, W. S. (1941). Vet. Rec., 53, 337.

Wallbach, G. (1935). Rev. Path. comp., 35, 605.

Weinberg, M., and Seguin, P. (1914). Ann. Inst. Pasteur, 28, 470: (1915). Ibid., 29, 323

Wirth, D. (1931). Grundlagen einer Klinischen Haematologie der Haustiere. Urban and Schwarzenberg: Berlin.

[Received for publication June 24th, 1944] 


\title{
STUDIES ON THE HAEMATOLOGY OF SHEEP IV. ERYTHROCYTIC AND THROMBOCYTIC PICTURES, AND VARIATIONS IN PHYSICAL ATTRIBUTES
}

\author{
By \\ H. H. Holman, \\ Animal Diseases Research Association, Moredun Institute, Edinburgh
}

\section{INTRODUCTION}

VERY little detailed work has been carried out on the erythrocytic picture of sheep other than observations made on post-haemorrhagic and haemolytic anaemia, and this work has been referred to where appropriate. The wide range that must be considered normal-due, at least in part, to unrecognised worm infestation-again produces difficulty. Nevertheless, it has been considered desirable to attempt to set standards for variations below the normal, that is, Anaemia ; and above the normal, that is, Polycythaemia rubra, but in view of the tentative nature of this work, discussion on aetiology has been limited to a minimum.

In the case of thrombocytes the only important change that has been recorded is the diversity of shape occurring in haemolytic anaemia recorded by Chamberlin (1933). Only a few isolated observations on the various physical attributes occur in the literature and no statements as to their value have been made.

The normal range and the daily variations have already been dealt with (Holman, 1944a, 1944b, 1944c), but for convenience normal means for various constituents have been included in Tables $\mathrm{V}$ and VII.

\section{ANAEMIA}

Anaemia signifies a lack of blood and is a symptom rather than a disease. In man it has been classified by two methods, one dependent on cause, the other on effect. The first method, in which classification is based on aetiology, is advocated by Vaughan (1936), who recognises three main classes; dyshaemopoietic anaemias due to failure or abnormality in blood production; post-haemorrhagic following haemorrhage; and haemolytic due to blood destruction within the body. The second method, in which classification is dependent on the alteration produced on the blood indices, was introduced by Wintrobe (1942), who formulated four main classes, namely, macrocytic, normocytic, simple microcytic and hypochromic microcytic. In man, where cell size plays such an important part in diagnosis, Wintrobe's classification is of great value, but in sheep where anaemia is mainly normocytic in type, the aetiological classification is to be preferred, and Vaughan's classification has been used in this article. 


\section{Post-haemorrhagic Anaemia}

Figures for a case of acute post-haemorrhagic anaemia produced by bleeding a sheep from the jugular vein, are recorded in Table I and, for comparison, results obtained by other workers are summarised in Table II. Holman and Pattison (1941) found that in lambs this type of anaemia could be produced, or accentuated, by the rapid healthy growth following the sudden removal of heavy worm infestations that had previously delayed their development.

Blood Loss and Regeneration.-It has been shown that a sheep can be killed by the removal of 3.2 litres of blood over a period of 66 hours (Table I). On the other hand, a sheep can endure such a loss if spread over a period of two weeks (Table II). Stippled cells and polychromatic cells were observed as early as 48 hours after the first bleeding but were not numerous. It can be seen from Table II that these are the common regenerative changes that occur. They are not, however, limited to the low blood counts recorded in Table II, and where bleeding is slight but continual these changes may be observed where the count is as high as 6.0 million; once stimulated by a low count they may persist and be present in blood samples giving red counts of 7.0 or even 9.5 millions. Jolly bodies are uncommon but my records include one case in which anisocytosis and the presence of these cells were the only abnormalities observed.

Reticulocytes were not recorded in this investigation, as it was found that polychromasia or punctate basophilia was a more sensitive guide to regeneration than the occurrence of reticulocytes in films stained by the dry film method, and that, with the wet film method, figures for reticulocytes increased minute by minute for several minutes, rendering this method time consuming and impractical for field work. In the rabbit, Whitby and Britton (1939) found that the sum of the polychromatic cells and the stippled cells were equal in number to the reticulocytes. There is no reason to believe that this is otherwise in the sheep, for Fourie observed that all polychromatic cells were also reticulocytes and Fraser showed a close correlation between the numbers of stippled cells and reticulocytes. It appears feasible, therefore, that had the figures for polychromatic cells been recorded, these would have supplied the deficiency.

Cell Size and Shape.-In sheep, one of the first changes apparent in post-haemorrhagic anaemia is anisocytosis, but in blood films from healthy sheep there is normally an irregularity in size. Abnormality is therefore largely dependent on personal opinion and should be diagnosed with caution unless indicated by an alteration in the Price-Jones curve. Such curves for the sheep detailed in Table I are given in Table III.

When, in anisocytosis, macrocytes and microcytes balance each other in volume the mean corpuscular volume (M:C.V.) remains the same and the anaemia is still termed normocytic. This was the case in Table I and also in Andrew's sheep (Table II).

Whitby and Britton (1939) and Wintrobe (1942) record that in 

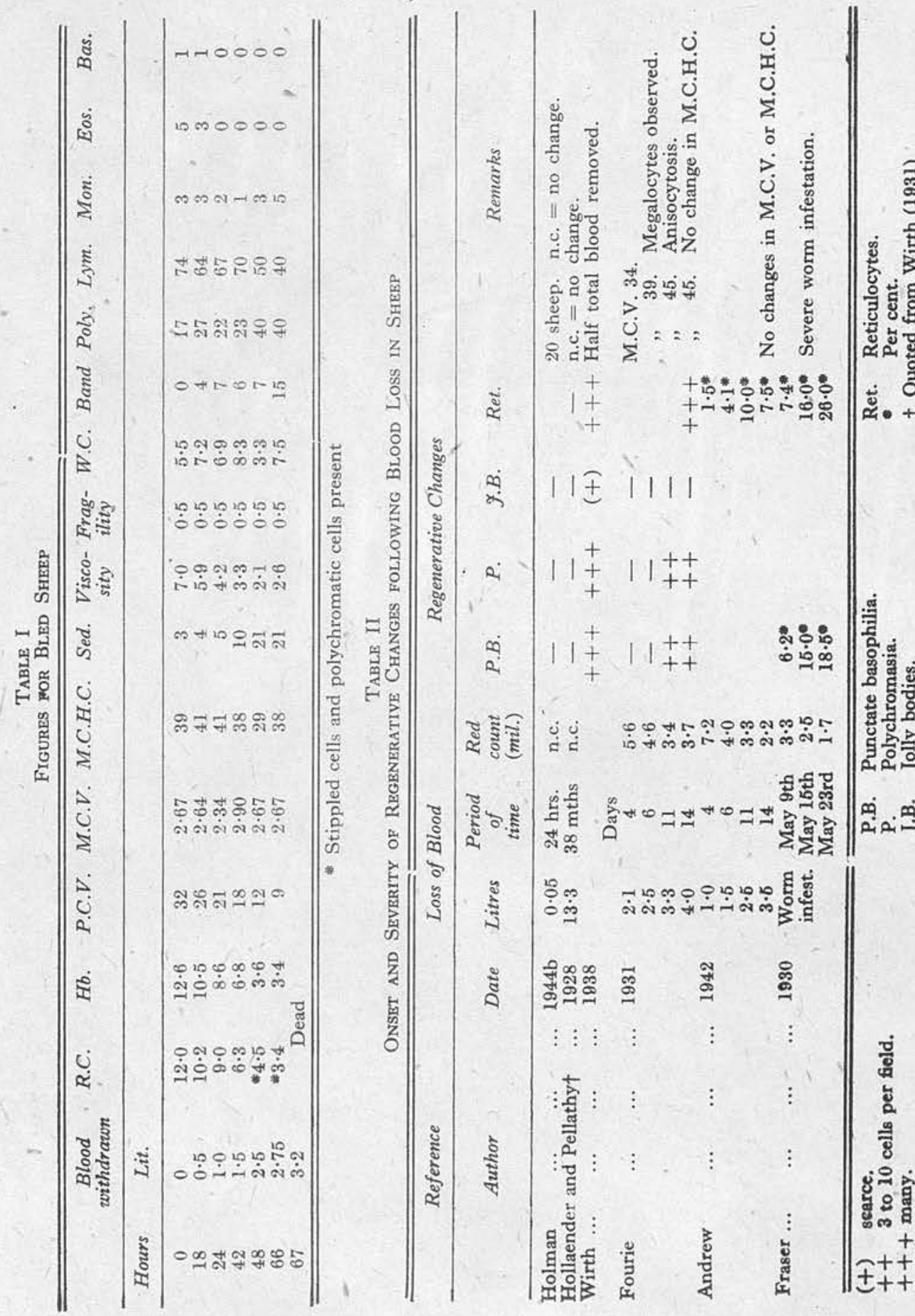

$$
\text { ๕ั่ }
$$

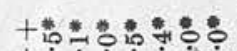

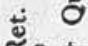

कूं $11 \pm 1111$

2. $\mid \begin{array}{ll}1+ \\ + \\ +\end{array}++$

$\stackrel{0}{2} \quad 11+11^{++}+$

욤

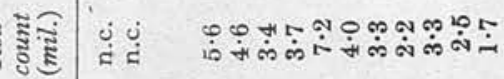

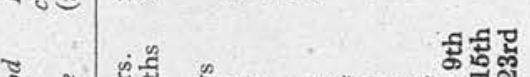

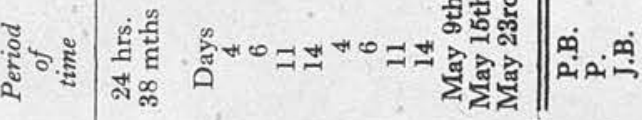

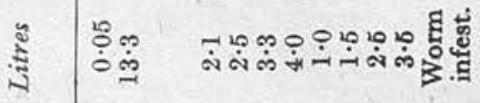

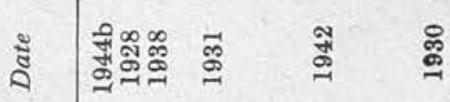
เัต
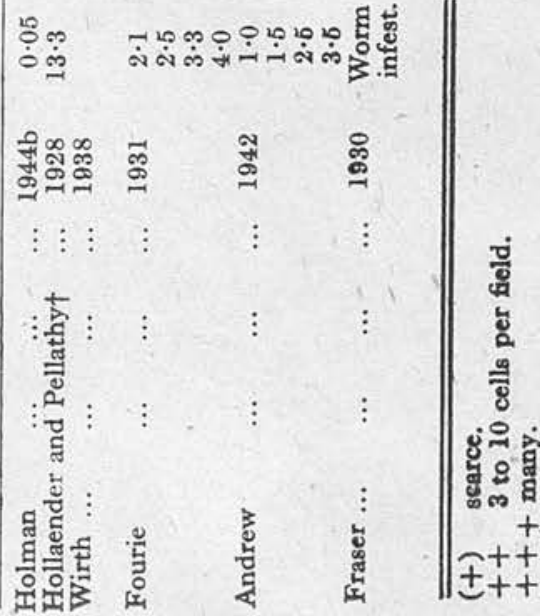
man if the stimulation of the bone marrow has been marked the anaemia may become macrocytic for a period of several days, and such a phenomenon is apparent in Fourie's sheep (Table II). Further, assuming Haemonchus contortus infestation to cause an uncomplicated post-haemorrhagic anaemia, Fourie demonstrated a slight irregular increase in cell size in three out of five cases, with one case showing a definite macrocytic anaemia, with an M.C.V. of 50 and later 70 c.micra. Holman and Pattison, investigating a mixed worm infestation in which $H$. contortus was predominant, found a macrocytic anaemia in four out of ten cases, with M.C.V.s of 37, 41, 41, and 43 c.micra. In these cases blood films did not show a "shift to the right " in the Price-Jones curves and therefore it was assumed that the increased cell volume must have been due to a spherocytosis. Poikilocytosis was not evident in the sheep used for Table I or in the sheep bled by Fourie; it was, however, evident in some of the sheep he infected with $H$. contortus.

TABLE III

Price-Jones Curves for Bled Sheep Detalled in Table I

\begin{tabular}{|c|c|c|c|c|c|c|c|c|}
\hline Time. Hrs. & 3 & $3 \cdot 5$ & 4 & $4 \cdot 5$ & 5 & $5 \cdot 5$ & 6 & $6 \cdot 5$ \\
\hline $\begin{array}{r}0 \\
42 \\
66\end{array}$ & $\begin{array}{l}-7 \\
6\end{array}$ & $\begin{array}{l}15 \\
34 \\
71\end{array}$ & $\begin{array}{l}100 \\
170 \\
134\end{array}$ & $\begin{array}{l}274 \\
203 \\
166\end{array}$ & $\begin{array}{r}100 \\
65 \\
77\end{array}$ & $\begin{array}{l}11 \\
20 \\
35\end{array}$ & $\begin{array}{r}-1 \\
10\end{array}$ & 1 \\
\hline
\end{tabular}

Haemoglobin Concentration.--In acute post-haemorrhagic anaemia the blood remains normochromic. This is the case in Table I and also in the examples given by Andrews and Fourie; the periods over which these sheep were bled did not exceed a fortnight. In chronic post-haemorrhagic anaemia the corpuscles become hypochromic and figures given by Fourie for three sheep infested with $H$. contortus for periods of over three weeks show this defect.

Physical Properties.- In Table I the figures for sedimentation give a logarithmic curve and those for viscosity a simple linear regression when the erythrocyte counts are taken as the independent variate. Fourie gives viscosity figures for one case of infestation and there, too, the figures are compatible with a straight line regression. Fragility remained constant.

Leucocytes and Thrombocytes.-In contrast to man, no leucocytosis was evident in the bled sheep detailed in Table I or in those bled by Fourie and Andrews. In Table I severe anaemia was accompanied by a slight neutrophilic reaction and the disappearance of eosinophils, and Andrews confirms this to some extent by giving a higher average for neutrophils and a lower one for eosinophils when comparing. his bled sheep to controls. 
No investigator has included a platelet count but in the case of the sheep detailed in Table I abnormal platelets - as described by Chamberlin (1933) in haemolytic anaemia-were seen, these included platelets as large as small erythrocytes, platelets with tails at one or both ends, and others round, sausage, or triangular in shape.

\section{Haemolytic Anaemia}

Selected details from accounts of haemolytic anaemia in sheep have been summarised in Table IV. It should be borne in mind, however, that some apparent differences are due to the amount of the noxa administered: thus in arsenical poisoning the dose was small and therefore produced mild regenerative changes, while with Type A toxin the dose was large and was lethal before regenerative changes were pronounced.

Haemolytic anaemia is in many respects similar to posthaemorrhagic anaemia and will not be treated in detail. The main difference lies in the liberation of blood pigment, evident either as icterus or haemoglobinuria, and an alteration in erythrocytic fragility.

TABLE IV

Haemolytic Anaemias

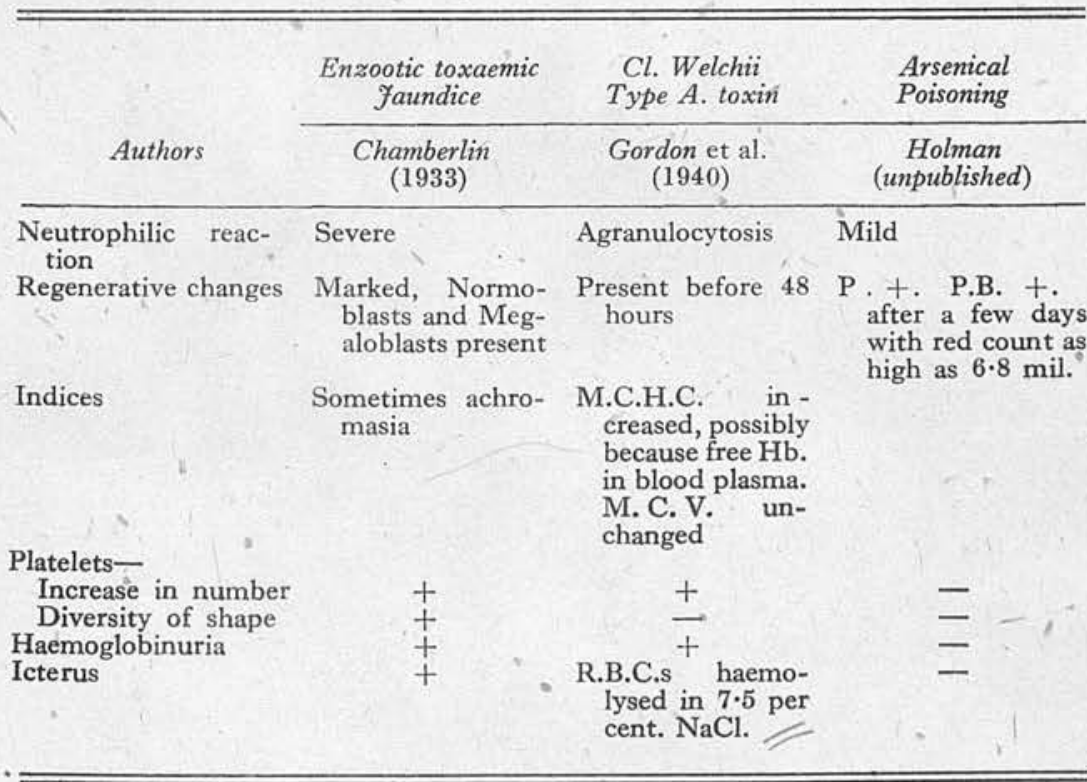

\section{Dyshaemopoietic Anaemias}

In the present state of knowledge any attempt to classify the dyshaemopoietic anaemias in sheep must necessarily be both sketchy and tentative. Various sets of circumstances associated with this 
type of anaemia are given in Table V, Part I, and, in contrast, some conditions in which pining or emaciation exist unaccompanied by anaemia are given in Part II.

From Table V, Part I, the existence of four types of dyshaemopoietic anaemia have been inferred. Firstly, a simple oligocythaemia in the case of inanition in a flock of sheep bearing a heavy worm burden; secondly, a hypochromic anaemia apparent in some cases of intestinal worms or of Johne's disease; thirdly, a macrocytic anaemia affecting pregnant ewes in certain districts of England, reported by Innes and Shearer (1940); and, fourthly, an aplastic anaemia seen in worm infested lambs severely affected with nodular necrosis.

TABLE V

Mean figures for ERythrocytes in Pining Conditions Dyshaemopoietic Anaemias

\begin{tabular}{|c|c|c|c|c|c|}
\hline$x$ & & Sheep & R.B.C.s & M.C.V. & M.C.H.C. \\
\hline $\begin{array}{c}\text { Inanition and heav } \\
\text { burden }\end{array}$ & vy worm & 12 & $9 \cdot 0$ & 26 & 43 \\
\hline $\begin{array}{c}\text { Intestinal worms } \\
\text { thiasis) }\end{array}$ & (helmin- & 14 & $9 \cdot 2$ & 26 & 34 \\
\hline Johne's disease & $\ldots \quad \ldots$ & 9 & $8 \cdot 6$ & 27 & 35 \\
\hline Nodular necrosis & $\ldots$ & 2 & $4 \cdot 5 \dagger$ & 29 & 36 \\
\hline $\begin{array}{l}\text { Hyperchromic ana } \\
\text { pregnant ewes }\end{array}$ & remia of & $9 \overline{7}$ & $6 \cdot 2$ & 59 & $\mathbf{N}$ \\
\hline \multicolumn{6}{|c|}{ Pining unaccompanied by anaemia } \\
\hline Scrapie $\quad \ldots$ & $\ldots$ & 16 & $11 \cdot 5$ & 25 & 41 \\
\hline Solway pinef... & $\ldots$ & 21 & $10 \cdot 3$ & 28 & 40 \\
\hline Cobalt pinef ... & $\ldots$ & 10 & $11 \cdot 6$ & 26 & 42 \\
\hline Normal & $\ldots$ & 100 & $11 \cdot 5$ & 27 & 41 \\
\hline
\end{tabular}

- Innes and Shearer (1940).

$\mathrm{N}=$ Normochromic - absolute figures for $\mathrm{Hb}$. not given.

+ Without regenerative changes.

I Stewart and Holman (1944).

It must be emphasised that this classification is very general in its character and easily criticised. For example, only some worminfested sheep showed hypochromia, while the presence of $H$. contortus in infestations must have complicated the picture by the production of some degree of post-haemorrhagic anaemia; the anaemia in Johne's disease may be partly or wholly due to the presence of intestinal worms ; and, finally, a sheep affected with diarrhoea may suffer from a slight anhydraemia through the loss of water from the bowel, and thus an oligocythaemia may become obliterated, and the figure for the red count then recorded may, be a high'value in the normal range.

Another difficulty exists in the fact that owing to the wide normal range the figures for individual animals may fall at a low value within the range, and to show abnormality it is necessary to take the average 
for a group of such animals and show that this differs significantly from the average of the normal range. Thus we are in the unfortunate position of having to designate some groups of animals each of which has a low normal count as abnormal, a decision that involves either an arbitrary judgment or the use of a statistical test.

Oligocythaemia. Simple. Anaemia.-In this type of anaemia there is a fall in the erythrocyte count without alteration in cell size or shape, or the appearance of immature cells. The figures given in Table V were obtained from a group of 12 hill sheep in apparent good health but showing worm egg counts of some 1,000 per $\mathrm{g}$. These sheep were housed in loose boxes and refused to feed. The erythrocyte counts averaged eleven million on the first day but had fallen to 9.7 four days later. At the end of a week the count was 9.0 million, at this time the sheep were learning to take food from the trough; a count made four days later was also $9 \cdot 0$ million.

This type of anaemia was also noticed in sheep at pasture during the months of February, March and April (Holman, 1944a) and it was pointed out that it persisted until the growth of fresh grass at the end of spring.

Hypochromic Anaemia.-This term refers to the combination of oligocythaemia and hypochromia ; the presence of an oligocythaemia distinguishes it from Chlorosis (Beattie and Dickson, 1943). It is regarded as occurring where there is interference with the anabolism of iron into haemoglobin, a cycle that requires the absorption of iron, copper and various food factors. In man this type of anaemia is usually microcytic but this does not appear to be the case in sheep. Groen (1940) states that where there is iron deficiency the resulting anaemia is rarely due to that cause alone and is usually the effect of a combination of several causes in which he includes the following : lack of iron, lack of stomach acid, a rapid period of growth, interference with absorption from the gut, and acute or chronic haemorrhage. He does not, however, distinguish between a normochromic oligocythaemia and a hypochromia but claims that either one or the other may be caused by iron deficiency.

Holman and Pattison noticed a hypochromic anaemia in rapidly growing lambs which were at pasture during the month of November. Those previously treated for worms showed an average M.C.H.C. of 32 per cent. and those untreated showed an average of 30 per cent. Hypochromia has also been noted in individual sheep suffering from intestinal worms or from infection with Johne's disease, and this may be due either to the interference with absorption from the gut, or, perhaps, where infestation with $H$. contortus is present, to chronic haemorrhage in which the iron reserves have been expended. $\mathrm{Re}-$ generative changes are apparent in some sheep where oligocythaemia is pronounced.

Hyperchromic Anaemia of Pregnant Ewes.-Innes and Shearer have shown that anaemia exists in ewes before and shortly after lambing. The districts in which this type of anaemia was apparent 
included Leicestershire, Derbyshire and Cambridgeshire. Erythrocyte counts were often as low as 7.0 million and sometimes regenerative changes were observed. There was no hypochromia and the weighted mean for 97 ewes from four different sources gave a mean corpuscular volume of 59 c.micra. as compared to 26 c.micra for control ewes. The anaemia is thus classified as hyperchromic or normochromic and macrocytic in type. The ewes in other respects appear to be in good health.

Before leaving this type of anaemia it is important to note that although the M.C.V. showed a large increase in cell size, Innes and Shearer could not demonstrate a significant increase in the Price-Jones curve*. This is in agreement with the findings of Holman and Pattison, when investigating the macrocytic anaemia present with a severe infestation of $H$. contortus. These two isolated observations strongly suggest that macrocytic anaemia in sheep constitutes an increase in depth of the corpuscles without alteration of the corpuscular diameter. Thus there is a point of similarity between macrocytic anaemia in sheep and the anaemia observed in acholuric jaundice in man.

Aplastic Anaemia.-This is distinguished by a low erythrocyte count, without any visible sign of regeneration; that is to say, the red' cells may remain normocytic and normochromic and there is no shift to the left as indicated by the appearance of immature corpuscles such as stippled cells or polychromatic cells. The point at which oligocythaemia ends and aplastic anaemia begins in the sheep is difficult to place.

Wirth (1938) studied regenerative changes in healthy sheep bled to half their normal count and on this basis perhaps it could be said that sheep with red counts as low as 5.5 mil. failing to show regenerative changes during succeeding days were probably suffering from aplastic anaemia.

Using this definition, cases of aplastic anaemia have been seen in lambs affected with nodular necrosis of the liver, in which oligocythaemia was progressive and fell as low as $4 \cdot 0$ mil., myeloid aplasia being indicated by an absence of regenerative changes and a diminution of the shift to the left seen in myeloid leucocytes. In this case aplastic anaemia was secondary to a hypochromic anaemia for both sheep had a haemoglobin concentration that was low in the normal , range.

\section{POLYCYTHAEMIA}

With the term polycythaemia the qualifying adjective "rubra" is understood, hence the term signifies an excess of erythrocytes. Polycythaemia has not been recorded as a primary disease in sheep

\footnotetext{
*In the diagram given by Innes and Shearer the terms "Normal ewe" and " 'Anaemic' ewe" were used to distinguish the two curves. Dr. Innes informs me that each was a composite curve built from the measurements of several thousand corpuscles on smears taken from a number of ewes. The statement made in Part 1 of this work, to the effect that a Price-Jones curve was obtained for " a pregnant ewe" is, therefore, inaccurate.
}

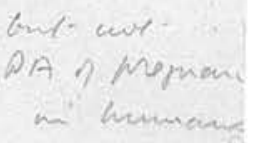


but secondary polycythaemia, or erythrocytosis, has been reported by Fourie as occurring in some cases of $H$. contortus infestation. It was apparent as an increase in the numbers of erythrocytes present for periods up to one fortnight after infestation, and was accepted as being due to the stimulation of haemopoiesis by a continuous haemorrhage.

Relative polycythaemia, or anhydraemia, denotes an apparent increase in red count due to an actual loss of water from the blood. It occurs in sheep affected by the action of $\mathrm{Cl}$. welchii type $\mathrm{D}$ toxin (Gordon et al.) and may be the cause of an occasional high count of, say, 13 or 15 million, in lambs scouring as an effect of worm infestation.

\section{STANDARDS FOR ERYTHROCYTES}

The difficulty of fixing standards for a population suffering from differing degrees of sub-clinical worm infestation was commented upon when discussing standards for leucocytes (Holman, 1944c). All that need be said here is that, in the case of the erythrocytic measurements, there is not the same wide variation as seen in leucocytes, and therefore the estimation of normality and abnormality based on the standard deviation is more reliable. Such estimates for individual animals are given in Table VI, in which abnormalities in erythrocytes are classified as mild, moderate and severe. In addition to these standards, the M.A.D. (95 per cent.) (Holman, 1944b) can be used to detect small changes in experimental animals.

TABLE VI

VARIATIONS IN ERYTHROCYTRS

\begin{tabular}{|c|c|c|}
\hline 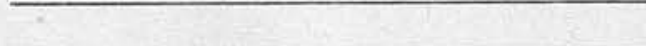 & Mild & Moderate \\
\hline 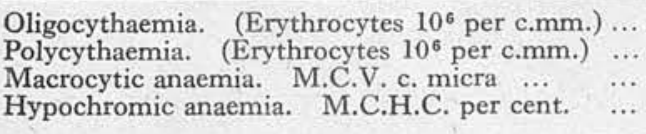 & $\begin{array}{lr}\ldots & 8 \text { to } 6 \\
\ldots & 15 \text { to } 17 \\
\ldots & 38 \text { to } 48 \\
\ldots & 33 \text { to } 28\end{array}$ & $\begin{array}{l}6 \text { to } 4 \\
17 \text { to } 19 \\
48 \text { to } 60 \\
28 \text { to } 24\end{array}$ \\
\hline $\begin{array}{l}\text { Anaemia if not judged by oli } \\
\text { Haemoglobin : g. per } 100 \mathrm{ml} . \\
\text { Haematocrit : } \text { per cent. }\end{array}$ & $\begin{array}{l}\text { ythaèmia } \\
\ldots \quad 9 \text { to } 7 \\
\ldots \quad 23 \text { to } 17\end{array}$ & $\begin{array}{r}7 \text { to } 5 \\
17 \text { to } 12\end{array}$ \\
\hline
\end{tabular}

\section{THROMBOCYTIC PICTURE}

The simple method of counting platelets that was used in this investigation was too unreliable an estimate to be a sensitive guide to small changes, but some increase in numbers was recorded in haemolytic anaemia, confirming Chamberlin's findings in haemolytic anaemia in Australia. An increase in post-haemorrhagic anaemia has not yet been recorded. No cases of thrombocytopenia have been reported in the sheep and the only important change in platelets would appear to be the change in shape observed by Chamberlin 
(as given under "post-haemorrhagic anaemia ") that occurs following an acute loss of blood.

In view of the fact that changes in platelet numbers or shape at present add nothing to what is more easily demonstrated by other measurements, such as the erythrocyte count, it is felt that, as yet, platelets counts have little value in the clinical haematology of sheep.

\section{PHYSICAL PROPERTIES}

Table VII gives the mean figures for various physical attributes of the blood for sheep suffering from a variety of pining conditions. Using the red count as the independent variate it can be seen that the figures for sedimentation in scrapie and Johne's disease fall along the line given by the bled sheep in Table I but that in worm infestation the rate appears less rapid. With viscosity, the figures for scrapie, hypochromic anaemia, and oligocythaemia also fall along the line given by Table I, but the other conditions, including the mean for healthy sheep, give smaller viscosity figures. The figures for specific gravity give a fairly straight line when plotted against the red count, with an exception in the case of oligocythaemia.

TABLE VII

Aykrage Value for Physical Properties in Pining Conditions

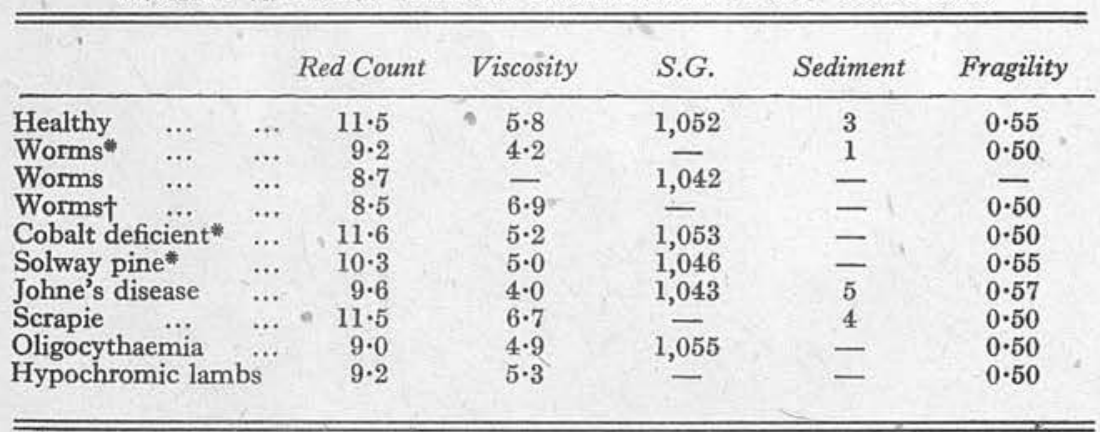

- Stewart and Holman (1944).

† Holman and Pattison (1941) mixed infestation with H. contortus predominant.

Although the mean figures for these ailments show differences in their correlation with the red count, an inspection of the individual figures showed little correlation with the different diseases and offered no easy method of differential diagnosis among the different conditions. These measurements, therefore, in the present state of knowledge, merely confirm what is more accurately measured by other methods, such as the haemoglobin estimation or erythrocyte count. In view of this it does not seem worth while setting standards for these qualities or recommending that they should be used in routine examinations until further investigations have shown what factors among sheep having the same red count are responsible for the wide variation in these measurements. 
The only abnormal figures for sedimentation rate were obtained from two ewes affected with gangrenous mastitis. Although the erythrocyte counts for these ewes were normal, falls of 22 and $32 \mathrm{~mm}$. per 24 hours were recorded. Abnormal viscosity figures were obtained in two ewes: one, affected with pregnancy toxaemia, in which, despite a normal erythrocyte count, the observed figure was 23 and the following day 20 ; the other, a ewe affected with enzootic pneumonia in which a figure of 9.8 was recorded. Other ewes, affected with pneumonia, gave figures of 8.8 and 8.2 for normal red counts.

Fragility was not affected by pining conditions and a change in fragility would appear specific for haemolytic anaemia, where erythrocytes may show total haemolysis in tubes containing even $7 \cdot 5$ per cent. of $\mathrm{NaCl}$. With fragility, however, the difficulty lies in consistently making up solutions of the exact strength with salt that is dried to the same degree, and it may well be that sheep recorded as normal with figures of as little as 0.45 , or as much as 0.65 per cent., represent errors in technique. It is therefore preferable either to use healthy sheep as a control or, with experimental animals, to make use of the M.A.D. ( 0.04 per cent. alteration in 24 hours).

With coagulation time the wide distribution destroys the utility of the normal range and among the numerous experimental and natural cases of disease that have been examined only one case of delayed coagulation time has been observed. This was a case of a ewe severely affected with jaundice in which the coagulation time was seven minutes; in addition, there was persistent bleeding from the puncture. For comparison, a less severe case of this disease, seen in a lamb, showed a coagulation time of only two minutes. Among the experimental animals were five sheep injected with fatal doses of $\mathrm{Cl}$. welchii type D toxin. Here, although the individual figures remained within the normal range, the decrease in coagulation time observed in the group was significant $(\mathrm{t}=5 \cdot 22, \mathrm{n}=4$ and $\mathrm{p}=0 \cdot 01 / 0.001)$. Here again, unless statistical tests are used, the M.A.D. of 1.5 minutes for coagulation time is the more sensitive standard for experimental animals, and with this standard two of the sheep showed a significant decrease in coagulation time with a third sheep on the border line with a decrease of 1.5 minutes.

\section{SUMMARY}

The anaemias of sheep are classified as post-haemorrhagic, haemolytic and dyshaemopoietic. Dyshaemopoietic anaemies are further classified as simple oligocythaemia, hypochromia, "hyperchromic " (normochromic macrocytic) anaemia of Innes and Shearer, and aplastic anaemia. Microcytic anaemia has not been observed and macrocytic anaemia is remarkable in that no increase in corpuscular diameter could be demonstrated.

Primary polycythaemia has not been recorded but secondary polycythaemia (erythrocytosis) was reported by Fourie, and relative 
polycythaemia (anhydraemia) occurred in some cases of worm infestation and in poisoning by $\mathrm{Cl}$. welchii type $\mathrm{D}$ toxin.

Standards for the classification of abnormalities in erythrocytes are given as a table.

Changes in the size and shape of thrombocytes have been recorded in haemolytic anaemia (Chamberlin) and in post-haemorrhagic anaemia. Thrombocytopenia has not been recorded. The counting of platelets by the technique employed (Holman 1944b) appears of little practical value.

Small changes in both fragility and coagulation time are more easily distinguished, where possible, by the use of the M.A.D. (Holman, 1944b) than by the use of the normal range. An increase in fragility was recorded in haemolytic anaemia due to $\mathrm{Cl}$. welchii type A toxin, and a decrease in coagulation time was produced by lethal doses of $\mathrm{Cl}$. welchii type D toxin.

Other physical measurements, specific gravity, sedimentation and viscosity, showed great irregularity and were of no help in a differential diagnosis among the pining conditions.

\section{RBFERENCES}

Andrew, J. S. (1942). F. agric. Res., 65, 1.

Beattie, J. M., and Dickson, W. E. C. (1943). A Textbook of Pathology. 4th ed. London: Heinemann.

Chamberlin, W. E. (1933). Aus. vet. F., 9, 2.

Fourie, P. J. J. (1981). Rep. Director vet. Research, Dept. Agric., Onderstep., S. Africa, 17, 495.

Fraser, A. C. (1930). Rep. Inst. anim. Path., Univ. Camb., 1, 114.

Gordon, W. S., Stewart, J., Holman, H. H., and Taylor, A. (1940). F. Path. Bact., 50, 251.

Groen, J. (1940). Chem. Weekblad, 37, 106. Quoted from: Biol. Abstracts (1941), 15, 23816.

Holman, H. H. (1944a). F. comp. Path., 54, 26; (1944b). Ibid., 4, $179 ;(1944 c)$. Ibid., 207.

Holman, H. H., and Pattison, I. H. (1941). Vet. Rec., 53, 491.

Innes, J. R. M., and Shearer, G. D. (1940). F. comp. Path., 53, 1.

Vaughan, J. M. (1936). The Anaemias. London: Oxford Univ. Press.

Whitby, L. E. H., and Britton, C. J. C. (1939). Disorders of the Blood. 3rd ed. London: Churchill.

Wintrobe, M. M. (1942). Clinical Haematology. Eondon: Kempton.

Wirth, D. (1931). Grundlagen einer Klinischen Hämatologie der Haustiere. Berlin: Urban and Schwarzenberg.

Wirth, D. (1938). 13th Inter. vet. Congress. ,p. 273.

[Received for publication August 29th, 1944] 


\title{
V.-A SURVEY OF BLOOD PICTURES IN SHEEP DISEASES
}

By

\author{
H. H. Holman \\ Animal Diseases Research Association, Moredun Institute, Gilmerton, Midlothian
}

\section{INTRODUCTION}

IN previous articles (Holman, 1944a, 1944b, 1944c, 1945) standards and definitions for blood abnormalities were determined, and it now remains to apply them to sheep diseases of which the blood picture has been observed. For the classification of diseases the arrangement given in the Report on Diseases of Farm Livestock, Section 2 (Anon, 1944) has been followed.

\section{DISEASES CAUSED BY BACTERIA}

\section{Entero-Toxaemic Diseases of Sheep}

In this group death is due to the toxins of the $\mathrm{Cl}$. welchii group of organisms. The effect of intravenous injection of fatal doses of these toxins has been investigated (Gordon, Stewart, Holman, and Taylor, 1940; Holman, unpublished), and the principal alterations in the blood picture are shown in the table. With Type A, the table shows the temporary agranulocytosis produced, lymphocytes and monocytes representing 97 or 98 per cent. of the leucocytes, and the haemolytic anaemia, indicated by low red counts accompanied by an increase in fragility. This anaemia with increased fragility also occurs in non-fatal cases. One case shows a very abnormal coagulation time. With Type B there was a leucopenia affecting both granular and non-granular" cells. With Type $\mathrm{C}$ there were no distinct changes. With Type D there was a leucopenia as with Type B as well as haemo-concentration and some decrease in coagulation time.

Lamb Dysentery. Hare and Glynn (1927) recorded the blood picture in an outbreak of lamb dysentery. Changes were limited to leucocytosis, although most lambs exhibited a neutrophilia some hours before death. The lower average red count apparent a few hours before death was mainly due to one lamb with a count of only $5 \cdot 3$ mil. Fraser (1930) recorded another outbreak in which red and white counts were made on only three lambs, the picture being similar to that mentioned above for Type B toxin, that is, a leucopenia without the haemo-concentration observed with Type D.

Pulpy Kidney Disease.-Death occurs so rapidly in this disease that it is hard to procure affected sheep before death. In the case recorded in the table the blood picture resembled that for Type D toxin.

\section{Staphylococcal Infections}

Different degrees of leucocytic reaction following experimental infections with Staph. aureus have been described (Holman, 1944c). Cases of natural infection are recorded in the table.

Gangrenous Mastitis of Ewes. Four cases are recorded; in the second case the severity of the infection caused a leucopenia and it. was sufficiently prolonged to set up toxic changes in the neutrophils.

Tick Pyaemia. The usual neutrophilic reaction is observed, and in one case a tendency to haemo-concentration is apparent.

Foint-Ill. Four cases are recorded. A pure growth of Staphylococcus was recovered from the synovial fluid in the two cases tested, but no neutrophilic reaction was observed presumably owing to the lesions being strictly localised. 
Paratuberculosis (Fohne's Disease). Ten cases in a late stage of infection are given. All showed a neutrophilia characterising the invasion phase of infection, although the degree of reaction varied from 'case to case. The erythrocytic picture for all sheep gave figures for the M.C.H.C. below the normal mean and in two the figures indicated a slight hypochromic anaemia.

Pyobacillosis : Infection due to Actinobacillus lignieresi. In three sheep examined from one outbreak, showing involvement of the lymph glands, abnormality, where present, was limited to a neutrophilia; the erythrocytic picture was normal although the red counts were low compared with those of three healthy sheep in the same flock. In another outbreak the haemograms were completely normal in two sheep in which the lesion was confined to an open abscess of the jaw.

Fusiformis necrophorus Infection in Lambs. Two lambs about six months old, were examined, both dying emaciated, with extensive necrotic areas of the liver at autopsy. In the first lamb, a neutrophilic reaction commenced 26 days before death, leading to a constant mild relative neutrophilia with occasional periods of leucocytosis. In the second, a slight relative neutrophilia was observed ten days before death, and later occasional periods of leucocytosis were apparent with a varying shift to the left. In both cases the neutrophilic reaction decreased with the onset of a myeloid hypoplasia before death. Oligocythaemia, apparent 23 days before death in one lamb and 33 days before death in the other, progressed to an aplastic anaemia. In a third case recorded, limited to a single sample from a three-week-old lamb which was suffering also from tickborne fever, the change was limited to a neutrophilic reaction.

\section{DISEASES CAUSED BY VIRUSES AND RICKETTSIA}

Louping-Ill : Trembling. Selected figures from the blood picture in louping-ill investigated by Holman (Taylor, Holman and Gordon, 1941) are recorded in the table. The first sample is pre-experimental. The second sample, taken two days after inoculation, shows a very slight neutrophilic reaction. The third sample, taken half-way through the course of the disease, is unremarkable, and the final sample taken 20 days after inoculation shows the eosinophilia of recovery. There is no neutropenia and staphylococcal infection can stimulate neutrophilia.

Contagious Pustular Dermatitis. Four sheep infected by scarification were examined over a period of 14 days. Scarification was followed by a slight, transient neutrophilia; later there was some decrease in eosinophils, followed on the 14th day by the eosinophilia of recovery.

Scrapie. Bleedings were carried out on 15 affected sheep. The first line in the table shows the averages for the first sample taken from each of the 15 sheep. The second line shows the averages for the last samples, taken from ten sheep, where these were taken more than nine days before death. The third line shows the last samples taken, from the five other sheep, less than ten days before death. Then alone abnormalities became apparent, consisting of eosinopenia and neutrophilia.

Tick-borne fever. The blood picture as recorded by Taylor et al. comprised a neutropenia followed by an esinophilia of recovery. Haemograms from these authors' records giving the minimum neutrophil proportion observed in four lambs are reproduced in the table. In one case the figure is of very low normal value. This neutropenia is obliterated if intercurrent infection stimulates a neutrophilic reaction. Rickettsial bodies may be seen in neutrophils, eosinophils and monocytes during the febrile stage of the disease, before the onset of neutropenia.

\section{DISEASES CAUSED BY ENDO-PARASITES}

Figures for sheep suffering from a severe mixed infestation in which Haemonchus contortus was predominant, are given in the table. In flock A, ten sheep were sampled; three exhibited a macrocytic anaemia, three a hypochromic anaemia, and one a slight neutrophilia ; in the remainder of the flock, the haemograms were normal. Changes in this flock following the administration of phenothiazine have been 
recorded by Holman and Pattison (1941). Among sheep sent in for diagnosis the same abnormalities can be seen, except that being more emaciated than the sheep in flock A, neutrophilia was always present, while one case showed anhydraemia due, perhaps, either to persistent scouring or to the onset of collapse.

These findings agree with those of Fourie (1931), who produced experimental infestations with $H$. contortus alone. In some cases he recorded a macrocytic anaemia and a neutrophilia that became evident some weeks after infestation. Fourie believed that macrocytosis was an attribute of post-haemorrhagic anaemia. Andrews (1942), also working with infestations of $H$. contortus, agreed that the anaemia was post-haemorrhagic in type, but did not record macrocytosis. Holman and Pattison (1941), however, suggested that where macrocytosis was also apparent, a dysfunction involving a haemopoietic principle might be involved.

In mixed infestations Fraser and later Holman and Pattison (1942) found that in the mild ones there was no alteration of the blood picture. Further, in 63 sheep where the worm egg counts varied from 0 to 2,500 , no correlation could be found between the counts and the figures for haemoglobin, neutrophils or eosinophils (Holman, unpublished). On the other hand, from the figures given by Stewart and Piercy (1935) for 30 sheep in a border pine area, in which worm egg counts varied over the same range, it was seen that both the haemoglobin concentration and the eosinophil percentage were very significantly higher where the worm egg counts were under 200 per g. but that the neutrophil percentage again showed no correlation.

In heavy infestations Fraser, and, later, Stewart and Piercy (1934) reported a lower neutrophil percentage. Considering the latitude of the normal range, the lack of correlation between the neutrophil percentage and the worm egg count in 93 sheep as recorded above, and in the case of Stewart and Piercy, the fact that the highest worm egg 'counts (those over 8,000 per g.) correlated with neutrophilia, their statement is not convincing.

When the blood picture of those infestations in which $H$. contortus is known to be absent, or only present in sparse numbers, is inspected in the table it will be seen that there is little chance of differentiating between infestation with one species and with another by means of the blood picture. Severe infestations of various types lead to hypochromic anaemia, neutrophilia and eosinopenia. A possible exception may occur in the case of liver fluke infestation, where dysfunction of the liver may lead to an aplastic anaemia as occurs when it is infected with $F$. necrophorus.

Three cases of sturdy (coenurus cerebralis infection) have been examined (not included in table). In one the cyst was present in the lumbar region causing paralysis in a hind limb and in the other two large cysts were present in the cerebrum. None of these cases showed any tendency to a neutrophilia or a neutrophilic shift, and the blood picture was completely normal with an eosinophil percentage varying from 2 to 8 , and basophil percentages of 0,2 and 3 . Haemograms from two sheep infested with coccidia gave a pattern similar to worm infestation with one sheep anaemic and the other showing anhydraemia and neutrophilia. Eosinophil percentages were normal.

A. review of the literature adds little of value for differential diagnosis among the various helminth infestations. Fourie (1937) produced a pure experimental infestation with Os. columbianum. His records showed periods of neutrophilia nine weeks after infestation and a recurrence before death. Eosinophils increased between the fifth and eighth weeks but then receded until death; there was a slight but continuous fall in erythrocytes to a figure of 8.4 mil. before death. Andrews (1938) produced an experimental infestation with C. curticei but only observed a simple leucocytosis. Wirth (1931), quoting work on liver fluke infestation, records a transient increase in leucocytes followed, in cases of severe infestation, by neutrophilia. Eosinophils increased early in infestation and could reach 47 per cent. of the count, but their proportion did not necessarily correlate with the severity of infestation. Anaemia corresponded to the degree of emaciation present. With regard to parasitic bronchitis, Mönnig (1941) states only that anaemia may be marked, while, with regard to tape worms, Burnett (1917) names several species that produce anaemia in cows and sheep but gives no figures. 


\section{DISEASE DUE TO METABOLIC DISORDERS}

Pine. The blood pictures for cobalt-deficiency pine and for "Solway" pine, including both the biochemical and cytological findings, were recorded by Stewart and Holman (1944); the averaged figures for the haemogram are repeated in the table. Normals from the same flocks have not been included. Where differences were found to occur among the affected lambs they showed a bias towards oligocythaemia, hypochromia and relative neutrophilia. These abnormalities could be explained on the grounds alone that the lambs which were emaciated were more subject to severe worm infestation. The same authors (unpublished data) fed a cobalt salt to a cobalt deficient ewe but failed to increase the red count, a result similar to that obtained by Josland (1937).

The blood picture for "Northumberland" pine, another condition dependent on a combination of deficiency and worm infestation, has been recorded by Stewart and Piercy (1935), who similarly concluded that changes in the blood picture, when present, were due to worm infestation.

The figures recorded by Innes (1935) of the blood picture of lambs affected with swayback are reproduced in the table: neutrophilia was apparent in some lambs and five out of the seven showed eosinopenia. Innes and Shearer (1940) presumed that the lower red counts were due to starvation. The possibility of worm infestation was not excluded.

Pregnancy Toxaemia. The haemogram of a ewe carrying twin lambs is recorded in the table; it agrees with the blood picture described by Clark (Groenwald, Graf, Bekker, Malan and Clark, 1941), who found that a relative and progressive neutrophilia, commencing several days before the onset of clinical symptoms, was the only change. The high red count arising in the ewe five hours before death presumably marks the onset of collapse.

Parturient Hypocalcaemia : Lambing Sickness. The only abnormality in the two cases recorded was a slight neutrophilia together with eosinopenia.

Double Scalp: Scappie. In addition to being affected with scappie, the two cases recorded unfortunately had high worm egg counts (2,000 and 11,000 per g.), and this forms an alternative explanation for the low red counts.

Inanition. Clark (Groenwald et al.), working on the blood picture of pregnancy toxaemia (Domsiekte), starved sheep that were known to be free from worms. He found that a relative neutrophilia occurred after about seven days' semi-starvation in pregnant ewes and after about 26 days in non-pregnant ewes. He made the important observation that after periods extending to 50 days on inadequate rations there was no alteration in the erythrocytic picture, as shown by haemoglobin estimation or haematocrit readings.

This observation supports those obtained in cobalt deficiency, scrapie, Solway pine, border pine and swayback, where inanition exists owing to the animal's inability to graze, and in which marked emaciation and debility may exist in sheep that show no sign of anaemia. It also suggests that when anaemia is seen in some sheep in flocks affected with these conditions it may be due to an intercurrent infestation with worms.

Enzootic Toxaemic faundice. Chamberlin'(1933). Hypochromic Anaemia. Hyperchromic Anaemia of Pregnant Ewes. Innes and Shearer (1940). These conditions are presumed to be due to metabolic disorders but have already been described under Anaemia (Holman, 1945). 
PATHOLOGY-H. H. HOLMAN-TWO-A

\section{DISEASES OF UNKNOWN AETIOLOGY}

Photosensitisation: Yellowses. Two cases are recorded: in one, the only abnormality was eosinopenia; in the other, which was severely affected, there was a marked neutrophilic reaction and an abnormally long coagulation time. This abnormal coagulation time was confirmed by a second test carried out 20 minutes later, and was intelligible through the finding later at post-mortem examination of an enlarged " nuţmeg" type of liver.

Enzootic Pneumonia. Cases from three outbreaks have been recorded and these have been arranged in the order that appears to portray the course of the reaction. In the first case examination was limited to a blood smear; in this there was a marked relative neutrophilia and a severe shift to the left but the total number of leucocytes appeared normal. In the second case a severe shift to the left was again apparent but the neutrophils were low in proportion and a leucopenia was recorded. In the third case haemograms from three sheep showed a leucopenia in which there was complete agranulocytosis. This sequence suggests that in this disease granular leucocytes are removed from the peripheral blood so fast that despite the increased production as shown by the severe shift to the left, the condition ends as an agranulocytosis.

\section{DISEASE DUE TO POISON}

Arsenic. Haemograms are recorded for two sheep given an intra-peritoneal injection of an arsenical compound. Unfortunately the preliminary red counts were already low. A slight neutrophilia is seen together with a steady fall in red count leading to regenerative changes.

Lead. Rupp (1928), quoted by Wirth, gave sheep $5 \mathrm{mg}$. of lead twice a week, sometimes by mouth and sometimes by subcutaneous injection. The red count was reduced, in one case to one-fifth of the original count, and between 18 to 32 days after the first dose punctate basophilia was observed, reaching a proportion up to eight corpuscles per 1,000; polychromasia and reticulocytes were present in the pre-experimental samples. Other authors failed to produce regenerative changes.

Phenothiazine. Two six-month-old lambs were each given a dose of $80 \mathrm{~g}$. of phenothiazine and another lamb was given twice this amount. No alteration was observed in the blood picture.

Sulphanilamide. Three cases are recorded in the table. Little change occurred in the leucocytic picture except for a terminal neutrophilia in the fatal case; there was no suggestion of agranulocytosis. Haemoglobinuria indicated haemolysis, but this was too slight to cause haemolytic anaemia. 


\section{SUMMARY OF SURVEY}

Entero-toxaemic Diseases. In lamb dysentery where, presumably, $\mathrm{Cl}$. welchii Type B toxin was predominant, a leucopenia without haemo-concentration occurred. The outbreak described by Hare and Glynn suggested that in some cases the gamma toxin might be predominant giving a reaction similar to Type $\mathrm{C}$ toxin. In pulpy kidney disease the reaction to Type D toxin was seen as a leucopenia together with haemo-concentration.

Pyogenic Organisms. There was a typical neutrophilic reaction varying in degree with the severity of infection and absent when infection was localised. Pyobacillosis involving lymph glands produced oligocythaemia.

Paratuberculosis. A variable neutrophilia occurred and there was a tendency towards hypochromic anaemia.

Fusiformis necrophorus Infection. A variable neutrophilia occurred with periods of leucocytosis. Oligocythaemia was progressive and terminated in an aplastic anaemia.

Viruses. No neutrophilic reaction, except that due to trauma, was observed. Eosinophils decreased during infection, except in scrapie, and increased during the recovery phase. Neutrophilia could be stimulated by intercurrent infections. In scrapie an eosinopenia and a slight neutrophilic reaction was usual for a period of a few days before death.

Rickettsia. With tick-borne fever, the bodies could be seen in neutrophils, monocytes and eosinophils during the febrile reaction, preceding the decrease in the proportion of neutrophil cells which usually amounted to neutropenia. Eosinophils decreased in numbers during the course of the disease and recovery was heralded by the usual increase.

Endo-parasites. Records from this survey and from a review of the literature show that neutrophilia may occur after some weeks in badly infested sheep. Eosinophils decrease in numbers - although in certain cases, with more mild infestations, this decrease is preceded by a transient eosinophilia : recovery is heralded by the usual eosinophilia. Where $H$. contortus is predominant anaemia is posthaemorrhagic and may be macrocytic; with liver flukes anaemia may be aplastic, and with other species there is a tendency to a hypochromic anaemia.

Metabolic Disorders. Excluding enzootic toxaemic jaundice, hyperchromic anaemia and hypochromic anaemia, no changes in the cytology were observed except those attributed either to starvation or worm infestation.

Unknown Aetiology. Yellowses, where severe, showed a marked neutrophilia, eosinopenia, and prolonged coagulation time. Enzootic pneumonia was accompanied by a marked neutrophilic shift, despite which leucopenia, and finally agranulocytosis, was observed.

Poisons. No general reaction can be laid down. 


\section{GENERAL DISCUSSION}

Haematology is based on measurement, and until the measurements for each constituent in each species are compared to absolute standards, rather than relative ones, veterinary literature will continue to contain different articles with the same figure recorded by one worker as, for example, a leucopenia, and by another as a normal leucocytic count. It is evident that comparative measurements between flock and flock, or herd and herd, ignore all environmental factors and allow full play for personal bias.

In these studies, therefore, an attempt has been made to set absolute standards for the sheep, acting on the principle that such standards can be adjusted as knowledge in the diagnosis of minor ailments is improved, but that in the meantime they afford a practical means of detecting gross changes and subordinating personal bias.

That the standards set are to some extent incorrect is suggested by the frequency distribution given for apparently healthy animals (Holman, 1944a) where, for example; the histogram for neutrophils shows a negative skew and the haemoglobin a positive one. The possible explanation of this bias towards neutrophilia and towards anaemia is suggested in this survey which shows that worm infestation and certain types of deficiency in diet bias the figures in that direction. Hence it would appear likely that if sheep suffering from deficient diet and worm infestation could be eliminated from among apparently healthy sheep, the normal range for some, perhaps most, constituents could be reduced.

To gain some perspective on the alteration in blood picture due to disease it is advantageous to compare these haemograms with those recorded for man, the only species for which extensive data are available. The difference in reaction in the case of pyogenic organisms and the difference in corpuscular shape in macrocytic anaemia between sheep and man has already been described (Holman, $1944 \mathrm{c}, 1945)$.

With regard to virus diseases, these, in man, generally produce a neutropenia, except where the central nervous system is involved, when a neutrophilia is observed. In sheep, although there is no neutrophilia, neutropenia is not apparent, nor is there a leucocytosis in virus infections that affect the central nervous system, such as louping ill and scrapie. In intestinal parasitism, H. contortus has its analogue in hookworm infestation in man, but again there is a difference, for in man the anaemia is hypochromic and there is a high eosinophil count, while in sheep there is a tendency for the anaemia to become hyperchromic and there is an eosinopenia. A hyperchromic anaemia does, however, occur in man due to the depredations of Diphyllobothrium latum, but here the anaemia is thought to be due to the failure of the gut to assimilate the haemopoietic principle (Whitby and Britton, 1939), whereas in H. contortus infestations in sheep the macrocytic anaemia has been regarded as an attribute of rapid haemopoiesis. The hyperchromic anaemia of pregnant ewes has an analogy in a nutritional macrocytic anaemia occurring in pregnant women and further it is of interest to note that a nutritional macrocytic anaemia also occurs in the dog where it is produced by the absence of nicotinic acid (Hadfield and Garrod, 1943). Agranulocytosis in man occurs either as an idiopathic disease associated with necrotic ulcerations or as a result of poisoning by various substances that include sulphanilamide. In the sheep, the evidence is against the hypothesis that even fatal doses of sulphanilamide produce agranulocytosis, but the condition is seen in both enzootic pneumonia and in fatal toxaemia due to $\mathrm{Cl}$. welchii, Type A, the latter being an organism that produces intense leucocytosis in man. These selected comparisons make it clear that, although analogies often exist between the blood pictures of man and sheep, as in all other experimental work it is a dangerous expedient to argue from one to the other on the assumption that the blood picture is similar in the two species. 


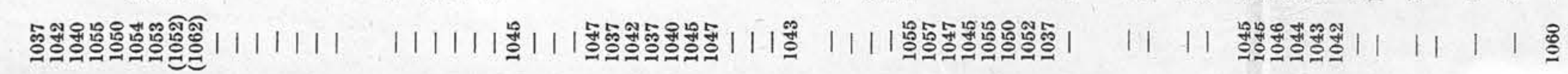

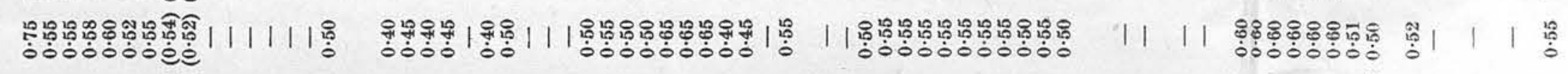

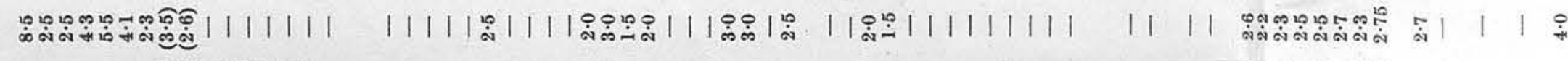

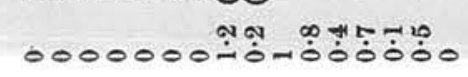

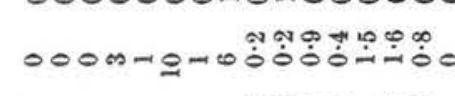

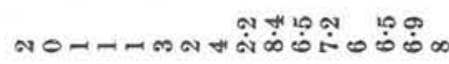

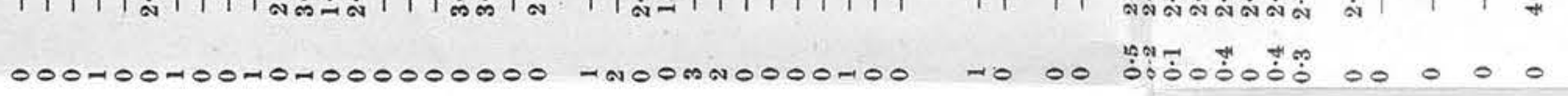

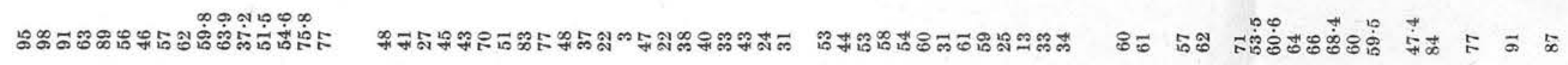

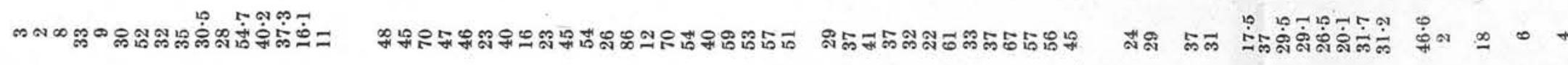

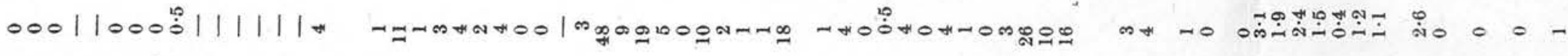

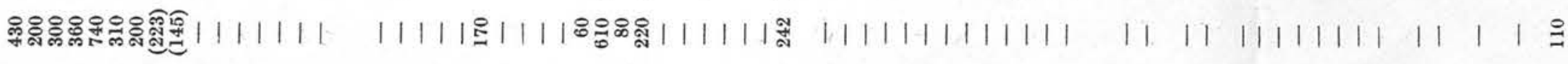

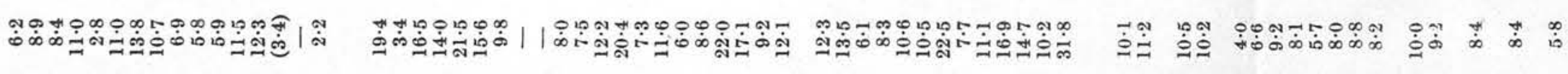

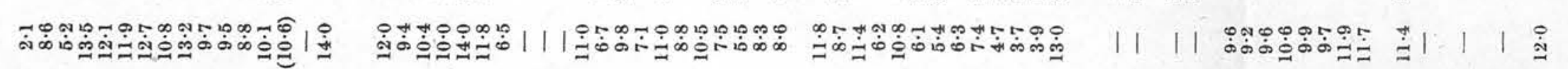

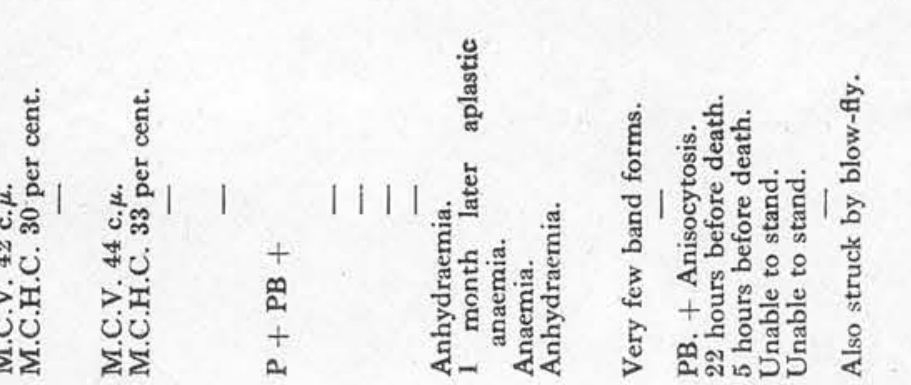

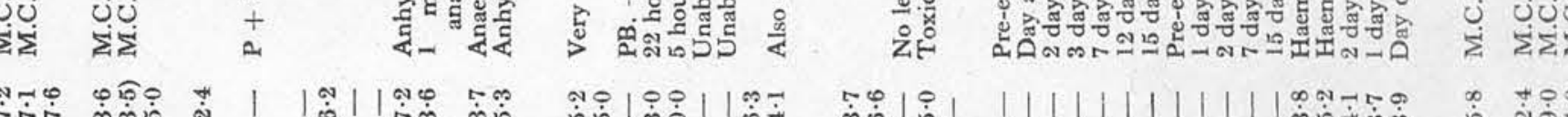

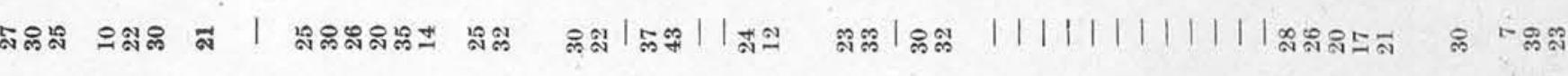

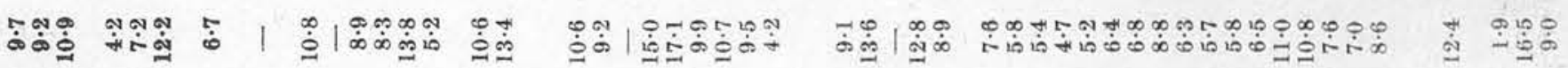

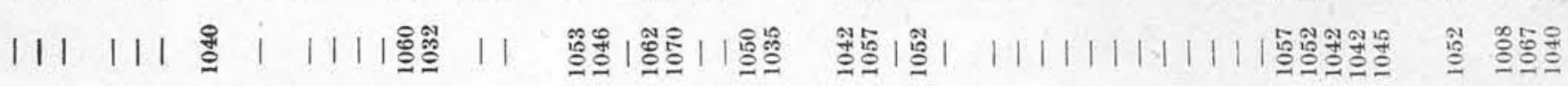

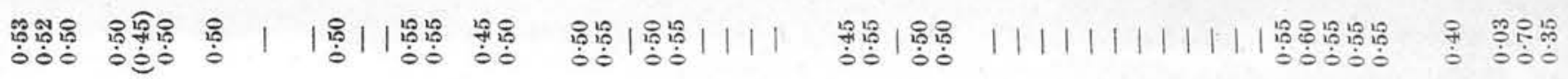

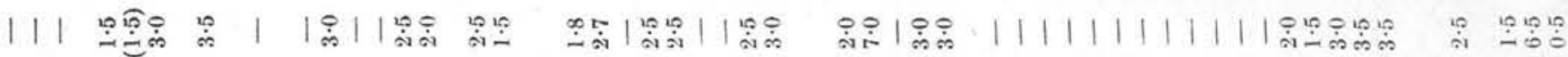

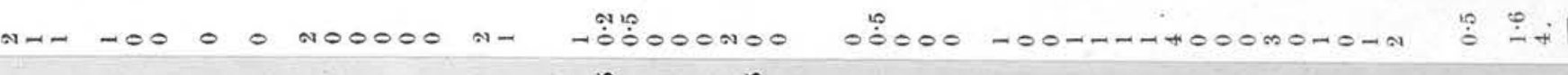
bon

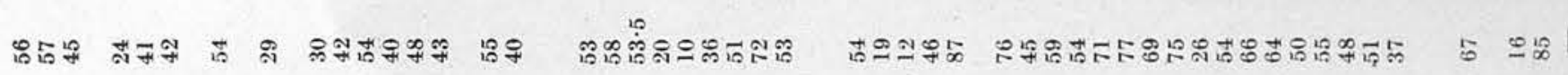

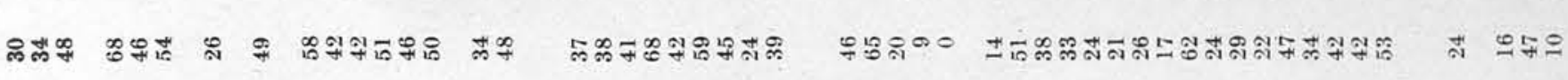

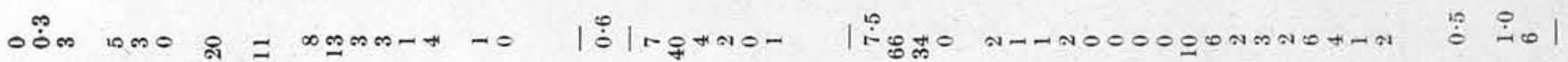

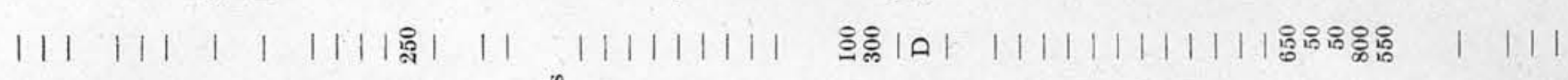

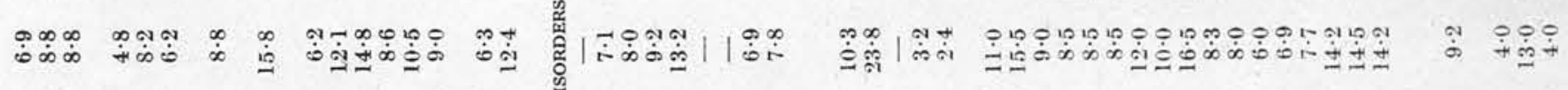

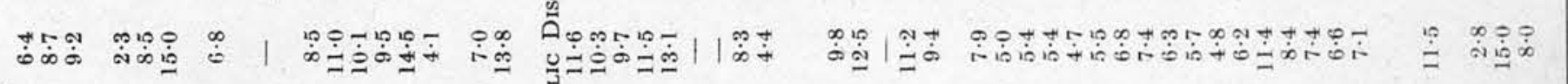

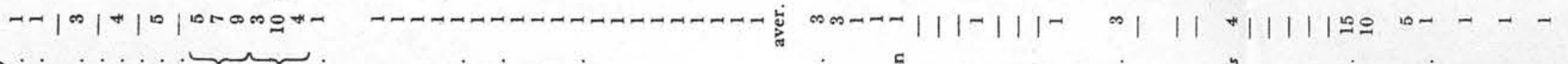

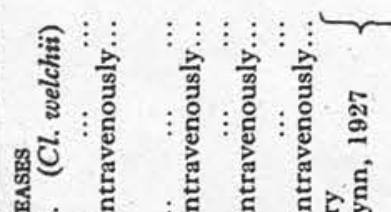




\title{
THE BLOOD PICTURE OF "PINING" CONDITIONS IN SHEEP
}

By

\author{
James Stewart and H. H. Holman, \\ Moredun Institute, Animal Diseases Research Association, Gilmerton, Midlothian
}

\section{INTRODUCTION}

THE blood picture of three sheep "pine" diseases, namely, Worm Infestation, Cobalt Deficiency, and Solway Pine, was investigated to ascertain whether differential diagnosis could be obtained. The symptoms in all three diseases are those of progressive debility: growth is retarded, soon after weaning lambs appear stunted and unthrifty, the wool becomes broken, a serous discharge from the eye is common, emaciation and weakness progress until the animal in a state of extreme asthenia is unable to rise, and it then usually dies. Correct diagnosis is a matter of great importance since losses are large despite routine anthelmintic treatment and the feeding of cobalt supplements in those areas where soils are known to be deficient in cobalt.

The methods used in blood examination have been described in previous papers by the authors (Stewart and Holman, 1940 ; Stewart, Gordon and McCallum, 1940 ; Holman and Pattison, 1941).

The data obtained in the present investigation are summarised in Table I, wherein the mean values and the standard deviation from the mean are presented as these figures furnish sufficient evidence to indicate the range of variation in concentration of each of the blood constituents. .

\section{NORMAL SHEEP}

The values are given in the Table for the chemical constituents of the blood of healthy lambs obtained from various parts of Scotland. From the comparative standpoint it may be stated that they were of the same age, circa six months, and were fed on a similar diet, namely, summer grass, to the "pining" lambs. The cytological picture and the normal variation in physical constituents of the blood were determined in animals that were more varied both in regard to age and diet, and included most of the above 40 lambs used for determining the chemical picture, as well as some adults.

Most of the values obtained are in keeping with those recorded by other authors. A wide range of concentration of most of the blood constituents and especially of the sugar, for which the mean was $61 \mathrm{mg}$. per $100 \mathrm{ml}$. with a S.D. of $10 \cdot 8$, is displayed.

\section{WORM INFESTATION}

Worm infestation is found in the greatest number of "pining" sheep. When it is not the primary it is often a secondary cause of much of the debility. As is well known, sheep in a weakened state 
TABLE

The Blood-Picture

\begin{tabular}{|c|c|c|c|c|c|c|c|c|c|}
\hline & \multirow{2}{*}{\multicolumn{3}{|c|}{ Normal Sheep }} & \multirow{2}{*}{\multicolumn{3}{|c|}{ Worm Infestation }} & \multirow{2}{*}{\multicolumn{3}{|c|}{$\begin{array}{l}\text { Healthy Lambs off } \\
\text { same Farms }\end{array}$}} \\
\hline & & & & & & & & & \\
\hline & $\begin{array}{l}\text { No. } \\
\text { of } \\
\text { Animals }\end{array}$ & $\begin{array}{l}\text { Mean } \\
\text { Value }\end{array}$ & $\begin{array}{l}\text { Stand. } \\
\text { Dev. } \\
\text { from } \\
\text { Mean } A\end{array}$ & $\begin{array}{c}\text { No. } \\
\text { of } \\
\text { Animals }\end{array}$ & $\begin{array}{l}\text { Mean } \\
\text { Value }\end{array}$ & $\begin{array}{l}\text { Stand. } \\
\text { Dev. } \\
\text { from } \\
\text { Mean }\end{array}$ & $\begin{array}{c}\text { No. } \\
\text { of } \\
\text { Animals }\end{array}$ & $\begin{array}{l}\text { Mean } \\
\text { Value }\end{array}$ & $\begin{array}{l}\text { Stand. } \\
\text { Dev. } \\
\text { from } \\
\text { Mean }\end{array}$ \\
\hline $\begin{array}{l}\text { Sugar (mg: per } 100 \\
\text { ml. blood) }\end{array}$ & 40 & $61 \cdot 0$ & $\pm 10 \cdot 8$ & 20 & $62 \cdot 5$ & $\pm 14 \cdot 1$ & 10 & $37 \cdot 1$. & $\pm 9 \cdot 1$ \\
\hline $\begin{array}{l}\text { Hb. (g. per } 100 \mathrm{ml} \text {. } \\
\text { blood) } \ldots\end{array}$ & 40 & $11 \cdot 2$ & $\pm 1 \cdot 1$ & 20 & $6 \cdot 9$ & $\pm 1 \cdot 61$ & 10 & $11 \cdot 3$ & \pm 0.48 \\
\hline $\begin{array}{l}\text { Cl. (mg. per } 100 \\
\text { ml. blood) }\end{array}$ & 40 & $507 \cdot 0$ & $\pm 20 \cdot 7$ & 18 & $543 \cdot 0$ & $\pm 58 \cdot 4$ & 10 & $494 \cdot 0$ & $\pm 11 \cdot 1$ \\
\hline $\begin{array}{l}\text { Ca. (mg. per } 100 \\
\text { ml. serum) }\end{array} \ldots$ & 40 & $10 \cdot 7$ & \pm 0.65 & 17 & $9 \cdot 5$ & \pm 0.85 & 10 & $9 \cdot 8$ & $\pm 1 \cdot 1$ \\
\hline $\begin{array}{l}\text { mi. serum) } \\
\mathrm{Na} \text {. (mg. per } 100\end{array}$ & 40 & $20 \cdot 5$ & $\pm 1 \cdot 84$ & - & - & - & - & - & - \\
\hline $\begin{array}{c}\text { ml. serum) } \\
\text { Inorg. P. (mg. per }\end{array}$ & 25 & $34 \cdot 0$ & $\pm 11 \cdot 2$ & 一 & - & - & - & - & $\therefore-$ \\
\hline $\begin{array}{l}100 \mathrm{ml} \text {. blood) } \\
\text { Total P. (mg. per }\end{array}$ & 40 & $5 \cdot 3$ & \pm 0.52 & 7. 18 & $4 \cdot 9$ & \pm 0.99 & 10 & $7 \cdot 0$ & \pm 0.9 \\
\hline $\begin{array}{l}100 \mathrm{ml} \text {. blood) } \\
\text { N.P.N. (mg. per }\end{array}$ & 40 & $9 \cdot 9$ & \pm 0.94 & 17 & $9 \cdot 6$ & $\pm 1 \cdot 2$ & 10 & $13 \cdot 5$ & $\pm 1 \cdot 6$ \\
\hline $\begin{array}{l}100-\mathrm{ml} \text {. blood) } \\
\text { Amino N. (mg. per }\end{array}$ & 40 & $33 \cdot 3$ & $\pm 5 \cdot 3$ & 19 & $39 \cdot 9$ & $\pm 13 \cdot 1$ & 10 & $44 \cdot 9$ & $\pm 3 \cdot 9$ \\
\hline $\begin{array}{l}100 \mathrm{ml} \text {. blood) } \\
\text { R. B. C.s million }\end{array}$ & 40 & $7 \cdot 3$ & $\pm 0 \cdot 47$ & 18 & $7 \cdot 4$ & $\pm 1 \cdot 64$ & 10 & $11 \cdot 5$ & $\pm 1 \cdot 7$ \\
\hline $\begin{array}{l}\text { per c.mm. } \\
\text { Pkd. cell vol. per }\end{array}$ & 100 & $11 \cdot 5$ & $\pm 1 \cdot 8$ & 16 & $9 \cdot 2$ & $\pm 2 \cdot 9$ & 10 & $13 \cdot 1$ & $\pm 1 \cdot 5$ \\
\hline $\begin{array}{cc}\text { cent. } \quad \ldots & \ldots \\
\text { M.C.V. }(\text { c. } \mu) & \ldots\end{array}$ & 100 & $29 \cdot 0$ & $\pm 4 \cdot 0$ & 15 & $22 \cdot 0$ & $\pm 4 \cdot 9$ & 10 & $31 \cdot 0$ & $\pm 2 \cdot 6$ \\
\hline $\begin{array}{l}\text { M.C.V. }(\text { c. } \mu) \\
\text { M. C. H. C. per } \\
\text { cent. }\end{array}$ & 100 & 27 & $\pm 3 \cdot 6$ & 15 & 26 & $\pm 6 \cdot 4$ & 10 & 24 & $\pm 3 \cdot 3$ \\
\hline $\begin{array}{l}\text { cent. } \ldots \\
\text { Fragility per cent. } \\
\mathrm{NaCl}\end{array}$ & 100 & $41 \cdot 0$ & $\pm 4 \cdot 0$ & 14 & $34 \cdot 0$ & $\pm 5 \cdot 8$ & 10 & $42 \cdot 0$ & $\pm 3 \cdot 1$ \\
\hline S.G. aq. $=1,000 \ldots$ & $\begin{array}{l}100 \\
100\end{array}$ & $\begin{array}{r}0.55 \\
1,052\end{array}$ & $\begin{array}{l} \pm 0 \cdot 04 \\
\pm 5\end{array}$ & $\underline{10}$ & $\underline{0.50}$ & \pm 0.04 & $\begin{array}{l}10 \\
10\end{array}$ & $\begin{array}{r}0.50 \\
1,055\end{array}$ & $\begin{array}{l} \pm 0 \cdot 04 \\
\pm 2\end{array}$ \\
\hline $\begin{array}{l}\text { Viscosity } \\
\text { W.C. thous. per }\end{array}$ & 100 & $5 \cdot 8$ & $\pm 1 \cdot 0$ & 10 & $4 \cdot 2$ & $\pm 1 \cdot 3$ & 10 & 6.5 & $\pm 1 \cdot 2$ \\
\hline $\begin{array}{l}\text { c.mm.... } \\
\text { Polymorphs per }\end{array}$ & 100 & $9 \cdot 2$ & $\pm 3 \cdot 1$ & 17 & $8 \cdot 7$ & $\pm 3 \cdot 4$ & 10 & $10 \cdot 6$ & $\pm 1 \cdot 8$ \\
\hline $\begin{array}{c}\text { cent. } \ldots \\
\text { Lymphocytes per }\end{array}$ & 100 & $24 \cdot 0$ & $\pm 9 \cdot 0$ & 17 & $52 \cdot 0$ & $\pm 16 \cdot 0$ & 10 & $34 \cdot 0$ & $\pm 10 \cdot 0$ \\
\hline $\begin{array}{l}\text { cent. } \ldots \\
\text { Monocytes per }\end{array}$ & 100 & $68 \cdot 0$ & $\pm 10 \cdot 0$ & 17 & $43 \cdot 0$ & $\pm 15 \cdot 0$ & 10 & $.55 \cdot 0$ & $\pm 9 \cdot 7$ \\
\hline $\begin{array}{c}\text { cent. } \ldots \\
\text { Eosinophils per }\end{array}$ & 100 & $3 \cdot 0$ & $\pm 2 \cdot 7$ & 17 & $4 \cdot 0$ & $\pm 3 \cdot 1$ & 10 & $7 \cdot 0$ & $\pm 1 \cdot 7$ \\
\hline Basophils per & 100 & $4 \cdot 0$ & $\pm 4 \cdot 5$ & 17 & 0.7 & $\pm 1 \cdot 4$ & 10 & 3.0 & $\pm 2 \cdot 7$ \\
\hline $\begin{array}{c}\text { cent. } \ldots \\
\text { Coagulation time }\end{array}$ & 100 & 0.5 & $\pm 0 \cdot 5$ & 17 & $0 \cdot 2$ & $\pm 0 \cdot 9$ & 10 & $1 \cdot 0$ & \pm 0.9 \\
\hline $\begin{array}{cc}\text { (min.) } & \ldots \\
\text { Liveweight } 1 \mathrm{~b} . & \ldots\end{array}$ & 100 & $\frac{2 \cdot 5}{-}$ & $\pm 1 \cdot 0$ & 8 & $2 \cdot 5$ & $\pm 1 \cdot 0$ & $\begin{array}{l}10 \\
10\end{array}$ & $\begin{array}{l}2 \cdot 0 \\
78\end{array}$ & $\begin{array}{l} \pm 0 \cdot 4 \\
\pm 7 \cdot 8\end{array}$ \\
\hline
\end{tabular}


I

of Pining Conditions

Deficiency

Solway Pine

\begin{tabular}{|c|c|c|c|c|c|c|c|c|}
\hline \multicolumn{3}{|c|}{ Pining Lambs } & \multicolumn{3}{|c|}{$\begin{array}{l}\text { Healthy Lambs off } \\
\text { same Farms }\end{array}$} & \multicolumn{3}{|c|}{ Pining Lambs } \\
\hline $\begin{array}{c}\text { No. } \\
\text { of } \\
\text { Animals }\end{array}$ & $\begin{array}{l}\text { Mean } \\
\text { Value }\end{array}$ & $\begin{array}{l}\text { Stand } \\
\text { Dev. } \\
\text { from } \\
\text { Mean }\end{array}$ & $\begin{array}{c}\text { No. } \\
\text { of } \\
\text { Animals }\end{array}$ & $\begin{array}{l}\text { Mean } \\
\text { Value }\end{array}$ & $\begin{array}{l}\text { Stand } \\
\text { Dev. } \\
\text { from } \\
\text { Mean }\end{array}$ & $\begin{array}{c}\text { No. } \\
\text { of } \\
\text { Animals }\end{array}$ & $\begin{array}{l}\text { Mean } \\
\text { Value }\end{array}$ & $\begin{array}{l}\text { Stand. } \\
\text { Dev. } \\
\text { from } \\
\text { Mean }\end{array}$ \\
\hline 8 & $26 \cdot 9$ & $\pm 1 \cdot 9$ & 22 & 50.5 & $\pm 8 \cdot 2$ & 22 & $42 \cdot 4$ & $\pm 15 \cdot 3$ \\
\hline 8 & $10 \cdot 6$ & \pm 0.6 & 22 & $11 \cdot 7$ & \pm 0.9 & 22 & $9 \cdot 2$ & $\pm 1 \cdot 9$ \\
\hline 8 & $516 \cdot 0$ & $\pm 19 \cdot 9$ & 22 & $498 \cdot 0$ & \pm 16.9 & 22 & $510 \cdot 0$ & $\pm 20 \cdot 6$ \\
\hline 10 & $10 \cdot 0$ & $\pm 0 \cdot 7$ & 22 & $11 \cdot 3$ & $\pm 0 \cdot 8$ & 22 & $10 \cdot 4$ & $\pm 0 \cdot 8$ \\
\hline- & - & + & 22 & 20.9 & $\pm 2 \cdot 6$ & 22 & $20 \cdot 2$ & $\pm 3 \cdot 1$ \\
\hline - & - & - & 22 & $34 \cdot 0$ & $\pm 5 \cdot 8$ & 22 & $34 \cdot 1$ & \pm 9.9 \\
\hline 8 & $7 \cdot 2$ & $\pm 1 \cdot 0$ & 22 & $5 \cdot 3$ & $\pm 1 \cdot 1$ & 22 & $4 \cdot 9$ & $\pm 1 \cdot 3$ \\
\hline 8 & $12 \cdot 8$ & $\pm 1 \cdot 8$ & 22 & $11 \cdot 1$ & $\pm 2 \cdot 2$ & 22 & $11 \cdot 2$ & $\pm 3 \cdot 1$ \\
\hline 8 & $44 \cdot 2$ & $\pm 5 \cdot 5$ & 22 & $35 \cdot 4$ & $\pm 8 \cdot 2$ & 22 & $34 \cdot 3$ & $\pm 5 \cdot 3$ \\
\hline 8 & $12 \cdot 0$ & $\pm 2 \cdot 1$ & 22 & $9 \cdot 2$ & $\pm 3 \cdot 8$ & 22 & $7 \cdot 4$ & $\pm 1 \cdot 9$ \\
\hline 10 & $11 \cdot 6$ & \pm 1.9 & 21 & $12 \cdot 2$ & $\pm 1 \cdot 6$ & 22 & $10 \cdot 3$ & $\pm 2 \cdot 4$ \\
\hline $\begin{array}{l}10 \\
10\end{array}$ & $\begin{array}{l}30 \cdot 0 \\
26\end{array}$ & $\begin{array}{l}3 \cdot 7 \\
3 \cdot 8\end{array}$ & $\begin{array}{l}22 \\
21\end{array}$ & $\begin{array}{l}33 \cdot 0 \\
28\end{array}$ & $\begin{array}{l} \pm 2 \cdot 7 \\
\pm 2 \cdot 4\end{array}$ & $\begin{array}{l}22 \\
22\end{array}$ & $\begin{array}{l}27 \cdot 0 \\
30\end{array}$ & $\begin{array}{l} \pm 5 \cdot 0 \\
\pm 3 \cdot 9\end{array}$ \\
\hline 10 & $39 \cdot 0$ & $3 \cdot 2$ & 22 & $38 \cdot 0$ & $\pm 2 \cdot 7$ & 22 & $40 \cdot 0$ & $\pm 5 \cdot 5$ \\
\hline $\begin{array}{r}10 \\
10 \\
8\end{array}$ & $\begin{array}{c}0.50 \\
1,053 \\
5 \cdot 2\end{array}$ & $\begin{array}{l} \pm 0.04 \\
\pm 5 \\
\pm 0.6\end{array}$ & $\begin{array}{l}22 \\
22 \\
22\end{array}$ & $\begin{array}{c}0 \cdot 55 \\
1,050 \\
5 \cdot 8\end{array}$ & $\begin{array}{l} \pm 0 \cdot 3 \\
\pm 4 \\
\pm 1 \cdot 1\end{array}$ & $\begin{array}{l}22 \\
22 \\
22\end{array}$ & $\begin{array}{c}0.55 \\
1,046 \\
5.0\end{array}$ & $\begin{array}{l} \pm 0 \cdot 02 \\
\pm 5 \\
\pm 4 \cdot 6\end{array}$ \\
\hline 10 & - & - & 22 & $9 \cdot 5$ & $\pm 4 \cdot 8$ & 22 & $7 \cdot 1$ & $\pm 3 \cdot 1$ \\
\hline 10 & $37 \cdot 0$ & $\pm 12 \cdot 0$ & 22 & $24 \cdot 0$ & \pm 6.5 & 22 & $38 \cdot 0$ & $\pm 15 \cdot 0$ \\
\hline 10 & $53 \cdot 0$ & $\pm 12 \cdot 0$ & 22 & $72 \cdot 0$ & $\pm 6 \cdot 0$ & 22 & $58 \cdot 0$ & $\pm 14 \cdot 0$ \\
\hline 10 & $7 \cdot 0$ & $\pm 1 \cdot 6$ & 22 & $2 \cdot 0$ & $\pm 1 \cdot 4$ & 22 & $2 \cdot 0$ & $\pm 1 \cdot 6$ \\
\hline 10 & $2 \cdot 0$ & $\pm 0 \cdot 8$ & 22 & $2 \cdot 5$ & \pm 2.5 & 22 & 1.5 & $\pm 2 \cdot 0$ \\
\hline 10 & $1 \cdot 0$ & \pm 0.6 & 22 & 0.5 & \pm 0.5 & 22 & $0 \cdot 2$ & $\pm 1 \cdot 0$ \\
\hline $\begin{array}{l}10 \\
10\end{array}$ & $\begin{array}{l}1 \cdot 8 \\
45\end{array}$ & $\begin{array}{l} \pm 0 \cdot 4 \\
\pm 2 \cdot 8\end{array}$ & $\frac{22}{-}$ & $2 \cdot 0$ & \pm 0.6 & 22 & $\frac{2 \cdot 7}{-}$ & \pm 0.7 \\
\hline
\end{tabular}


the variations observed may be due to the type of pasture on which the lambs were grazing.

The blood picture of the pining lambs on the cobalt-deficient pasture shows variations from the blood picture of normal lambs for the most part similar to those observed in the case of the cobaltfed healthy lambs ; the blood sugar was even lower with a much smaller deviation from the mean. It is only for the haemoglobin that any difference can be seen between healthy and pining lambs on the same farm. The mean values were $11 \cdot 3 \mathrm{~g}$, and $10 \cdot 6 \mathrm{~g}$. respectively, but it will be observed that $10 \cdot 6 \mathrm{~g}$. is still within the range of normality. It is not nearly so low as the haemoglobin of lambs suffering from worm infestation. The red cell count of the pining lambs while slightly lower than that of the cobalt-fed lambs, was higher than that regarded as normal for the species. It must be understood that although these cobalt-deficient lambs showed marked retardation in growth and listlessness, they were not in the manifest clinical condition covered by the term " pine."

Therefore it would appear that cobalt deficiency in itself does not cause anaemia nor does it materially interfere with haemoglobin formation. Anaemia only becomes apparent as the lambs develop severe debility. The view would, therefore, be disproved that the function of cobalt in metabolism is linked with haemoglobin formation, a belief which seems to have arisen when cobalt deficiency was thought to be related to iron deficiency. The results substantiate the findings of Robscheit-Robbins and Whipple (1942), who found that cobalt did not affect haemoglobin formation. It would appear that cobalt plays some other physiological role, one probably more intimately associated with growth since mature sheep do not seem to suffer from cobalt deficiency.

\section{SOLWAY PINE}

This is a "pining" condition, the symptoms of which closely resemble those of parasitic infestation and cobalt deficiency. As far as can be ascertained the condition is localised to the foothills, of the Criffel Mountain from New Abbey to Kirkgunzeon and to many farms in the Auchencairn district near the Solway Firth. Mortality is high and the disease has led to cessation of sheep breeding in several of the districts where it was most prevalent. Instead, farmers have resorted to "flying stócks" since adult animals are not susceptible to the disease. It affects lambs at a much younger age than does cobalt deficiency or worm infestation. Severe clinical symptoms are obvious soon after weaning and by the end of July large numbers of lambs are seriously affected. Farmers aver that the symptoms are obvious long before weaning.

The disease appears to be related to granitic soils which are very common in the districts mentioned above. Soil and pasture analyses reveal that both are very low in minerals, especially magnesium 
and potassium. In at least one of the areas, the cobalt content of the pasture is low but what rôle, if any, cobalt deficiency plays in the etiology of the disease has yet to be determined. Experimentation along the line of mineral feeding is in progress.

Towards the end of July samples of blood and faeces for examination were taken from 22 affected lambs and from 22 of the healthiest lambs on three farms in the Kirkgunzeon area. The results are shown in Tables I and II. Worm egg counts show that the lambs on these farms were carrying a rather high worm burden, but that in only a few of the affected lambs was it higher than in the apparently normal lambs. It was observed that those lambs showing the severest clinical symptoms of pine or debility were those which had the highest faecal worm egg counts but, as has already been mentioned, this is a frequent finding in debilitated animals. Since the egg count distribution curve of the healthy lambs is similar to that of the pining lambs except in the case of those showing severest symptoms, it is inferred that the primary cause of the pining is not worm infestation. This view is to a certain extent confirmed by the fact that pining is just as prevalent on those farms in these districts where routine anthelmintic treatment is carried out as on those where no anthelmintics are given.

From Table I it will be seen that the mean values of all the chemical constituents of the blood of the healthy sheep on the Solway farms are in close agreement with those of normal sheep. The greatest difference is seen in the values of blood sugar, namely, $50.5 \mathrm{mg}$. compared with $61 \mathrm{mg}$. It will be noticed that even the mean value of $50.5 \mathrm{mg}$. is well above the mean of the blood sugars of the healthy Ross-shire lambs $(37 \cdot 1 \mathrm{mg}$.). In the case of the pining Solway lambs the blood sugar was much lower than the normal, being of the order of the Ross-shire lambs, and showing a large variation amounting to a S.D. of $15 \cdot 3$, around a mean value of $42 \cdot 4 \mathrm{mg}$.

The greatest divergence from the normal was observed in the haemoglobin values of the pining lambs. A mean value of $9 \cdot 2 \mathrm{~g}$. with a S.D. of 1.9 was found for the latter as compared with a mean of 11.7 and a S.D. of 0.9 for the healthy lambs on the same farm. The large standard deviation shows that the range was very wide, the haemoglobin values of a few of the lambs being less than $7 \mathrm{~g}$. It is probable that the fall in haemoglobin in these few lambs was associated with the worm infestation or general debility. To some extent this is confirmed by the individual records of the physical properties, since in most cases in the affected group the low haemoglobin figures were related to a simple oligocythaemia except in two lambs which showed a definitely hypochromic normocytic anaemia (M.C.H.C. $29 \cdot 8$ per cent. and $30 \cdot 8$ per cent.). The worm egg counts of these two sheep were 12,780 and 5,200 per $g$. respectively. 
Changes in the other constituents of the blood were insignificant and the slight changes in the physical properties were probably due to the decrease in red cell volume.

\section{CONCLUSIONS}

The results do not give promise that blood analyses will be of much service in differentiating the three types of "pining" discussed. In sheep affected with a heavy worm infestation or severe debility there is an anaemia with an appreciable neutrophilic reaction. A simple hypochromic anaemia arising from other causes is, however, known to occur in sheep. On the other hand, where there is no fall in the blood haemoglobin and red cell count in cases of severe "pining," the cause is unlikely to be worm infestation and it may be cobalt deficiency.

As more knowledge upon the cobalt status of soil and pasture is forthcoming, and the soil properties and degree of pining can be correlated, a soil and pasture analysis will be a better guide to the type of pining present than will be blood examination.

The data presented in this paper do not lend support to the theory that the physiological role of cobalt is associated with haemoglobin formation.

\section{REFERENCES}

Fourie, P. J. J. (1931). 17th Rept. Div. vet. Services, Onderstepoort, South Africa, 493.

Fraser, A. C. (1930). Rept. Dir. Inst. anim. Path., Camb., 1, 114.

Holman, H. H., and Pattison, I. H. (1941). Vet. Rec., 53, 491.

Robscheit-Robbins, F. S., and Whipple, G.H. (1942). F. exp. Med., 75, 481.

Stewart, J., and Holman, H. H. (1940). Vet. Rec., 52, 157.

Stewart, J., Gordon, W. S., and McCallum, J. W. (1940). Ibid., 52, 237.

Stewart, J., and Mitchell, R. L., and Stewart, A. B. (1941). Emp. F. exp. Agric., 9, 145.

Stewart, W. L., and Crofton, H. D. (1943). Vet. Rec., 55, 3.

[Received for publication May 26th, 1943] 


\section{Reprinted from The JouRnal OF PATHOLOGY AND BACteriology \\ Vol. L, No. 2, pp. 251-269, 1940}

Blood Changes and Post-mortem Findings following Intravenous Inoculation of Sheep with Culture Filtrates of $\mathrm{Cl}$. welchii, Types A, C and D

BY

W. S. GORDON, JAMES STEWART, H. H. HOLMAN AND A. WILSON TAYLOR

From the Animal Diseases Research Association, Moredun Institute, Gilmerton, Edinburgh 

SHEEP WITH CULTURE FILTRATES OF $C L$. WELCHII, TYPES A, C AND D

\author{
W. S. Gordon, James Stewart, H. H. Holman, \\ and A. WILSON TAYLOR \\ From the Animal Diseases Research Association, \\ Moredun Institute, Gilmerton, Edinburgh
}

THE information available in regard to the intra-vitam effects of Cl. welchii toxin on the blood refers mainly to its hæmolytic action. Further, the clinical and experimental observations made deal with the toxæmia caused by $\mathrm{Cl}$. welchii of classical gas gangrene, very little attention having been paid to the toxins formed by other members of the group. The literature relating to the classification of the different types of $\mathrm{Cl}$. welchii has recently been reviewed by Dalling and Ross (1938) and McCoy and McClung (1938).

The object of the present paper is to record and compare the symptoms, changes in the chemical and physical properties of the blood and post-mortem findings following the intravenous inoculation of sheep with culture filtrates of $\mathrm{Cl}$. welchii of types A, C and D in Wilsdon's classification (1931), and evidence will be presented to show that, while no characteristic blood picture follows the injection of type $\mathrm{C}$ toxin, type A produces a marked hæmolytic anæmia and type D a typical anhydræmia. Minor differences in symptoms, blood picture and post-mortem findings are also recorded.

In the course of a bacteriological investigation of grass sickness in horses, the toxin of $\mathrm{Cl}$. welchii type $\mathrm{D}$ was detected in filtrates prepared from the contents of the small intestine of a small proportion of horses affected with the peracute or acute form of the disease (Gordon, 1934). About the same time Dr Henry Dryerre (unpublished experiments) detected a marked and progressive rise in the hæmoglobin and sugar content of the blood of affected horses, together with a slight fall in the blood calcium. Massive doses of a culture of $\mathrm{Cl}$. welchii type D were therefore given by the mouth to three horses, which died after showing similar blood changes.

It was observed by one of us (J. S.) that urine from cases of "pulpy kidney disease" in sheep (an entero-toxæmia caused by the toxin of $\mathrm{Cl}$. welchii type D) contained a great deal of sugar unaccompanied by albumin. 
This suggested that in this type of toxæmia the toxin must affect the normal sugar metabolism so as to raise the blood sugar above the threshold value. Blood samples from a few cases showed that the sugar content was indeed high, in some cases over $350 \mathrm{mg}$. compared with the normal 70-80 mg. per 100 c.c. This upset of sugar metabolism could not be detected in animals affected with lamb dysentery or with "struck" - entero-toxæmias caused by the toxins of $\mathrm{Cl}$. welchii types $\mathrm{B}$ and $\mathrm{C}$ respectively.

The severe anæmia which characterises certain cases of gas gangrene infection in man has been noted by a number of investigators. Klotz and Holman (1911) found it to be an outstanding feature in a series of infections occurring in coal mines. Bull and Pritchett (1917), who first demonstrated the existence of the soluble toxin in vitro, recognised its hæmolytic properties. It has been shown (Report on the anaerobic infections of wounds, 1919) that filtrates of $\mathrm{Cl}$. welchii of classical gas gangrene are hæmolytic both in vitro and in vivo, and produce necrosis of skin and muscle and marked œdema of the subcutaneous tissues. The hæmolytic action in vivo is best seen after intravenous inoculation, though it can also be demonstrated constantly in mice which die after intramuscular injection. Bull and Pritchett relate the case of a rabbit which, prior to a dose of 1.0 c.c. of toxin intravenously, had a red cell count of $5 \cdot 4$ millions. Seven hours after inoculation the count was only 1.0 million per c.mm. In a pigeon an initial count of $4 \cdot 28$ million red cells fell $27 \frac{1}{2}$ hours after inoculation to 0.8 million. Henry (1922) records that rapidly progressive anæmia was a familiar feature of gas gangrene during the European War. Blood counts a few hours before death invariably showed a serious depletion in the number of red cells and counts of less than one million per c.mm. were not infrequent in rapidly developing cases.

Chamberlin (1933), in acute cases of enzootic toxæmic jaundice-a disease of sheep and cattle in Australia, sudden in its onset and characterised by anæmia, intense icterus and hæmoglobinuria-records red corpuscle counts of $0 \cdot 8-3.5$ million as compared with a normal count (Norris and Chamberlin, 1929) of 11-12 million. Rose and Edgar (1936) conclude that this disease is essentially an entero-toxæmia due to $\mathrm{Cl}$. welchii type A and have renamed it entero-toxæmic jaundice of sheep and cattle.

Thus there is evidence of the occurrence of acute hæmolytic anæmia in the toxæmia caused by $C l$. welchii type $\mathrm{A}$, whereas the observations of the biochemists at this Institute, referred to above, suggest that in the toxæmia due to type D there is a progressive rise in the hæmoglobin content of the blood:

\section{METHODS}

\section{Origin, preparation and typing of filtrates}

Types A and C filtrates were prepared from strains N.C.T.C. 26 and W. 49 obtained from the Wellcome Physiological Research Laboratories, type D from a culture, H. 35/4, isolated at this Institute from the contents of the small intestine of a horse which had died of acute grass sickness.

Cultures were grown in meat broth $(p H$ H $7 \cdot 6)$ prepared from horse flesh. Types $\mathrm{A}$ and $\mathrm{C}$ were incubated for 11 hours, type $\mathrm{D}$ for 6 days at $37^{\circ} \mathrm{C}$. The cultures were examined for purity, elarified by filtration through paper pulp and passed through a British Berkefeld candle. The A and C filtrates were precipitated by the addition of 70 per cent. ammonium sulphate and the precipitate was dried in vacuo over calcium chloride. The dry stable 
product was reconstituted for use by dissolving $100 \mathrm{mg}$. in 5.0 c.c. of saline. The type D filtrate was retained in the liquid state and its toxicity for mice remained constant throughout. The filtrates are hereafter referred to as toxins.

For each toxin the M.L.D. was determined in mice intravenously and the M.R.D. in guinea-pigs intradermally in a large number of animals over a period of several months as well as the M.H.D. in vitro, i.e. the amount required to produce 50 per cent. hæmolysis in a 6 per cent. saline suspension of sheep red cells. The results are recorded in table I.

TABLE I

Result of titration of toxins

\begin{tabular}{|c|c|c|c|}
\hline Type of toxin & $\begin{array}{c}\text { M.L.D. in mice I.V. } \\
\text { (mg.) }\end{array}$ & $\begin{array}{c}\text { M.R.D. in } \\
\text { guinea-pigs I.D. } \\
\text { (mg.) }\end{array}$ & $\begin{array}{c}\text { M.H.D. in vitro with } \\
6 \text { per cent. sheep red } \\
\text { cells in saline (mg.) }\end{array}$ \\
\hline A & 0.6 & 0.18 & 0.08 \\
C & 0.02 & 0.016 & 0.14 \\
D & 0.004 & 0.01 & 0.40 \\
\hline
\end{tabular}

The toxins were typed by mixing them with different antitoxins in vitro and, after contact for one hour, inoculating mice intravenously from each mixture. The antisera used were type A (G.G. 3269) and type C (R. 3589), prepared in horses and kindly supplied by the Wellcome Physiological Research Laboratories, and type D (H. 35/4) prepared in a horse at this laboratory from culture H. $35 / 4$. Each filtrate behaved as an orthodox type according to Wilsdon's classification. Thus $0 \cdot 3$ c.c. of type A toxin was neutralised by 0.001 c.c. of type $A$ serum and by 0.1 c.c. of type $C$ and 0.01 e.c. of type $\mathrm{D}$ serum. Type $\mathrm{C}$ toxin in a dose of 0.01 c.c. was neutralised by 0.001 c.c. of type $\mathrm{C}$ serum but not by 0.1 c.c. of types $\mathrm{A}$ and D. Type D toxin in a dose of 0.002 c.c. was neutralised by 0.0009 c.c. of type D serum but not by 0.1 c.c. of types $A$ and $C$ serum.

\section{Biochemical methods}

Sugar was estimated by the Folin and Wu colorimetric method, nonprotein-nitrogen by a Nesslerisation method, hæmoglobin by the Newcomer disc method, creatinine by the picric acid-sodium hydroxide method, amino-acid nitrogen by the Folin and Wu naphthoquinone-sulphonic acid method, calcium by the Kramer and Tisdall method, magnesium by a modification of the Denis method, phosphates by the Fiske and Subbarrow methods, chloride by Whitehorn's variation of Volhard's method, and potassium by the cobaltinitrite precipitation and permanganate titration method.

\section{Examination of the blood}

The coagulation time, erythrocyte count, total and differential leucocyte counts, platelet count, fragility of red cells, specific gravity, corpuscular volume and sedimentation rate were determined. The technique is recorded in more detail by Stewart and Holman (1940) and was briefly as follows.

The coagulation time was determined by a modification of the capillary tube method in which the tubes were held suspended in a flask containing water at $39^{\circ} \mathrm{C}$. For the differential leucocyte count films were stained by 
Pappenheim's method as modified by Piney (1931) and counted by the four-field meander method. For the erythrocyte count blood was diluted to $1: 200$ in a Thoma pipette. The average difference when counts were checked by another operator was 6 per cent. Following the erythrocyte count the unstained platelets were counted in the hæmocytometer. Although not accurate this method was considered to be capable of demonstrating gross changes had these occurred. The fragility of the erythrocytes was determined by adding one drop of blood to tubes containing different concentrations of sodium chloride. The concentration in which complete hæmolysis occurred overnight was regarded as the fragility figure. The specific gravity was ascertained by adding a drop of blood to tubes containing different proportions of benzol and chloroform. The specific gravity of the fluid in the tube in which the corpuseles remained suspended was recorded. The corpuscular volume was obtained by filling two small hæmatocrit tubes with blood, centrifuging these for one hour at 4000 r.p.m. and taking the mean of the readings. The sedimentation rate was recorded as the fall in centimetres occurring in 24 hours in a column of blood contained in glass tubes about $4 \mathrm{~mm}$. in diameter.

\section{EXPERIMENTAL}

In determining the approximate lethal dose of the toxins for sheep the work of Mason (1935) was very helpful. He determined the lethal dose of the toxins of some anaerobes for mice and sheep and expressed the result as a ratio between the M.L.D. for the mouse and the number of such doses per $\mathrm{kg}$. body-weight which proved lethal for sheep. In our experiments sheep were inoculated in the first instance with a number of mouse lethal doses per $\mathrm{kg}$. which was unlikely to prove fatal. Thereafter others were given a larger dose until a lethal dose was obtained. Altogether 11 sheep were inoculated intravenously with type A toxin, 6 with type C and 9 with type D. The results are recorded in table II.

If the smallest lethal dose of the various toxins for sheep is expressed as the number of mouse lethal doses per kg. bodyweight, the ratios mouse M.L.D. : sheep M.L.D. are, for type A, $1: 11$, for type C, $1: 45$ and for type D, $1: 25$. The ratio for type D toxin given by Mason is $1: 12.5$ but the difference in materials, weight of mice and number and breed of sheep may account for the discrepancy. In all the animals which died the period of illness was short and it was found impossible to produce a chronic clinical condition by administering a sublethal dose of toxin. The result also indicates that sheep are relatively more susceptible than mice to type A toxin.

Before inoculation the sheep were weighed, the wool over the jugular vein on each side of the neck was removed and normal blood samples were obtained. The toxins were injected into the jugular vein and thereafter blood samples were withdrawn from this vessel, 40 c.c. at each bleeding. About 2.0 c.c. were transferred immediately to a small Petri plate for a coagulation test and the preparation of films. The remainder was divided between two bottles. In one the blood was allowed to clot; the other 
TABLE II

Toxicity of different types of $\mathrm{Cl}$. welchii toxin for sheep

\begin{tabular}{|c|c|c|c|c|c|c|}
\hline $\begin{array}{l}\text { Type of } \\
\text { toxin }\end{array}$ & $\begin{array}{l}\text { Sheep } \\
\text { no. }\end{array}$ & Breed & $\begin{array}{c}\text { Weight } \\
\text { (kg.) }\end{array}$ & Dose (mg.) & $\begin{array}{l}\text { Dose expressed as } \\
\text { no. of mouse M.L.L. } \\
\text { per kg. body-weight }\end{array}$ & Result \\
\hline \multirow[t]{11}{*}{ A } & 2 & S. & $27 \cdot 2$ & $100 \cdot 0$ & $6 \cdot 0$ & Lived \\
\hline & 325 & & $22 \cdot 7$ & $81 \cdot 6$ & $6 \cdot 0$ & \multirow{2}{*}{, } \\
\hline & 1000 & B.F. & $19 \cdot 5$ & $120 \cdot 0$ & $10 \cdot 0$ & \\
\hline & & B.F. & $21 \cdot 3$ & $140 \cdot 0$ & $10 \cdot 0$ & Died, 31 hrs. \\
\hline & 59 & B.F. & $22 \cdot 2$ & $146 \cdot 0$ & $11 \cdot 0$ & , 18 hrs. 10 mins, \\
\hline & 60 & B.F. & $21 \cdot 3$ & $166 \cdot 0$ & $13 \cdot 0$ & " 3 hrs. 5 mins. \\
\hline & 324 & S. & $33 \cdot 6$ & $262 \cdot 0$ & $13 \cdot 0$ & " $\quad 6 \mathrm{hrs} .30$ mins. \\
\hline & 3 & B.F. & $18 \cdot 1$ & $160 \cdot 0$ & $14 \cdot 0$ & ", 9 hrs. \\
\hline & 61 & B.F. & $21 \cdot 3$ & $192 \cdot 0$ & $15 \cdot 0$ & ", $\quad 3$ hrs. 50 mins. \\
\hline & 52 & B.F. & $17 \cdot 7$ & $160 \cdot 0$ & $15 \cdot 0$ & $" \quad 2$ hrs. 5 mins. \\
\hline & 944 & B.F. & $15 \cdot 4$ & $200 \cdot 0$ & $21 \cdot 0$ & " 2 hrs. 30 mins. \\
\hline \multirow[t]{6}{*}{ C } & 322 & S. & $59 \cdot 5$ & $46 \cdot 0$ & $40 \cdot 0$ & \multirow{6}{*}{$\begin{array}{l}\text { Lived } \\
\text { Died, } 45 \text { mins. } \\
\text {, } 1 \mathrm{hr} .20 \text { mins. } \\
\Longrightarrow \quad 40 \text { mins. } \\
\Longrightarrow \quad 4 \mathrm{hrs.} 5 \text { mins. } \\
, \quad 1 \mathrm{hr} .\end{array}$} \\
\hline & 321 & S. & $63 \cdot 6$ & $56 \cdot 2$ & $45 \cdot 0$ & \\
\hline & 659 & H.В. & $48 \cdot 6$ & $42 \cdot 0$ & $45 \cdot 0$ & \\
\hline & 660 & H.В. & $65 \cdot 9$ & $64 \cdot 0$ & $50 \cdot 0$ & \\
\hline & 661 & H.В. & $55 \cdot 4$ & $54 \cdot 0$ & $50 \cdot 0$ & \\
\hline & 636 & H.В. & $60 \cdot 0$ & $72 \cdot 0$ & $60 \cdot 0$ & \\
\hline \multirow[t]{9}{*}{ D } & 637 & H.В. & $65 \cdot 4$ & $2 \cdot 6$ & $10 \cdot 0$ & Lived \\
\hline & 629 & H.В. & $62 \cdot 7$ & $3 \cdot 0$ & 12.5 & \multirow{2}{*}{, } \\
\hline & 657 & H.В. & $61 \cdot 3$ & $4 \cdot 8$ & $20 \cdot 0$ & \\
\hline & 339 & B.F. & $20 \cdot 9$ & $1 \cdot 9$ & $23 \cdot 0$ & $"$ \\
\hline & 658 & H.B. & $67 \cdot 3$ & $6 \cdot 2$ & $25 \cdot 0$ & \\
\hline & 338 & B.F. & $25 \cdot 4$ & $2 \cdot \overline{4}$ & $25 \cdot 0$ & , 2 hrs. \\
\hline & 639 & H.В. & $64 \cdot 5$ & $7 \cdot 6$ & $30 \cdot 0$ & \multirow{2}{*}{$\begin{array}{l}\text {, } 1 \mathrm{hr} .45 \text { mins. } \\
\text {, } 1 \mathrm{hr} .30 \text { mins. }\end{array}$} \\
\hline & 650 & H.В. & $76 \cdot 8$ & $12 \cdot 2$ & $40 \cdot 0$ & \\
\hline & 634 & H.В. & $75 \cdot 0$ & $12 \cdot 0$ & $40 \cdot 0$ & $1 \mathrm{hr} .15$ mins. \\
\hline
\end{tabular}
S. $=$ Suffolk
B.F. $=$ Blackface
H.B. = Half-bred

contained potassium oxalate and sodium fluoride and was shaken vigorously to prevent clotting. This provided sufficient material for the biochemical and physical examination of the blood. Typical examples of the changes following the injection of each type of toxin have been selected for graphic representation in the text.* Post-mortem examination of animals which died included the histological examination of the liver, kidneys, lungs and heart wall.

\section{Type A toxin}

\section{Symptoms}

Sheep inoculated with a lethal dose of type A toxin developed an increased respiratory rate shortly after injection. This became progressively more marked until there developed an acute dyspnœa accompanied by the appearance of blood-stained froth at the nostrils. There was incoordination of gait and muscular weakness, which increased until the animal was unable to stand.

* The detailed records of all the observations made on the blood obtained from the sheep under experiment have been deposited in the General Library, British Museum (Natural History), London, S.W. 7. 
Fluid fæces were passed, tinged with blood in no. 59, and marked hæmoglobinuria developed in all cases. No significant variation in body temperature occurred except in no. 324, whose temperature rose from $102 \cdot 6^{\circ} \mathrm{F}$. at the time of inoculation to $108^{\circ} \mathrm{F}$. fifteen minutes before death. Death occurred suddenly in all cases without evidence of coma.

\section{Post-mortem findings}

A characteristic feature was the presence of hæmorrhages in different parts of the body. In the alimentary tract the mucous membrane of the abomasum almost invariably showed hæmorrhages ranging from petechiæ to extensive extravasations. Petechial hæmorrhages were noticed on both surfaces of the small intestine and in no. 59 the contents were chocolate coloured. The liver and kidneys were much darker than normal. The urine was dark, due to blood pigment. The mucous membrane of the bladder appeared normal. The condition of the lungs ranged from acute congestion to hæmorrhagic œdema. In several cases the trachea and bronchi were filled with blood-stained froth. Hæmorrhages under serous membranes were usually present, particularly over the diaphragm, mesentery and omentum. Subcutaneous sub-endocardial and sub-epicardial hæmorrhages were present in all cases.

Histologically the liver showed necrobiotic changes together with round-celled infiltration of Glisson's capsule. Changes were most apparent round the central vein. The lungs showed some hyperæmia of the alveolar capillaries with œdematous exudation into the alveoli in some areas. In one section a small hæmorrhage was observed. The kidneys showed marked nephrosis. A large amount of colloidal material was seen in the form of hæmoglobin cylinders within the tubules and as an extravasation between the tubules. This material was most apparent in the lumen of the convoluted tubules in the subcapsular part of the cortex but was also observed in Henle's loop and in some collecting tubules. In the heart sub-endocardial hæmorrhages were present, erythrocytes lying free under the endocardium and permeating between the muscle fibres and around Purkinje's fibres to a depth of 1-2 mm. The mucous membrane of the abomasum in most cases was congested and sections prepared from the most acute lesions revealed intense congestion of the capillaries and larger blood vessels, with extravasation of blood into the mucous membrane.

\section{Physical changes in the blood}

The changes which occurred in the blood of sheep no. 61 after inoculation are typical and are shown graphically in fig. 1.

It will be seen that the number of red corpuscles fell from 
9 million to 2 million per c.mm. in 3 hours. This was accompanied by a fall in specific gravity from 1055 to 1035 , an increase in sedimentation rate, a fall in the total cell volume from 30 per cent. to 4 per cent. and an increase in the fragility of the red cells. No constant change in the clotting time was observed, although sheep

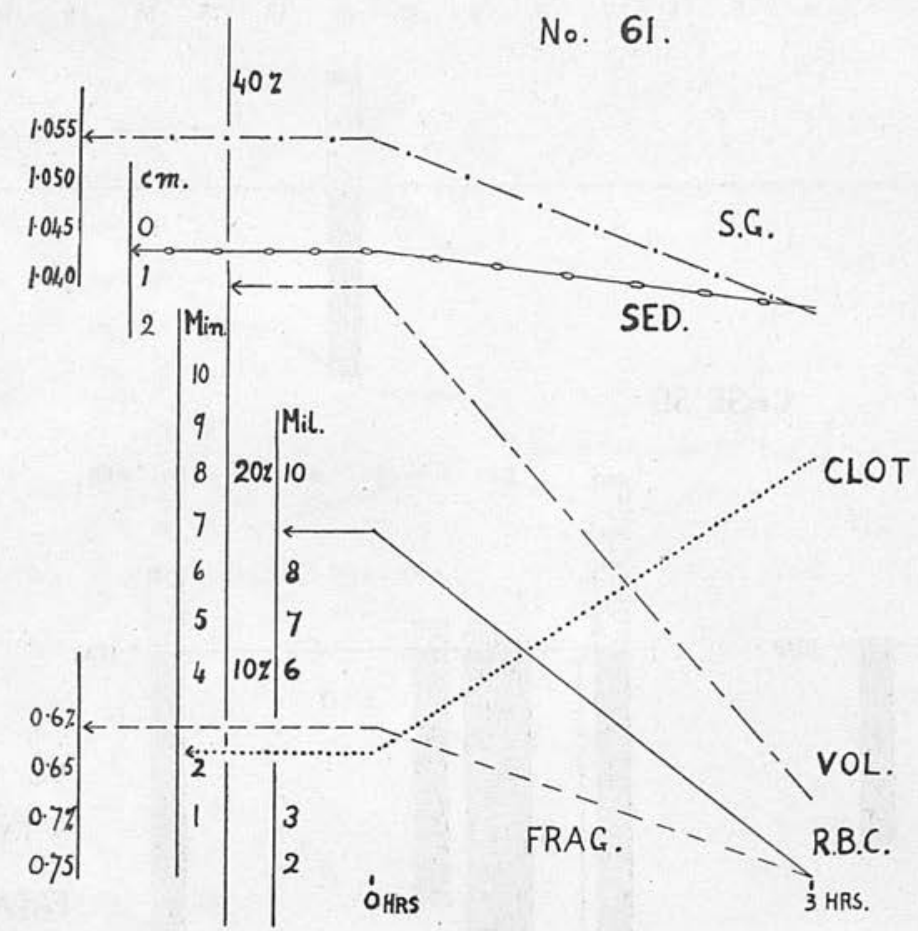

FIG. 1.-Physical changes in the blood following the injection of type A toxin.

no. 61 showed an increase. A rise in the colour index occurred in all sheep which received a lethal dose : in films a few cells were seen showing polychromasia and there was an appearance of anisocytosis but no measurements were made.

\section{Leucocytic reaction}

Fig. 2 depicts the leucocytic changes in sheep which received a lethal dose. Agranulocytosis developed within an hour of inoculation (no. 324). This was followed within a few hours by a progressive increase in granulocytes until, as in no. 59, 11 hours after injection the neutrophils had returned to about half their pre-inoculation figure and by 18 hours a further increase was recorded. The polynuclear index of no. 59 before inoculation was $2.65 ; 11$ hours after inoculation it fell to 1.76 and rose again to 1.95 eighteen hours after, which suggests that the return towards the normal count was accompanied by a slight shift to 
the left. Little change occurred in the absolute number of lymphocytes, while the monocytes showed a tendency to decrease. In one animal which received a non-lethal dose there was a slight absolute neutrophilia 2 hours after inoculation.

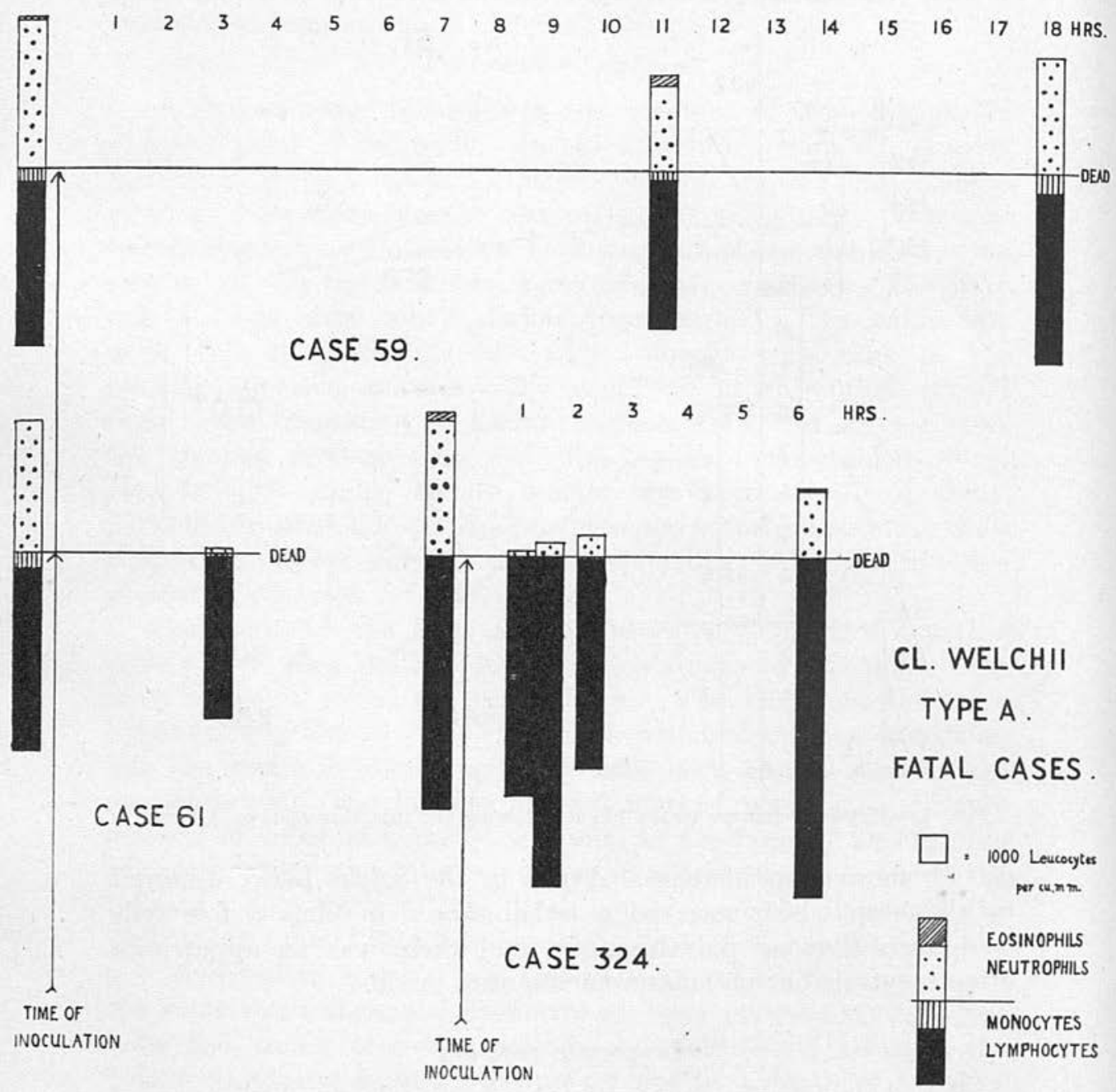

Fig. 2.-Leucocytic reactions in sheep which received a lethal dose of type A toxin.

\section{Biochemical changes in the blood}

Fig. 3 depicts the sequence of changes in sheep 61 and shows that the most striking changes were the rapid fall in the hæmoglobin and serum calcium, the hæmoglobin from $10 \cdot 1$ to $4.0 \mathrm{~g}$. per 100 c.c. and the calcium from 8.00 to $5.06 \mathrm{mg}$. per 100 c.c. These falls occurred whether the animal lived or died. There was no significant change in the other constituents. The sugar 


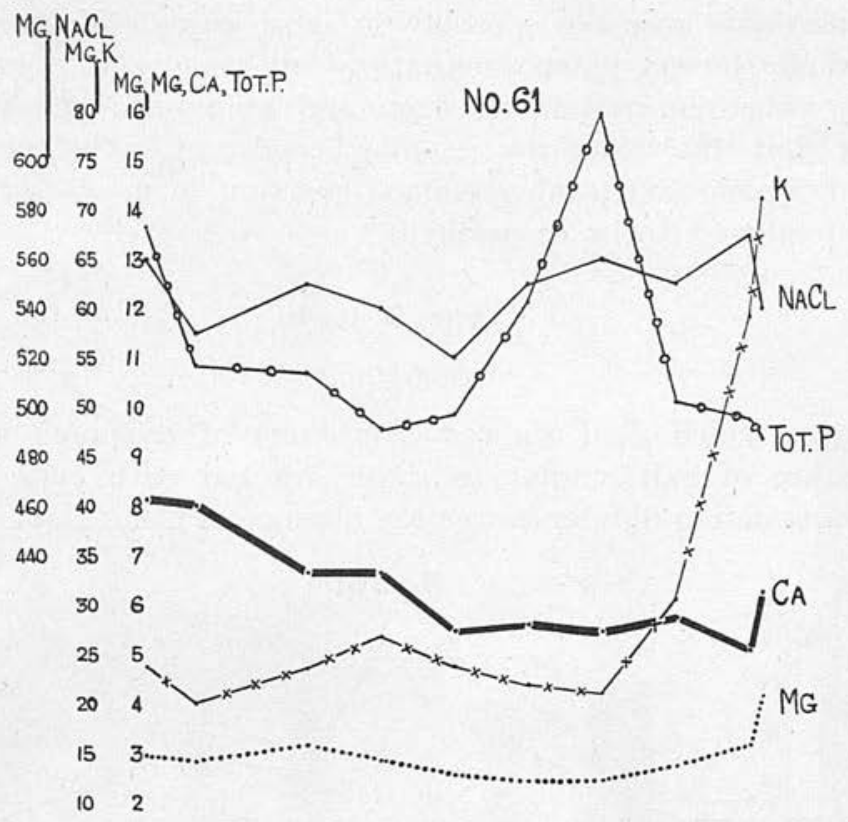

MG.N.P.

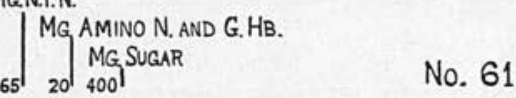

$60 \quad 19 \quad 375$

$\begin{array}{lll}55 \quad 18 \quad 350 & \end{array}$

50 $\quad 17 \quad 325$

$45 \quad 16 \quad 300$

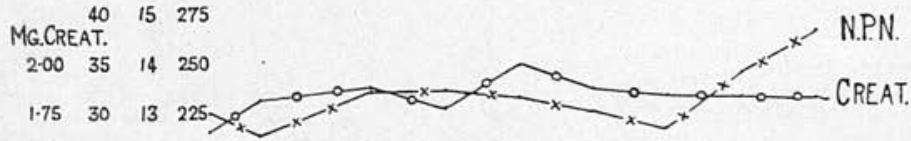

$\begin{array}{llll}1.50 & 25 & 12 \quad 200\end{array}$

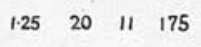

1.0

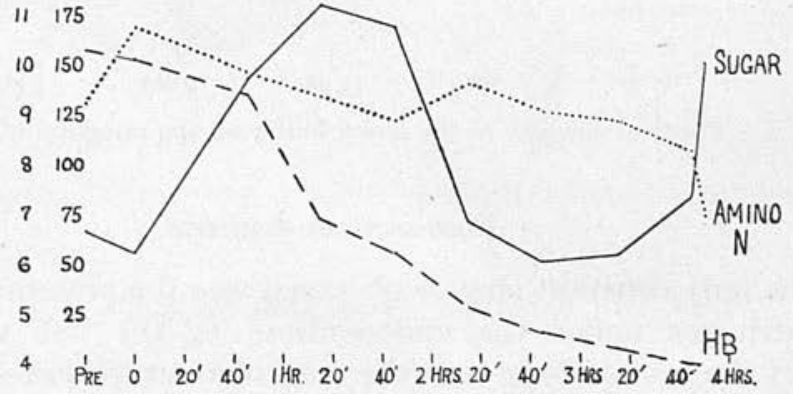

Fra. 3.-Biochemical changes in the blood following the injection of type A toxin. 
rose in no. 61 but fell considerably in other cases, e.g. no. 324 ; the creatinine rose considerably in most cases. Magnesium and potassium showed much fluctuation but usually rose just before death. The non-protein nitrogen and amino-nitrogen fluctuated widely but the chlorides remained constant. The phosphates, both inorganic and total, remained constant in most cases, with a slight tendency to rise occasionally.

\section{Type G toxin}

\section{Symptoms}

Sheep which died showed symptoms of dyspnœa and incoordination of gait similar to those injected with type A toxin. The outstanding difference was the absence of hæmoglobinuria.
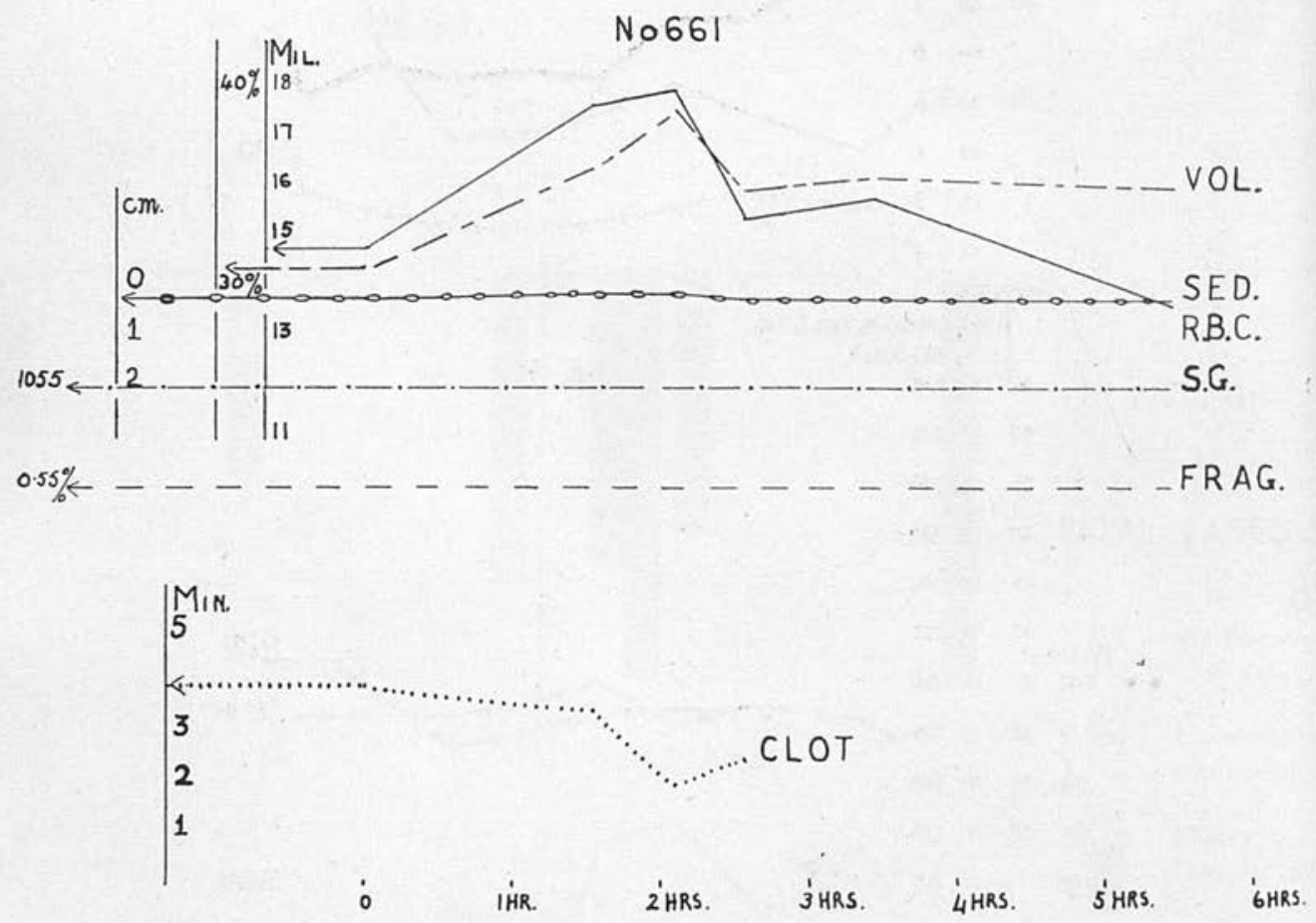

Fig. 4.-Physical changes in the blood following the injection of type C toxin.

\section{Post-mortem findings}

The only constant change observed was the presence of petechial hæmorrhages under the endocardium of the left ventricle. In no. 321 the hæmorrhage took the form of an extensive extravasation. In no. 660 there was one large hæmorrhage under the visceral pleura and the serous surface of the abomasum of no. 661 was congested. 
Histologically the œdematous condition of the lung, so noticeable with type A toxin, was absent. Some of the alveoli contained erythrocytes, dust cells and plasma: exceptionally one or two around a bronchiole contained œdematous exudate. In the kidney hyaline droplets were observed in Bowman's capsules and in the lumen of the tubules. Slight extravasations of blood were seen between the tubules in the cortical rays and in one case definite hæmorrhages were present among the convoluted tubules.

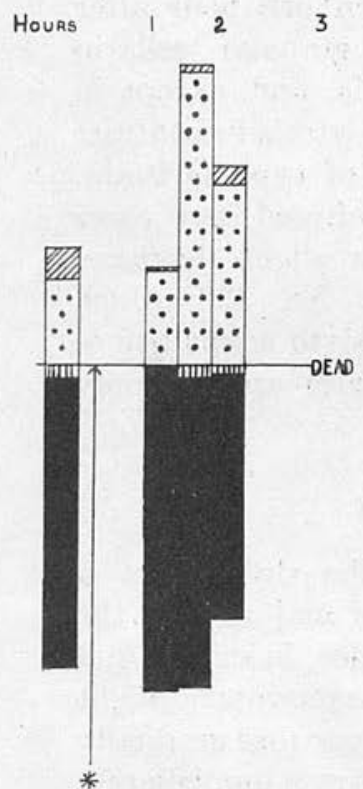

CASES

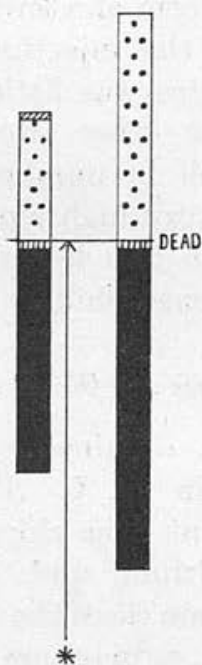

636

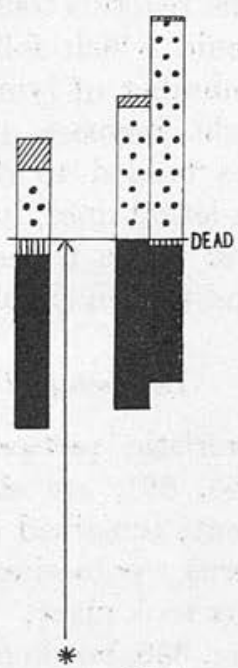

659

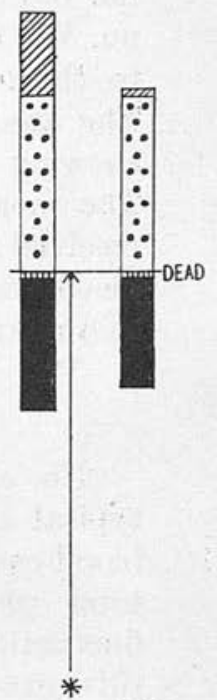

321
FATAL CASES.

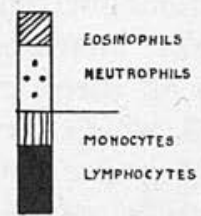

Fig. 5.-Leucocytic reactions in four sheep which received a lethal dose of type C toxin.

\section{Physical changes in the blood}

Sheep no. 661 (fig. 4) is representative of the effect of C toxin on the blood. No marked alteration occurred apart from a temporary rise in the number of red blood corpuscles and this was not observed in all the animals. In 3 of the 5 animals that 
died the fragility of the erythrocytes was increased, and in three in which the clotting time was observed, this was decreased. No significant change occurred in the colour index and films showed an unaltered appearance of the erythrocytes and platelets.

\section{Leucocytic reaction}

Although a slight fall in the number of granulocytes occurred in nos. 661 and 321, the agranulocytosis which characterised the reaction to type A toxin was not apparent even one hour after inoculation (fig. 5). The slight reduction in granular cells in no. 661 was followed by an absolute neutrophilia, and, except in no. 321 , the final reaction took the form of a leucocytosis in contrast to the leucopenia which followed the injection of type D toxin. The absolute number of lymphocytes was little altered, two cases showing a slight increase and the other two a slight decrease. The monocytes tended to diminish in number. No. 322, which received a non-lethal dose, had a very high leucocyte count before inoculation, and hence the reaction two hours later appears only as a relative and not an absolute neutrophilia.

\section{Biochemical changes in the blood}

No characteristic picture was obtained. The data from a typical case, no. 661, are shown in fig. 6 . The majority of the blood constituents remained constant - the chlorides, inorganic and total phosphorus, potassium, calcium and magnesium. Slight fluctuations only took place. In some cases the sugar rose gradually till death, e.g. no. 659 , but in no. 661 , as in others, it rose immediately after injection and fell again suddenly to reach a normal value before death. In one or two cases it remained constant. The non-protein nitrogen and amino-nitrogen showed small increases in some animals but in others remained practically constant. The creatinine remained constant in most cases but in nos. 661 and 659 a slight increase took place. The hæmoglobin remained constant in all sheep in which death occurred within a few hours, but in no. 3 , which survived, it fell gradually within 48 hours from $10 \cdot 8$ to 7.85 g. per 100 c.c., and even two months after injection was found to be only $6.65 \mathrm{~g}$. per 100 c.c.

\section{Type D toxin}

\section{Symptoms}

Dyspnœa and incoordination of gait were again the prominent symptoms. In addition, there were symptoms suggestive of disturbance of nerve function such as the twisting of the head to one side and pleurothotonos. Tremors were observed along the 
MGNACL

MGK

${ }_{80}{ }_{16}^{\text {Mg,MG,CA, Tot.P,IN.P. N } \quad \text { No. } 661}$

$\begin{array}{lll}800 & 75 \quad 15\end{array}$

$\begin{array}{lll}580 & 70 & 14\end{array}$

$\begin{array}{lll}560 & 65 & 13\end{array}$

$540 \quad 60 \quad 12$

$520 \quad 55 \quad 1$

500

480

$460 \quad 40 \quad 8$

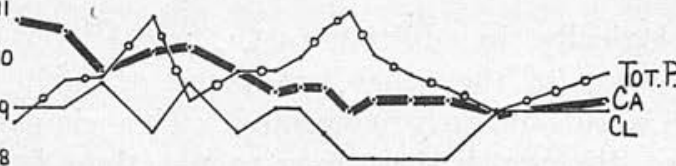

$440 \quad 35 \quad 7$

306

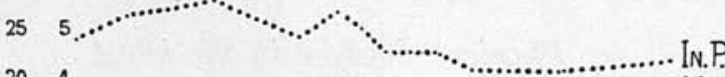

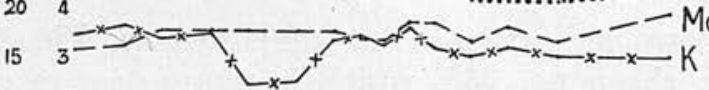

102

MG.N.P.N.

MG.AMINo N, AND G. HB.
$\left.\right|_{20}$ MGSUGAR.
No. 661

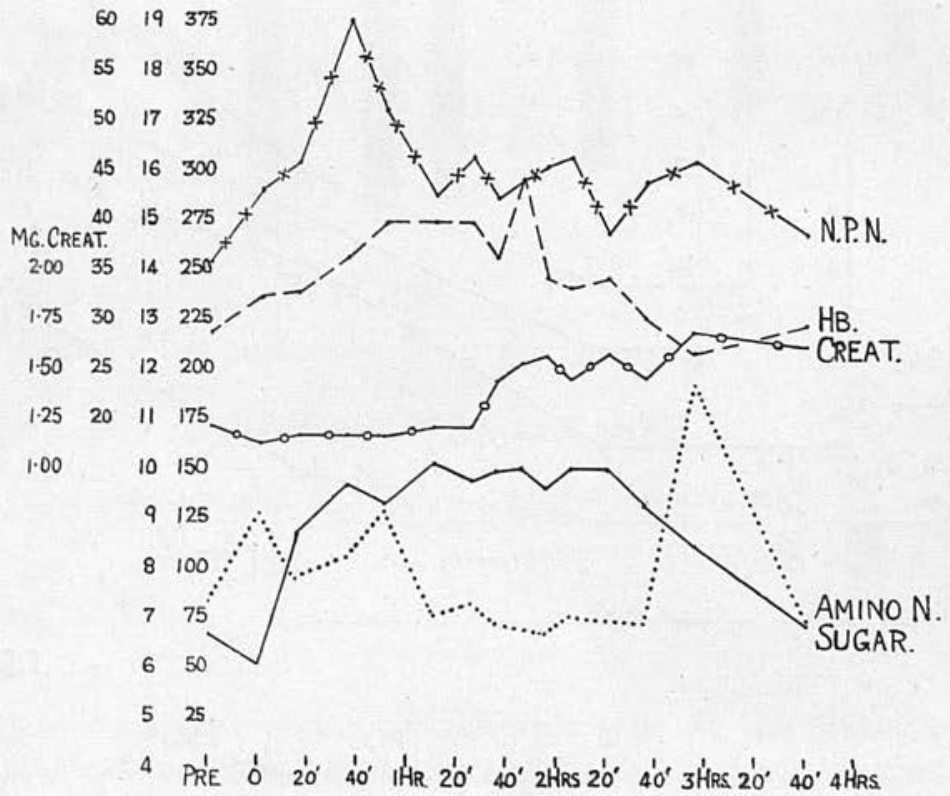

FIG. 6.-Biochemical changes in the blood following the injection of type $\mathrm{C}$ toxin. 
muscles of the back and the animals showed a desire to make use of fixed objects as aids in support. Death often occurred after a short period of coma.

\section{Post-mortem findings}

Again the most constant lesions were sub-endocardial and sub-epicardial hæmorrhages, mainly along the course of the coronary vessels. The lungs appeared congested and the blood vessels prominent. The liver was darker than normal owing to venous congestion.

Histologically, in addition to the usual liver damage observed after injection of the other two types of toxin, the sinusoids of the liver were obviously congested. This change was sufficiently marked to distinguish these liver preparations from those obtained from sheep which had died from the other toxins. The changes in the lung and kidney were similar to those due to type $\mathrm{C}$ toxin.

\section{Physical changes in the blood}

These were indicative of an anhydræmia. Fig. 7 depicts the findings in sheep no. 338, which is representative of the group.

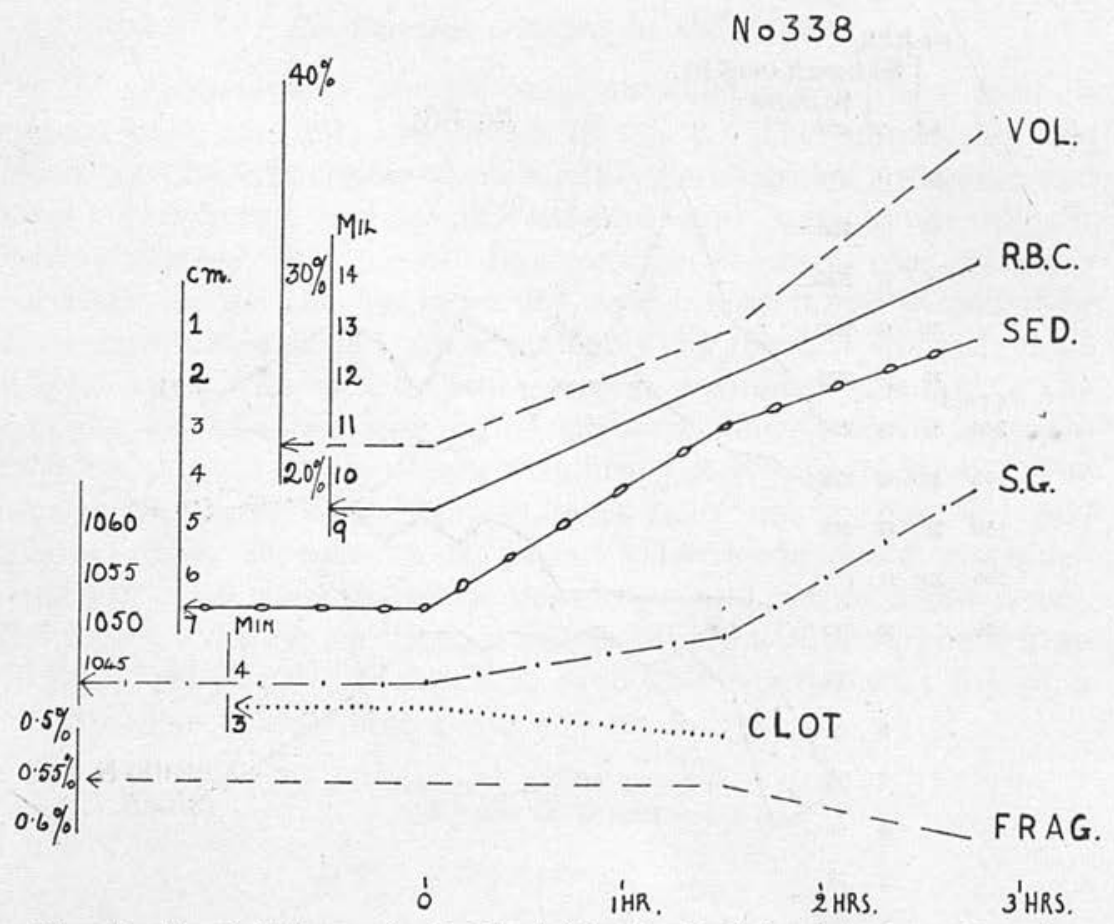

Frg. 7.-Physical changes in the blood following the injection of type D toxin.

A definite polycythæmia occurred, the red cell count rising from a pre-inoculation figure of $9 \cdot 5$ million to $14 \cdot 6$ million per c.mm. 
This was accompanied by a rise in specific gravity from 1045 to 1065 and an increase in the total cell volume from 22 to 38 per cent. There was a decrease in the sedimentation rate and the blood clotted more rapidly. In two of the five sheep which died the fragility of the red cells was slightly increased. No significant change occurred in the colour index. In the four animals which received a sub-lethal dose there was a slight oligocythæmia, and the specific gravity and total cell volume decreased proportionally. Films showed no abnormality of the erythrocytes or platelets except in one case, which showed anisocytosis and a single polychromasic cell.

\section{Leucocytic reaction}

Fig. 8 shows that in all four animals which received a lethal dose there was a fall in the number of granular cells but much

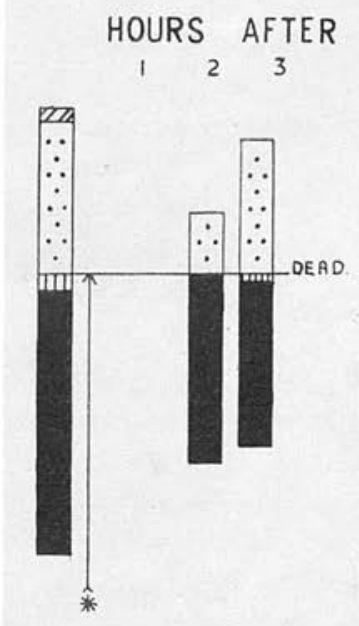

CASES 338.

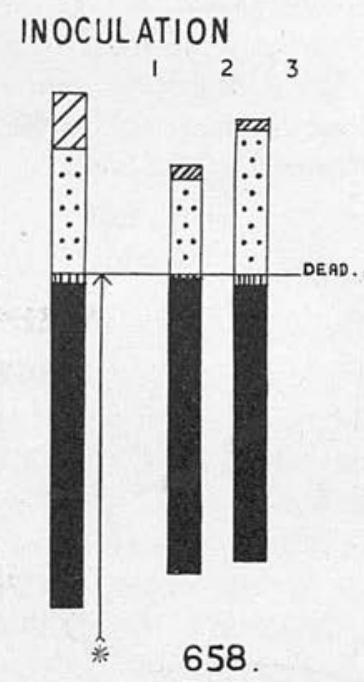

658.

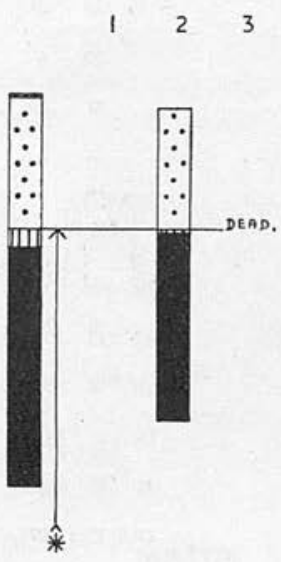

639.

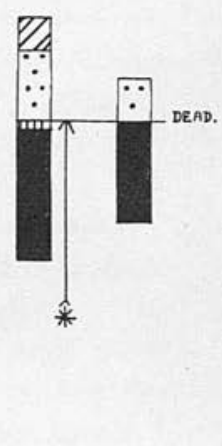

634.
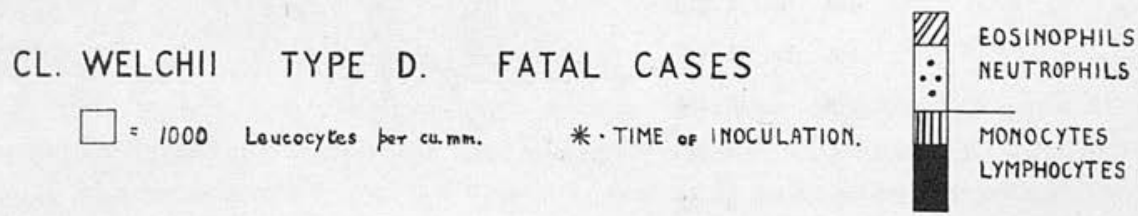

FIG. 8.-Leucocytic reactions in four sheep which received a lethal dose of type $\mathrm{D}$ toxin.

less than with type A toxin. As with type $A$, the reaction was greatest one hour after inoculation and tended to decrease after 2-3 hours. This reaction was in distinct contrast to the neutrophilia after type $\mathrm{C}$ toxin. Each of the four animals receiving a lethal dose showed a decrease in the absolute number of lymphocytes, 

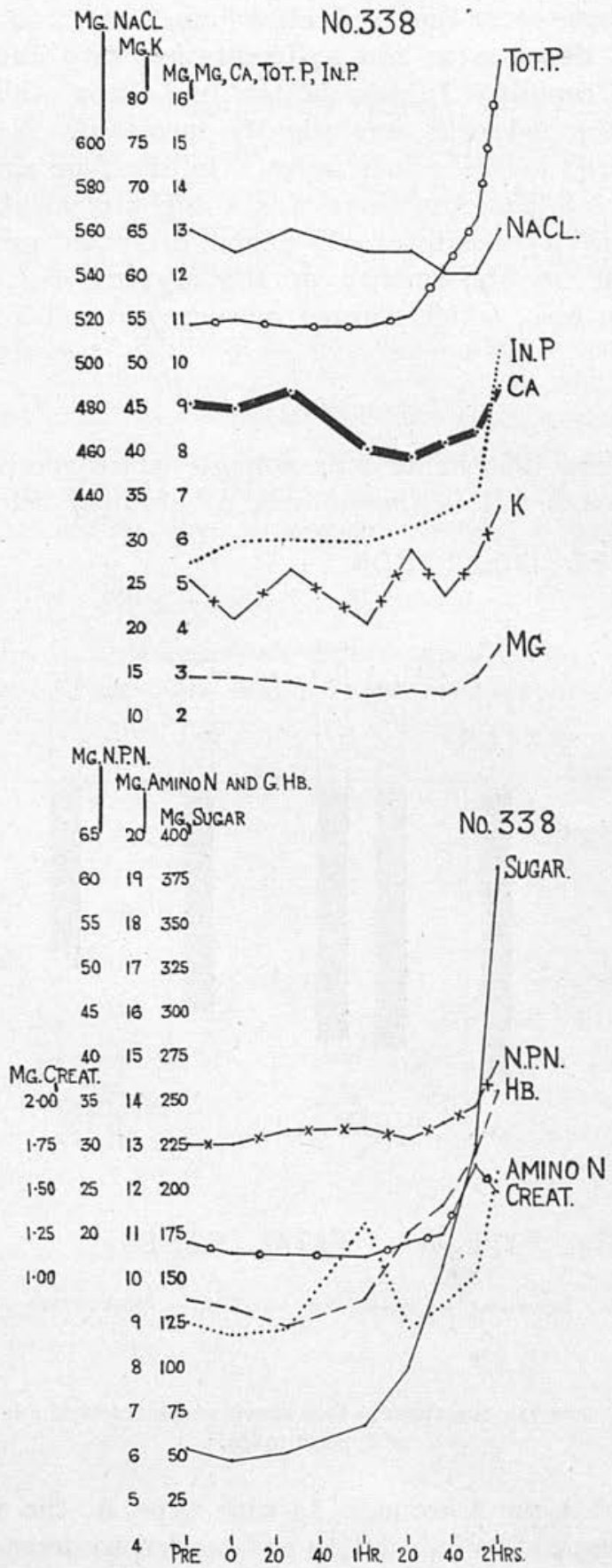

Frg. 9.-Biochemical changes in the blood following the injection of type $\mathrm{D}$ toxin. 
and in nos. 338 and 658 , from which three samples were obtained, this change was progressive. Since a decrease in the monocytes also occurred the sum of the reactions represented a leucopenia.

As with the other toxins, sheep which received a non-lethal dose showed an absolute neutrophilia two or more hours after inoculation.

\section{Biochemical changes in the blood}

Type D toxin produced the greatest effect on the blood constituents but only if a lethal dose were injected. The data from sheep no. 338 are shown in fig. 9. Most of the blood constituents showed a large increase after inoculation. The rise was most marked in the hæmoglobin and sugar. In no. 658 the hæmoglobin rose from 13.0 to $19.0 \mathrm{~g}$. and the sugar from 55.5 to $121.2 \mathrm{mg}$. per 100 c.c., while in no. 338 (fig. 9) the hæmoglobin rose from $9 \cdot 3$ to $14 \cdot 28 \mathrm{~g}$. and the sugar from $47 \cdot 1$ to $380 \cdot 1 \mathrm{mg}$. per 100 c.c. The phosphate, both inorganic and total, magnesium, potassium, non-protein nitrogen, amino-acid nitrogen and creatinine all showed substantial rises. The calcium either remained constant or fell slightly. The chloride usually remained constant but in some cases fell to a very slight extent, as in no. 658. The picture described above and represented in fig. 9 is that of a typical anhydræmia in which the organic constituents of the blood are usually considerably increased while the inorganic constituents are either slightly increased or even slightly decreased, the chloride usually falling to a significant extent. With type D toxin the blood picture described was found in all sheep which died. In those which were given a sublethal dose both the inorganic and total phosphorus tended to fall slightly, while the other constituents remained constant or fluctuated to a small degree. The hæmoglobin content of no. 339 , which survived, fell rapidly to $6.83 \mathrm{~g}$. after 48 hours and even one month after inoculation had not regained its normal value.

\section{SUMMARY}

The symptoms, intra-vitam effects on the blood and postmortem findings following the intravenous inoculation of sheep with the toxins of $\mathrm{Cl}$. welchii types A, C and D have been compared. With the exception of hæmoglobinuria, which occurred only in sheep inoculated with type A, no marked difference in symptoms was observed. Type A toxin produced a rapid fall in the number of red blood corpuscles with a corresponding fall in hæmoglobin, specific gravity and total cell volume, an increase in the sedimentation rate and an increase in red cell fragility. No specific blood changes followed the inoculation of type $\mathrm{C}$ toxin. Type $\mathrm{D}$ toxin produced a rise in the number of red corpuscles with a corresponding 
rise in hæmoglobin, specific gravity and total cell volume. There was a decrease in sedimentation rate and, with the exception of calcium and chloride, a marked rise in the inorganic and organic constituents of the blood. Anisocytosis and slight polychromasia followed the injection of type A toxin but was not observed after a lethal dose of either C or D. Wallbach (1935) reviews work which showed that the injection of toxins was followed by a transient agranulocytosis and this in turn by a neutrophilia. In the case of the welchii toxins A and D there was a temporary fall in the number of granular cells followed by a return more or less to the original figure. Two hours after inoculation agranulocytosis was still present with type A toxin, while with type D the granular leucocytes were still slightly lowered; with type C there was a slight neutrophilia. Two hours after inoculation with non-lethal doses of all three types there was a neutrophilia. Type D toxin was exceptional in that it also caused a reduction in the number of lymphocytes. The out-standing histological differences were that sheep killed with type A toxin showed an œdematous exudate in the alveoli of the lungs and a large amount of colloidal material in the kidneys in the form of hæmoglobin cylinders within the tubules and extravasated between the tubules, whereas these changes were not observed in sheep inoculated with types C and D. Sheep inoculated with type D showed marked congestion of the sinusoids in the liver : this was absent in sheep which had received types $\mathrm{A}$ and $\mathrm{C}$.

\section{Conclusion}

As a result of these experiments it may be concluded that whereas the toxin of $\mathrm{Cl}$. welchii type $\mathrm{C}$ produces no specific blood changes, that of type A produces a marked hæmolytic anæmia, while that of type $\mathrm{D}$ produces an anhydræmia.

We are indebted to Dr R. A. O'Brien for sera and to Professor T. Dalling and Dr R. F. Montgomerie for kindly placing cultures at our disposal.

\section{REFERENCES}

Bull, C. G., And Pritchett, 1917. J. Exp. Med., xxvi, 119.

I. W.

Chamberlin, W. E. . . . 1933. Austral. Vet. J., ix, 2.

Dalling, T., AND Ross, H. E. 1938. J. Comp. Path. Therap., li, 235.

Gordon, W. S. . . . . . 1934. Vet. Rec., xiv, N.S., 1016.

HENRY, H. . . . . . . 1922. This Journal, xxv, 1.

Klotz, O., and Holman, 1911. J. Inf. Dis., ix, 251.

W. L.

Mason, J.H. . . . . . 1935. Onderstepoort J. Vet. Sci., v, 61.

McCoy, E., And McClung, 1938. Bact. Rev., ii, 47.

L. S. 
Norris, J. H., AND Chamber- 1929. Austral. J. Exp. Biol. Med. Sci., LIN, W. E. vi, 285.

Pinty, A. . . . . . 1931. Recent advances in hæmatology, 3rd ed., London, p. 318.

Report on the anaerobid 1919. Medical Research Committee, Spec. INFECTIONS OF WOUNDS

Rose, A. L., AND Edgar, G. . 1936. Austral. Vet. J., xii, 212.

Stewart, J., and Holman, 1940. Vet. Rec., lii, 157.

H. H.

WaLlBach, G. · . . . . 1935. Rev. path. comp., xxxv, 605.

Wirsdon, A. J. . . . . 1931. Second Report of the Director of the Institute for Animal Pathology, Univ. Cambridge, p. 53. 


\title{
Observations on the Blood-Picture of Sheep Treated with Phenothiazine
}

\author{
H. H. HOLMAN AND I. H. PATTISON,
}

Animal Diseases Research Association,

Moredun Institute, Gilmerton, Midlothian

Introduction.-Errington and Westerfield (1940), and others, have shown that the administration of phenothiazine to horses produces an anaemia. In a recent paper (19+1) we have discussed an anaemia in lambs affected with parasitic gastritis and treated with phenothiazine; the evidence suggested that the anacmia was not due to the drug, although it was admitted that this had not been completely proved. As far as the leucocytic picture was conserned it was stated that the effect of phenothiazine, if any, was slight.

An experiment with phenothiazine instituted by the Agricultural Research Council and carried out at Mo:cdun Institute by Dr. D. O. Morgan and Mr. J. E. N. Sloan provided an opportunity for studying the effect of phenothiazine on the blood-picture of sheep and of comparing results with those obtained in the paper referred to above.

History OF THE FLOCK.-A flock of 67 Cheviot lambs which had been grazed over a restricted area for a period of about four weeks in order to increase their worm-burden, was used for the experiment. At the end of this period the worm-egg counts averaged about 1,000 eggs per gramma of faeces, but all the lambs were clinically healthy.

Thirty-six of the lambs were then brought indoors and fed on concentrates and hay. The remainder were moved to "clean pasture" and were supplied with concentrates and hay in addition to the grass available. Before the first blood examination the lambs of the "inside group" were allowed seven days in which to become accustomed to dry food and new surroundings.

Serial bleedings of 16 selected lambs indoors were carried out in order to observe transitory or progressive blood changes. In addition, single bleedings of eight other lambs of the "indoor group,"' and of 31 lambs out-of-doors were carried out, at a tim? (three to four wecks later) when the findings of the previous investigation suggested that enaemic changes were likely to be apparent.

TeChNiQue. Administration of Phenothiazine.-Phenothiazine was supplied by Imperial Chemical Industries, Limited. The appropriate close was given either as a draught of phenothiazine suspension, or in the form of $5 \mathrm{~g}$. tablets of phenothiazine. A stomach-tube was used for administering doses of suspension containing an smount greater than $50 \mathrm{~g}$.

Worm-egg Counts.-The technique described by Gordon and Whitlock (1939) was used for all worm-egg counts.

Haematology.-All estimations were made in the manner described in our paper mentioned above. Haemoglobin was determined by a Zeiss Ikon hacmometer, viscosity by a Denning Watson tube, and fragility was measured by recording maximum haemolysis in sodium chloride solutions varying by 0.05 per cent. - Coagulation time was determined by a capillary tube method in the manner described by Stewart and Holman (1940). Oxalated blood was used for all estimations except coagulation time.

EXPERIMENT.-The lambs of the "inside group" selected for serial bleedings were: (a) Four control animals which received no phenothiazine. (b) Two animals at each of the following doses: 5 g., 10 g., 20 g., 40 g., 80 g., and 160 g. of phenothiazine in suspension.

Eight other lambs of the "inside group" were bled once, 24 days after treatment with phenothiazine. Two of these animals had each reccived $30 \mathrm{~g}$. of the drug in tablet form, two, $30 \mathrm{~g}$. in "suspension, two $50 \mathrm{~g}$. in tablet form, and two $50 \mathrm{~g}$. in suspension.

The 31 " outside lambs" were bled once, 34 days after treat'ment. The amounts of phenothiazine administered to these animals are detailed in Table. 


\section{Results}

The results, shown in Table (see p. 215), have been summarised in order to present them in the least possible space.

Inspection of the complete haematological data, and of their summarised form as presented in the table does not reveal any significant difference between the blood-pictures of control and treated animals .

\section{Discussion}

When the lambs were first brought indoors it was noted that, for a longer or shorter period, every animal refused to eat dry food. Weighings carried out at this time indicated a steady loss of weight. It has been stated that seven days elapsed befo:e the first bleeding was carried out, but even at this time few of the lambs were feeding properly. This lack of appetite and general physiological upset is reflected in the blood-picture of all the animals during the three preliminary bleedings and for two days after treatment. Thereafter the condition of both control and treated animals slowly improved.

This sudden change of environment, however, affected some Jambs more severely than others. It soon became apparent that of the 16 lambs selected for bleeding, three were not thriving at all ; they showed marked lack of appetite, were listless, and weak. The doses of phenothiazine which had been administered to these three lambs were 5 g., 20 g., and $160 \mathrm{~g}$. respectively. The animal which had received $20 \mathrm{~g}$. of phenothiazine died 15 days after treatment, and post-mortem examination revealed nodular liver necrosis together with liver-fluke infestation. The $5 \mathrm{~g}$. dose animal was slaughtered 31 days after treatment and nodular liver necrosis was found, but there was no evidence of fascioliasis. The third of these three animals (that which had received $169 \mathrm{~g}$.) was slaughtered 48 days after treatment and was found to be heavily infested with Fasciola hepatica and Dictyocaulus filaria. Therefore, because the experiment was concerned only with the effect of phenothiazine, these animals were discarded.

Besides the lack of appetite which has been ascribed to the sudden transition from life in the open to confinement in a loose-box, it was noted that those lambs which received the $80 \mathrm{~g}$. and $160 \mathrm{~g}$. doses ate practically nothing for about three days after administration of the drug. This has been accepted by us as an explanation of the somewhat lower figures for red cell counts which were apparent in the individual records in these animals.

In our previous paper it was stated that blood changes possibly attributable to phenothiazine were slight. In the case of one animal which received two doses of phenothiazine, the first administration was followed by a neutrophilia, and the second administration by a neutrophilic shift to the left. A slight progressive decrease in neutrophils was noted in the treated group.

In the present experiment, however, no neutrophilia was noted, and the possible significance of an increase of band forms sug-, gested by the records of individual lambs of the "inside group" was nullified by differential counts made on animals of the "outside group."

\section{Summary}

The therapeutic dose of phenothiazine for lambs is regarded as being between $10 \mathrm{~g}$. and $20 \mathrm{~g}$.; no specific change was detected in the blood of 25 lambs receiving more than this dose.

Acknowledgment.-We are grateful to Dr. J. Russell Greig for his continued interest in this experiment.

\section{REFERENCES}

Errington, B. T., and Wesierfieid, C. (1940.) Vet. Med., 35, 688.

Holman, H. H., and Pattison, I. H. (19+1.) Vet. Rec., 53, 491.

Gordon, H. MCLL., and Wirtlock, H. V. (1939.) $\mathscr{f}$. Counc. Sci. Industr. Res., 12,50 .

Steivart, J. and Holman, H. H. (1940.) Vet. Rec.. 52, 157. 


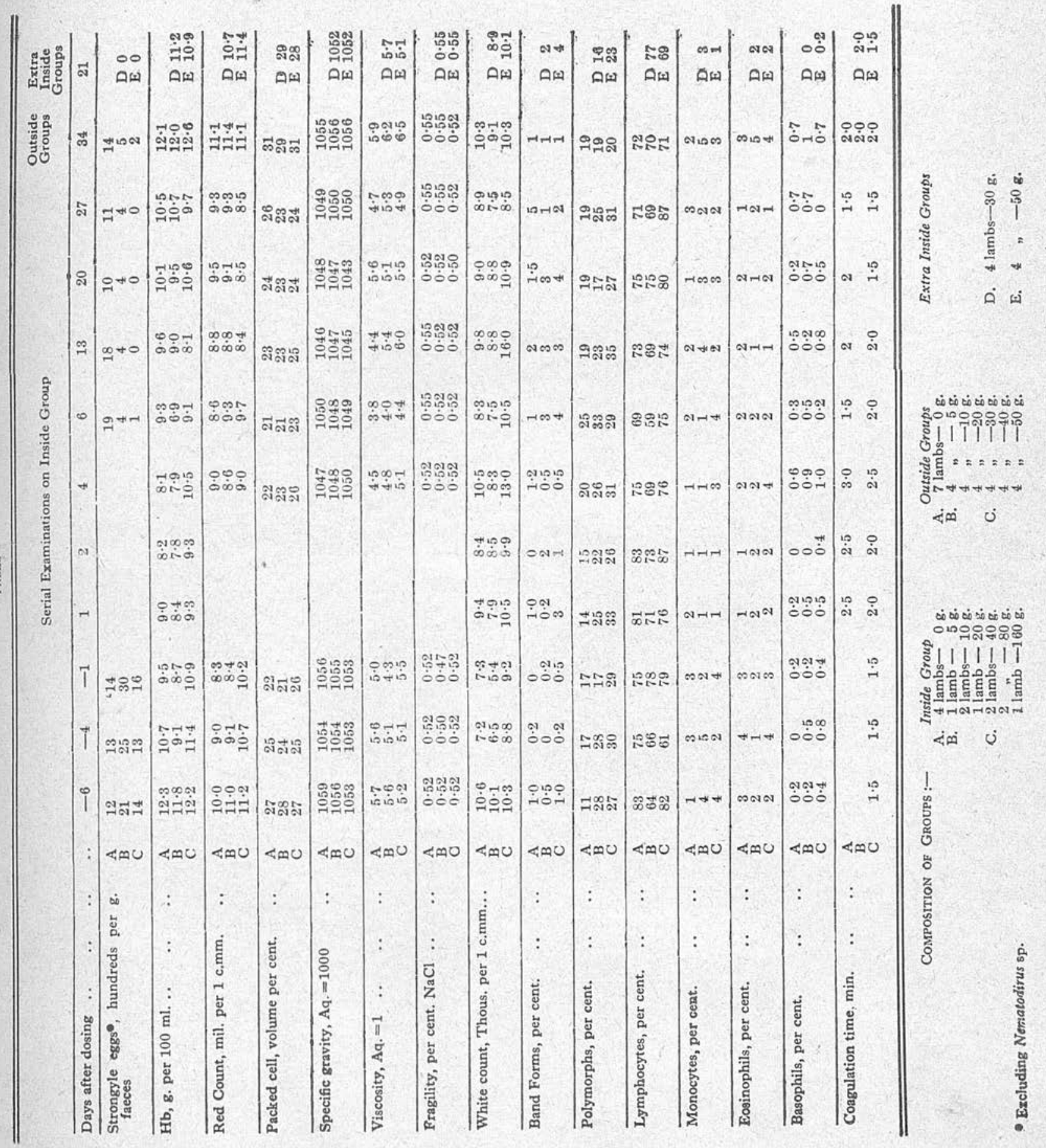




\title{
A STUDY OF THE BLOOD PICTURE OF LAMBS SUFFERING FROM PARASITIC GASTRITIS
}

\author{
H. H. HOLMAN and I. H. PATTISON,
}

Animal Diseases Research Association, Moredun Institute, Gilmerton, Midlothian

\section{INTRODUCTION}

Fourie (1931) investigated the blood changes associated with the experimental infestation of sheep with Haemonchus contortus. He concluded that death was due to a post-haemorrhagic anaemia, this conclusion being supported by the presence of material reacting as a blood pigment in the abomasum, and the absence of haemosiderun deposits in the body. This work created the impression that in natural mixed infestations in which $H$. contortus was present the anaemia concomitant with infestation was posthaemorrhagic in type, and an important pathological factor in the disease.

Previous observations by Fraser (1930) did not support this view in that he recorded large depositions of haemosiderin, and on this finding founded the hypothesis of a haemolytic anaemia. Stewart (1933), working with lambs similarly infested, referred to Fourie's work and reported that he had been unable to demonstrate the presence of blood in the abomasum.

In this work the opportunity offered by a natural outbreak of parasitic gastritis was utilised in an endeavour to add to these results, to study blood changes in lambs treated with phenothiazine as compared with those left untreated, and to correlate these findings with changes in weight. The experiment was concerned primarily with blood changes in the lambs and the economic value of phenothiazine as an anthelmintic was not particularly considered.

\section{HISTORY OF THE FLOCK}

A flock of 50 lambs, recently purchased, was not thriving. Nine deaths had occurred and the owner had sold four in an emaciated condition. Viscera from a dead lamb were forwarded to the Institute for diagnosis; Haemonchus contortus and Ostertagia circumcincta were identified and the contents of the large bowel gave a concentration of 25,000 worm eggs per gramme. These findings, in conjunction with the symptoms, led to a diagnosis of parasitic gastritis.

\section{TECHNIQUe}

Treatment.-Phenovis liquid (I.C.I., a 56 per cent. weight/volume suspension of phenothiazine in water with a dispersing agent) was administered as a draught at the rate of 0.75 gramme per kilo. live weight.

Egg Counts.-Preliminary egg counts were carried out by the technique described by Taylor (1939). The final count was made by Dr. D. O. Morgan, using the technique given by Gordon and Whitlock (1939).

Haematology.-When leucocytes only were to be examined blood was obtained by pricking a small vein in the ear. For a full blood examination 1.c.c. of blood was taken from the jugular vein. A drop of blood was ejected for a blood smear, and the remainder was discharged into a tube containing $2.5 \mathrm{mg}$. of a mixture of four parts potassium oxalate and one part sodium fluoride, and was well shaken. Smears were treated with Leishman's stain and 200 cells were classified, but all other measurements were - carried out with the oxalated blood. For white and red cell counts blood was diluted with acetic acid or saline by means of Piney pipettes. Viscosity was measured by a Denning Watson tube. Cell volume was estimated by centrifuging blood in small haematocrit tubes for one hour, and recording the mean of two measurements. Haemoglobin was estimated by a Zeiss Ikon haemometer. Fragility was measured by recording maximum haemolysis in sodium chloride solutions varying by 0.05 per cent. Price-Jones curves were made by the method of Hynes and Martin. Special staining for reticulocytes was not considered necessary, since in various species these have been found equivalent to the polychromatic cells together with cells showing punctate basophilia.

The table of normals (over-leaf) is given for comparison and to call attention to the wide variation present in apparently healthy sheep when using the. above technique. Haemoglobin figures fall within the range of figures recorded for a large number of sheep by other members of the Institute using the more accurate Newcomer disc method of estimation.

Effect of Phenothiazine.-Two lambs were not expected to live and were removed from the flock; the remaining 35 lambs were brought in from pasture on September 12th and folded on cabbages. They were divided into two groups, 18 being treated with phenothiazine on September 12th and again on the 19 th and the rest serving as controls. 


\begin{tabular}{|c|c|c|c|c|}
\hline & $\begin{array}{l}\text { Mini- } \\
\text { mum }\end{array}$ & $\begin{array}{c}\text { Maxi- } \\
\text { mum }\end{array}$ & Mode & $\begin{array}{c}\text { Number } \\
\text { of sheep } \\
\text { esti- } \\
\text { mated }\end{array}$ \\
\hline Red count (millions) & $7 \cdot 1$ & $17 \cdot 5$ & $11 \cdot 0$ & 40 \\
\hline Haematocrit $(\%)$... & $21 \cdot 0$ & $39 \cdot 0$ & $30 \cdot 0$ & 40 \\
\hline $\begin{array}{c}\text { Haemoglobin (haemo- } \\
\text { meter)* } \ldots\end{array}$ & $11 \cdot 2$ & $15 \cdot 0$ & $12 \cdot 5$ & 25 \\
\hline Viscosity (times water) & $4 \cdot 3$ & $7 \cdot 8$ & $6 \cdot 1$ & 18 \\
\hline Fragility $(\% \mathrm{NaCl}) \ldots$ & 0.45 & 0.65 & 0.55 & 40 \\
\hline $\begin{array}{l}\text { White count (thou- } \\
\text { sands) }\end{array}$ & $4 \cdot 1$ & $17 \cdot 2$ & $9 \cdot 0$ & 60 \\
\hline Neutrophiles (\%) ... & $13 \cdot 0$ & $60 \cdot 0$ & $25 \cdot 0$ & 60 \\
\hline Lymphocytes (\%) ... & $33 \cdot 0$ & $84 \cdot 0$ & $57 \cdot 0$ & 60 \\
\hline Monocytes $(\%) \quad \ldots$ & 0 & $15 \cdot 0$ & $2 \cdot 0$ & 60 \\
\hline Eosinophiles (\%) & 0 & $21 \cdot 0$ & $1 \cdot 0$ & 60 \\
\hline Basophiles (\%) $\quad \ldots$ & 0 & $4 \cdot 0$ & of & 60 \\
\hline $\begin{array}{c}\text { Mean corpuscular } \\
\text { volume }(\text { c. } \mu)\end{array}$ & $19 \cdot 0$ & $36 \cdot 0$ & $27 \cdot 0$ & 40 \\
\hline
\end{tabular}

* Nineteen sheep within the limits of 12 to 13.5 gramme per $100 \mathrm{ml}$.

$\dagger$ Áverage 0.3 per cent.

The following indices have been used :-

Mean corpuscular volume (c. $\mu$ )

Packed cell volume (c.c.) per litre

Erythrocyte count in millions per c.mm.

Mean corpuscular haemoglobin $(\gamma \gamma)$

Haemoglobin in grammes per litre

Erythrocyte count in millions per c.mm.

Mean corpuscular haemoglobin

concentration (per cent.)

$\frac{\text { Haemoglobin grammes per litre }}{\text { Packed cell volume as a percentage }} \times \frac{10}{1}$

Effect on Intestinal Infestation.-Table No. 1 deals with worm-egg counts and indicates the toxic action of phenothiazine on trichostrongyle worms. Before dosing, the faecal preparations showed a variety of worm-eggs among which those of Trichuris sp. and Strongyloides sp. were identified. No attempt was made to classify the trichostrongyle eggs, but no Nematodirus eggs were apparent. Seven days after the second administration of phenothiazine the eggs of Strongyloides sp. only were discovered in the faeces of the treated lambs, but untreated lambs continued to show the original variety of eggs. Sixteen days after the second administration, out of 12 samples from treated lambs four showed no worm-eggs at all, and five others showed eggs of the Strongyloides sp. alone, while among the untreated lambs trichostrongyle worms continued to predominate.

Effect on Weight.-The live weight gains of treated and untreated lambs are shown in Table No. 2. During the first three weeks the treated lambs increased in weight more than twice as quickly as the untreated, and at the final weighing, nearly two months after administration of phenothiazine, were still gaining weight more rapidly than the controls. To begin with, the control group had a heavier average weight than that of the treated group. Accordingly, it might be inferred that the folding of the lambs on cabbages by affording better nutrition enabled the more illthriven treated lambs to increase towards their normal weight more rapidly than the less abnormal controls. However, the increases in weight shown by individual lambs commencing at identical weights does not support this inference. Examining the figures for the total gain in weight, as given in Table II, by the $\chi^{2}$ test, according to the following table :-

\begin{tabular}{lrrrr}
\hline \hline Gain in Weight & $\begin{array}{c}\text { More } \\
\text { than } \\
15 \mathrm{lb} .\end{array}$ & $\begin{array}{c}15 \mathrm{lb} . \\
\text { or } \\
\text { less }\end{array}$ & Total \\
\hline Treated lambs & $\ldots$ & 14 & 2 & 16 \\
Untreated lambs & $\ldots$ & 4 & 12 & 16 \\
\cline { 2 - 5 } & & 18 & 14 & 32 \\
\hline \hline
\end{tabular}

then $\chi^{2}=12.69$, and $\mathrm{P}=$ less than 0.001 , showing that the result is highly significant.

Table I.-Worm-Egg Counts.

\begin{tabular}{|c|c|c|c|c|c|c|}
\hline \multirow{2}{*}{ Date } & \multicolumn{3}{|c|}{ Treated Lambs } & \multicolumn{3}{|c|}{ Untreated Lambs } \\
\hline & $\begin{array}{l}\text { Number of } \\
\text { Samples }\end{array}$ & $\begin{array}{l}\text { Average } \\
\text { Count }\end{array}$ & Remarks & $\begin{array}{l}\text { Number of } \\
\text { Samples }\end{array}$ & $\begin{array}{l}\text { Average } \\
\text { Count }\end{array}$ & Remarks \\
\hline $26 / 9 / 40$ & 10 & 100 e.p.g. & $\begin{array}{l}\text { Eggs of various tricho- } \\
\text { strongyles, of Stron- } \\
\text { gyloides sp., and of } \\
\text { Trichuris sp. } \\
\text { Eggs of Strongyloides } \\
\text { sp. only }\end{array}$ & 10 & $\begin{array}{l}1,500 \text { e.p.g. } \\
3,700 \text { e.p.g. }\end{array}$ & $\begin{array}{l}\text { Eggs of yarious tricho- } \\
\text { strongyles, of Stron- } \\
\text { gyloides sp., and of } \\
\text { Trichuris sp. } \\
\text { Eggs of various tricho- } \\
\text { strongyles, of Stron- } \\
\text { gyloides sp., and of } \\
\text { Trichuris sp. }\end{array}$ \\
\hline $5 / 10 / 40$ & 12 & 95 e.p.g. & $\begin{array}{l}\text { Four samples showed } \\
\text { no eggs. Tricho- } \\
\text { strongyle eggs in } \\
\text { three samples. Stron- } \\
\text { gyloides sp. eggs } \\
\text { made up about } 90 \\
\text { per cent. of the total } \\
\text { count }\end{array}$ & 8 & 542 e.p.g. & $\begin{array}{l}\text { Trichostrongyle eggs in } \\
\text { e ve ry s a m p le. } \\
\text { Strongyloides sp. eggs } \\
\text { made up about } 22 \\
\text { per cent of the total } \\
\text { count. }\end{array}$ \\
\hline
\end{tabular}


TABLE II

Weight in pounds

Treated LambS

\begin{tabular}{|c|c|c|c|c|c|c|}
\hline No. & Sex & $12 / 9$ & $5 / 10$ & $\begin{array}{r}\text { Gain on } \\
\text { Cabbages }\end{array}$ & $2 / 11$ & $\begin{array}{l}\text { Total } \\
\text { Gain }\end{array}$ \\
\hline & & Lb. & Lb. & Lb. & Lb. & Lb. \\
\hline 1 & E.L. & 75 & 85 & 10 & 96 & 21 \\
\hline 2 & W. & 100 & 106 & 6 & 128 & 28 \\
\hline 3 & E.L. & 85 & 91 & 6 & 103 & 18 \\
\hline 4 & W. & 93 & 108 & 15 & 126 & 33 \\
\hline 5 & E.L. & 88 & 98 & 10 & 106 & 18 \\
\hline 6 & W. & 92 & 101 & 9 & 118 & 26 \\
\hline 7 & E.L. & 94 & 102 & 8 & 118 & 24 \\
\hline 8 & W. & 86 & 104 & 18 & 116 & 30 \\
\hline 9 & E.L. & 89 & 97 & 8 & 116 & 27 \\
\hline 10 & E.L. & 86 & 97 & 11 & 106 & 20 \\
\hline 11 & E.L. & 101 & 110 & 9 & - & - \\
\hline 12 & W. & 106 & 116 & 10 & 126 & 20 \\
\hline 13 & E.L. & 94 & 102 & 8 & 112 & 18 \\
\hline 14 & W. & 104 & 111 & 7 & 124 & 20 \\
\hline 15 & E.L. & 85 & 95 & 10 & 101 & 16 \\
\hline 16 & E.L. & 91 & 100 & 9 & 101 & 10 \\
\hline 17 & E.L. & 100 & 110 & 10 & 5 & $\bar{z}$ \\
\hline 18 & E.L. & 95 & 104 & 9 & 110 & 15 \\
\hline Total ... & & 1,664 & 1,837 & 173 & 1,807 & 344 \\
\hline Average & & $92 \cdot 4$ & $102 \cdot 1$ & $9 \cdot 5$ & $112 \cdot 9$ & $21 \cdot 5$ \\
\hline
\end{tabular}

UNTREATED LAMBS

\begin{tabular}{|c|c|c|c|c|c|c|}
\hline No. & Sex & $12 / 9$ & $5 / 10$ & $\begin{array}{l}\text { Gain on } \\
\text { Cabbages }\end{array}$ & $2 / 11$ & $\begin{array}{l}\text { Total } \\
\text { Gain }\end{array}$ \\
\hline & & Lb. & Lb. & Lb. & Lb. & Lb. \\
\hline 19 & E.L. & 95 & 108 & 14 & 111 & 17 \\
\hline 20 & W. & 116 & 118 & 2 & 131 & 15 \\
\hline 21 & E.L. & 95 & 103 & 8 & 111 & 16 \\
\hline 22 & E.L. & 86 & 90 & 4 & 94 & 8 \\
\hline 23 & E.L. & 104 & 103 & -1 & 112 & 8 \\
\hline 24 & W. & 122 & 123 & 1 & 135 & 13 \\
\hline 25 & E.L. & 104 & 104 & 0 & 112 & 8 \\
\hline 26 & E.L. & 91 & 100 & 9 & 110 & 19 \\
\hline 27 & E.L. & 107 & 109 & 2 & 118 & 11 \\
\hline 28 & W. & 116 & 121 & 5 & 124 & 8 \\
\hline 29 & E.L. & 104 & 110 & 6 & 126 & 22 \\
\hline 30 & W. & 104 & 111 & 7 & - & $\overline{1}$ \\
\hline 31 & E.L. & 102 & 104 & 2 & 116 & 14 \\
\hline 32 & W. & 115 & 111 & -4 & 124 & 9 \\
\hline 33 & W. & 108 & 104 & -4 & 106 & -2 \\
\hline 34 & E.L. & 85 & 87 & 2 & 98 & 13 \\
\hline 35 & W. & 96 & 98 & 2 & 110 & 14 \\
\hline Total & & 1,749 & 1,804 & 55 & 1,838 & 193 \\
\hline Average & & $102 \cdot 9$ & $106 \cdot 1$ & $3 \cdot 2$ & $114 \cdot 9$ & $12 \cdot 1$ \\
\hline
\end{tabular}

E.L. $=$ Ewe lamb.

W. $=$ Wether.

Effect on Blood.-The possible effect of phenothiazine on the leucocytic picture is mentioned at the end of the section on leucocytic changes, and the fall in red count after treatment is discussed at the end of the section on anaemic changes and their correlation with weight.

\section{Leucocytic Changes}

Fourie claimed little specificity for the leucocytic changes seen in his experimental sheep. He recorded a terminal neutrophile leucocytosis and commented on the absence of eosinophilia. However, in sheep at the stage of recovery there was some increase in the number of eosinophiles. Fraser also noted a relative neutrophilia accompanied in severely infested sheep by an eosinopenia. In slight infestations he found little abnormality except some suggestion of eosinophilia.

Our observations on severely infested sheep sent to the Institute for diagnosis are in accordance with these results, and we have noted little other abnormality.

In this investigation five lambs from the treated group and five from the control group were examined for leucocytic changes. A preliminary examination was made while the lambs were still at pasture and before treatment, counts were made twice a week during the period the lambs were folded on cabbages and a final examination was made on November 2nd, some four weeks after their return to pasture. Unfortunately, present exigencies do not permit the publication of the full tables but the total and differential counts averaged for each group are shown diagrammatically in Fig. 1.

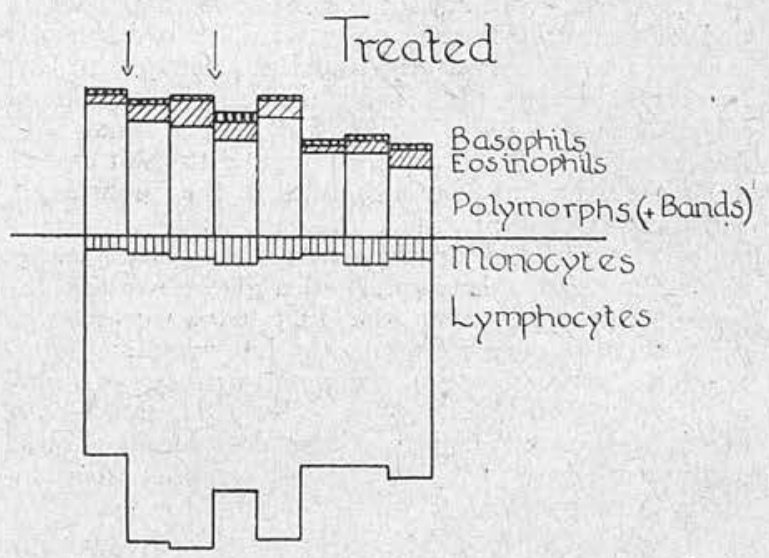

Untreated

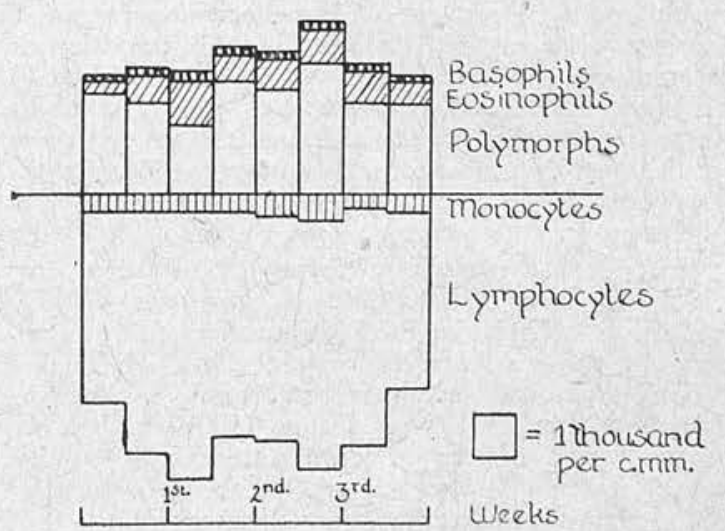

Fig. 1.-Averaged Total and Differential Leucocyte Counts. 
At the preliminary bleeding there was little abnormality among the ten selected lambs with the exception of a rather high average for monocytes and the presence of basophiles in nine of the ten films.

During the period the flock was folded on cabbages the following changes were observed. Samples taken four days after being folded on cabbages showed an absolute increase in lymphocytes; this persisted for two weeks in the treated group and for three weeks in the untreated group. In both groups the eosinophiles increased during this period, averaging 4 per cent. in the treated group and 8 per cent. in the untreated group, both figures being double that found in the preliminary examination. Basophiles were frequently present in films from the treated group and always present in the untreated group, where they sometimes averaged 5 per cent. of the differential count. The neutrophiles provided a contrast between the two groups in that the treated group showed a slight progressive decrease throughout the period while the untreated group showed a slight increase that reached its peak on the 18 th day and then subsided.

At the final bleeding, after return to pasture, the differential counts were similar to those of the preliminary bleeding.

Two severely affected lambs were not included in the main experiment. They were separated from the flock, housed, given dry food, and one was treated with phenothiazine. Blood samples were taken frequently in order to observe any transient changes in the leucocytic picture following the administration of phenothiazine. On October 3rd both animals had improved in health and were returned to their owner.

Neither showed a neutrophilia at the preliminary bleeding, although the untreated lamb showed a slight neutrophilia on two occasions subsequently, while the treated lamb showed a slight neutrophilia lasting five days after the first administration of phenothiazine, and a shift to the left reaching a proportion of five young and ten band forms out of a total of 40 per cent. neutrophile cells after the second administration of phenothiazine. Both lambs showed an increase in eosinophiles and basophiles after removal from pasture.

In view of the close connection between the presence of parasitic "eosinotactic" substances and a blood eosinophilia, as demonstrated by Weinberg and Seguin (1914-15), it is interesting to note that in this experiment there was no evidence of the presence of such a substance except in lamb No. 23, in which on one occasion the number of eosinophiles reached 27 per cent., and that the reaction of the eosinophiles was similar to that found in inflammatory processes, that is, the presence of an eosinopenia during the acute phase of the disease, followed by a slight eosinophilia during the recovery stage.

Apart from the work of Jorpes (1939) suggesting that the function of basophiles is connected with the. production of heparin, little is known of the significance of these cells in the blood. The high level of basophiles present in the untreated lambs is therefore of interest, particularly as Porter (1937) has shown that they also appear in large numbers in another type of worm infestation, namely, the infestation of guinea-pigs with Metastrongylus elongatus.

The effect of phenothiazine per se on the leucocytic picture would appear to be small, and the increase of lymphocytes, eosinophiles, and monocytes, following its administration seems more readily explained as part of the " recovery phase " of the worm infestation, with a post-infective lymphocytosis, an eosinophilia of recovery, and an increase in monocytic defence. The only changes likely to be associated with the effect of phenothiazine were those shown in the severely affected lamb, in which the first administration was succeeded by a neutrophilia and the second administration by a neutrophilic shift to the left, and the slight progressive decrease in neutrophils occurring in the treated group.

\section{Physical Properties of the Blood and Examination FOR ANAEMIA}

The five sheep in each group selected for the examination of the leucocytic picture were also utilised for a more complete examination of the blood. Such an examination was carried out on three occasions. A preliminary examination on September 12 th, just prior to dosing and segregation on cabbages; a second examination on October 5 th, at the termination of the experimental period on cabbages, and a final examination on November 2nd, after the flock had been returned to pasture for four weeks. The details of these examinations are given in Table No. III.

At the first examination, preliminary to treatment, the figures for both haemoglobin and for the red count were low, each with nine out of ten samples below the normal mode. In contrast, the figures for the packed cell volume were within the normal range and were grouped about the mode, thus the figures for the mean corpuscular volume were high and in lambs Nos. $5,19,21$ and 23 were above the range given by 40 normal sheep.

No abnormality was suggested by the figures obtained for red cell fragility, but viscosity figures were high compared with those estimated for a small number of normal sheep.

Blood smears made at the time these samples were obtained showed little deviation from normal except in the case of one of the severely affected lambs kept indoors. In smears from this lamb an occasional cell showing punctate basophilia was noted, together with anisocytosis, poikilocytosis and polychromasia. The platelets in these films were abnormal in number and morphology. An average of eight was counted in each field of the 1/12th objective, and the morphological abnormalities were similar to those described by Chamberlin (1933) in haemolytic anaemia. These abnormal forms included platelets as large as erythrocytes, and platelets with a "tail " at one or both ends. Round, oval, sausage and triangular forms were also present.

At the second blood examination, at the end of the period during which the flock was folded on cabbages, an unexpected contrast between the two groups was apparent in that, while the red count in the untreated group had risen from an average of $7 \cdot 9$ to one of $9 \cdot 1$ millions, the average for the treated group had fallen from $9 \cdot 2$ to $6 \cdot 4$ millions. During this period regenera. tive changes were apparent in some smears from three lambs in the treated group and one in the untreated group; two lambs in the treated group showed, in addition, changes in the morphology of platelets, as described by Chamberlin. Red cell fragility remained normal and the viscosity now appeared to correlate with the red blood counts. 
TABLE III.

\begin{tabular}{|c|c|c|c|c|c|c|c|c|c|c|c|c|c|}
\hline \multirow{2}{*}{ No. } & \multirow[b]{2}{*}{ Date } & \multirow[b]{2}{*}{$\begin{array}{l}\text { Frag- } \\
\text { ility }\end{array}$} & \multirow[b]{2}{*}{$\begin{array}{l}\text { Vis- } \\
\text { cosity }\end{array}$} & \multicolumn{3}{|c|}{ Red Cells } & \multicolumn{3}{|c|}{ Indices } & \multicolumn{4}{|c|}{ Price-Jones Curves } \\
\hline & & & & $\begin{array}{l}\text { Count } \\
\text { per } \\
\text { c.mm. }\end{array}$ & $\begin{array}{c}\mathrm{Hb} \\
\text { grammes } \\
\text { per } \\
100 \mathrm{ml} .\end{array}$ & $\begin{array}{c}\text { Haemat- } \\
\text { ocrit }\end{array}$ & $\begin{array}{c}\text { M.C.H. } \\
\gamma \gamma\end{array}$ & $\begin{array}{l}\text { M.C.V. } \\
\text { c. } \mu\end{array}$ & $\underset{\%}{\text { M.C.H:C }}$ & $\begin{array}{c}\text { Modal } \\
\text { diam. } \\
\mu\end{array}$ & $\begin{array}{c}\text { Av. } \\
\text { diam. }\end{array}$ & $\begin{array}{c}\text { Stand. } \\
\text { deviat. } \\
\qquad \mu\end{array}$ & $\begin{array}{l}\text { Calc. } \\
\text { mean } \\
\text { av. } \\
\text { thick }\end{array}$ \\
\hline \multirow[t]{2}{*}{1} & $12 / 9$ & 0.50 & $7 \cdot 6$ & $9 \cdot 2$ & $10 \cdot 9$ & 25 & $12 \cdot 0$ & 27 & 44 & $4 \cdot 5$ & $4 \cdot 3$ & $0 \cdot 31$ & $1 \cdot 8$ \\
\hline & $2 / 10$ & $\begin{array}{l}0.50 \\
0.45\end{array}$ & $4 \cdot 0$ & $7 \cdot 7$ & $7 \cdot 9$ & 22 & $10 \cdot 2$ & 29 & 35 & $4 \cdot 5$ & 4.8 & 0.41 & 1.5 \\
\hline \multirow[t]{3}{*}{2} & $\begin{array}{l}2 / 11 \\
12 / 9\end{array}$ & $\begin{array}{l}0.45 \\
0.55\end{array}$ & $\begin{array}{l}5 \cdot 5 \\
6 \cdot 8\end{array}$ & 10.3 & $8 \cdot 6$ & 31 & $8 \cdot 3$ & 30 & 28 & $4 \cdot 5$ & $4 \cdot 5$ & 0.26 & 1.9 \\
\hline & $2 / 10$ & $\begin{array}{l}0.55 \\
0.50\end{array}$ & $\begin{array}{l}6 \cdot 8 \\
3 \cdot 2\end{array}$ & $\begin{array}{r}10 \cdot 2 \\
5 \cdot 0\end{array}$ & $10 \cdot 5$ & 31 & $10 \cdot 3$ & 30 & 34 & $4 \cdot 0$ & $3 \cdot 8$ & 0.37 & $2 \cdot 6$ \\
\hline & $2 / 11$ & 0.50 & $5 \cdot 0$ & $\begin{array}{l}5 \cdot 0 \\
9 \cdot 2\end{array}$ & $\begin{array}{r}5 \cdot 8 \\
\times \quad 9.0\end{array}$ & $\begin{array}{l}15 \\
28\end{array}$ & $11 \cdot 6$ & 30 & 39 & $4 \cdot 5$ & $4 \cdot 8$ & 0.44 & $1 \cdot 7$ \\
\hline \multirow[t]{3}{*}{3} & $12 / 9$ & 0.45 & $7 \cdot 0$ & $\begin{array}{r}9 \cdot 2 \\
11 \cdot 2\end{array}$ & $\begin{array}{r}9 \cdot 0 \\
12 \cdot 8\end{array}$ & $\begin{array}{l}28 \\
30\end{array}$ & $9 \cdot 8$ & 30 & 32 & $4 \cdot 5$ & $4 \cdot 6$ & 0.56 & $1 \cdot 8$ \\
\hline & $2 / 10$ & 0.45 & $4 \cdot 1$ & $7 \cdot 4$ & 11.5 & & $\begin{array}{l}11 \cdot 4 \\
15 \cdot 4\end{array}$ & $\begin{array}{l}27 \\
30\end{array}$ & 43 & $4 \cdot 0$ & $4 \cdot 2$ & 0.31 & $1 \cdot 9$ \\
\hline & $2 / 11$ & 0.45 & $5 \cdot 6$ & $9 \cdot 4$ & 10.0 & 28 & $\begin{array}{l}15 \cdot 4 \\
10 \cdot 6\end{array}$ & $\begin{array}{l}30 \\
30\end{array}$ & 52 & $4 \cdot 5$ & $4 \cdot 7$ & 0.43 & $1 \cdot 8$ \\
\hline \multirow[t]{3}{*}{4} & $12 / 9$ & 0.55 & $6 \cdot 2$ & $9 \cdot 4$ & 9.8 & 31 & $10 \cdot 3$ & & $\begin{array}{l}36 \\
32\end{array}$ & $4 \cdot 5$ & $4 \cdot 6$ & $0 \cdot 32$ & $1 \cdot 8$ \\
\hline & $2 / 10$ & 0.55 & $4 \cdot 5$ & $5 \cdot 8$ & 6.0 & 17 & $10 \cdot 3$ & $\begin{array}{l}33 \\
29\end{array}$ & $\begin{array}{l}32 \\
35\end{array}$ & $4 \cdot 5$ & $4 \cdot 3$ & $0 \cdot 25$ & $2 \cdot 8$ \\
\hline & $2 / 11$ & 0.50 & $4 \cdot 7$ & $8 \cdot 4$ & 6.8 & 23 & 8.1 & 27 & $\begin{array}{l}35 \\
30\end{array}$ & $4 \cdot 5$ & $4 \cdot 4$ & 0.46 & $1 \cdot 9$ \\
\hline \multirow[t]{3}{*}{5} & $12 / 9$ & 0.55 & $6 \cdot 5$ & $6 \cdot 1$ & $10 \cdot 0$ & 25 & $16 \cdot 4$ & 41 & $\begin{array}{l}30 \\
40\end{array}$ & $\begin{array}{l}4 \cdot 5 \\
4 \cdot 0\end{array}$ & $4 \cdot 5$ & 0.40 & $1 \cdot 7$ \\
\hline & $2 / 10$ & 0.50 & $3 \cdot 5$ & $5 \cdot 9$ & $7 \cdot 6$ & 18 & $13 \cdot 0$ & 30 & 42 & $\begin{array}{l}4 \cdot 0 \\
5 \cdot 0\end{array}$ & $4 \cdot 0$ & 0.42 & $3 \cdot 2$ \\
\hline & $2 / 11$ & 0.55 & $6 \cdot 0$ & $8 \cdot 5$ & $10 \cdot 4$ & 28 & $12 \cdot 2$ & 33 & 37 & $\begin{array}{l}5 \cdot 0 \\
4 \cdot 5\end{array}$ & $\begin{array}{l}5 \cdot 1 \\
4 \cdot 6\end{array}$ & $\begin{array}{l}0.47 \\
0.46\end{array}$ & $\begin{array}{l}1 \cdot 5 \\
2 \cdot 0\end{array}$ \\
\hline \multirow[t]{3}{*}{ Av. } & $12 / 9$ & $0 \times 50$ & $6 \cdot 8$ & $9 \cdot 2$ & $10 \cdot 8$ & 28 & $11 \cdot 8$ & 30 & 39 & $4 \cdot 2$ & $\begin{array}{l}4 \cdot 0 \\
4 \cdot 1\end{array}$ & $\begin{array}{l}0.40 \\
0.33\end{array}$ & $2 \cdot 4$ \\
\hline & $2 / 10$ & 0.50 & $3 \cdot 8$ & 6.4 & $7 \cdot 8$ & 19 & $12 \cdot 2$ & 30 & 41 & $4 \cdot 6$ & $4 \cdot 7$ & 0.44 & 1.7 \\
\hline & \multicolumn{6}{|c|}{ Controls } & $9 \cdot 8$ & 30 & 32 & $4 \cdot 5$ & $4 \cdot 5$ & 0.40 & $1 \cdot 8$ \\
\hline \multirow[t]{3}{*}{19} & $12 / 9$ & 0.50 & $7 \cdot 0$ & $7 \cdot 8$ & $9 \cdot 8$ & 29 & $12 \cdot 5$ & 37 & 32 & 4. & 4. & 0.30 & 2 . \\
\hline & $2 / 10$ & 0.55 & $4 \cdot 7$ & $7 \cdot 6$ & $8 \cdot 7$ & 23 & $11 \cdot 4$ & 30 & 38 & $4 \cdot 5$ & $4 \cdot 4$ & 0.38 & $2 \cdot 0$ \\
\hline & $2 / 11$ & 0.55 & $5 \cdot 9$ & $9 \cdot 1$ & $9 \cdot 6$ & 28 & $10 \cdot 5$ & 31 & 34 & $4 \cdot 5$ & $4 \cdot 4$ & 0.41 & $2 \cdot 0$ \\
\hline \multirow[t]{3}{*}{20} & $12 / 9$ & 0.50 & $8 \cdot 0$ & $9 \cdot 0$ & $8 \cdot 0$ & 30 & $8 \cdot 9$ & 33 & 27 & $4 \cdot 0$ & $4 \cdot 1$ & 0.32 & $2 \cdot 5$ \\
\hline & $2 / 10$ & $0 \cdot 50$ & $5 \cdot 8$ & - $10 \cdot 7$ & $9 \cdot 6$ & 30 & $9 \cdot 0$ & 28 & 32 & $4 \cdot 3$ & $4 \cdot 3$ & $0 \cdot 17$ & $1 \cdot 9$ \\
\hline & $2 / 11$ & 0.45 & $5 \cdot 3$ & $10 \cdot 4$ & $7 \cdot 6=$ & 30 & $7 \cdot 3$ & 29 & 25 & $4 \cdot 0$ & $4 \cdot 2$ & 0.27 & $2 \cdot 1$ \\
\hline \multirow[t]{3}{*}{21} & $12 / 9$ & $0 \cdot 50$ & $7 \cdot 0$ & $.5 \cdot 8$ & $8 \cdot 6$ & 25 & $14 \cdot 8$ & 43 & 34 & $4 \cdot 0$ & $4 \cdot 2$ & 0.41 & $3 \cdot 1$ \\
\hline & $2 / 10$ & 0.50 & $5 \cdot 3$ & $9 \cdot 2$ & $9 \cdot 2$ & 26 & $10 \cdot 0$ & 28 & 35 & $4 \cdot 5$ & $4 \cdot 6$ & 0.20 & $1 \cdot 7$ \\
\hline & $2 / 11$ & 0.55 & $5 \cdot 9$ & $10 \cdot 1$ & $8 \cdot 2$ & 28 & $8 \cdot 1$ & 28 & 29 & $4 \cdot 0$ & $4 \cdot 3$ & 0.43 & $2 \cdot 0$ \\
\hline \multirow[t]{3}{*}{22} & $12 / 9$ & 0.45 & $5 \cdot 1$ & $9 \cdot 3$ & $8 \cdot 5$ & 24 & $9 \cdot 1$ & 26 & 35 & $4 \cdot 0$ & $4 \cdot 2$ & 0.38 & $1 \cdot 9$ \\
\hline & $2 / 10$ & 0.50 & $5 \cdot 0$ & $8 \cdot 6$ & $8 \cdot 6$ & 24 & $10 \cdot 0$ & 28 & 36 & $4 \cdot 5$ & $4 \cdot 6$ & 0.32 & $1 \cdot 7$ \\
\hline & $2 / 11$ & $0 \cdot 50$ & $4 \cdot 7$ & $9 \cdot 1$ & $8 \cdot 2$ & 26 & $\begin{array}{r}9 \cdot 0 \\
9.3\end{array}$ & 29 & 31 & $4 \cdot 5$ & $4 \cdot 4$ & 0.32 & $1 \cdot 9$ \\
\hline \multirow{2}{*}{23} & $12 / 9$ & 0.55 & $8 \cdot 0$ & $7 \cdot 3$ & $10 \cdot 4$ & 30 & $14 \cdot 3$ & 41 & 35 & $4 \cdot 0$ & $4 \cdot 0$ & $0 \cdot 32$ & $3 \cdot 3$ \\
\hline & $2 / 10$ & 0.55 & $7 \cdot 0$ & $9 \cdot 2$ & 8.4 & 25 & $9 \cdot 1$ & 27 & 34 & $4 \cdot 5$ & $4 \cdot 7$ & $0 \cdot 36$ & 1.5 \\
\hline \multirow{3}{*}{ Av. } & $\begin{array}{l}2 / 11 \\
12 / 9\end{array}$ & $\begin{array}{l}0.55 \\
0.50\end{array}$ & $\begin{array}{l}4 \cdot 4 \\
7 \cdot 0\end{array}$ & $\begin{array}{l}9 \cdot 5 \\
7 \cdot 9\end{array}$ & $\begin{array}{l}8 \cdot 4 \\
9 \cdot 1\end{array}$ & $\begin{array}{l}25 \\
28\end{array}$ & $\begin{array}{r}8.8 \\
1.5\end{array}$ & $\begin{array}{l}26 \\
35\end{array}$ & $\begin{array}{l}34 \\
3 .\end{array}$ & $4 \cdot 5$ & $4 \cdot 7$ & $0 \cdot 34$ & $1 \cdot 5$ \\
\hline & $2 / 10$ & 0.50 & $5 \cdot 5$ & $\begin{array}{l}7 \cdot 9 \\
9 \cdot 1\end{array}$ & 8.9 & 26 & 9.8 & $\begin{array}{l}55 \\
29\end{array}$ & $\begin{array}{l}32 \\
34\end{array}$ & $\begin{array}{l}4 \cdot 0 \\
4 \cdot 5\end{array}$ & $4 \cdot 1$ & $0 \cdot 34$ & $2 \cdot 9$ \\
\hline & $2 / 1-1$ & 0.50 & $5 \cdot 2$ & $9 \cdot 7$ & $6 \cdot 6$ & 27 & $6 \cdot 8$ & 28 & 24 & $4 \cdot 3$ & $\begin{array}{l}4 \cdot 5 \\
4 \cdot 4\end{array}$ & $\begin{array}{l}0.28 \\
0.35\end{array}$ & $\begin{array}{l}1.8 \\
1.9\end{array}$ \\
\hline \multirow{4}{*}{$\begin{array}{r}\text { Bled } \\
615\end{array}$} & Sheep & & & & & & & & & & & & \\
\hline & $19 / 11$ & 0.50 & $7 \cdot 0$ & $12 \cdot 0$ & $12 \cdot 6$ & 32 & $10 \cdot 4$ & 27 & 41 & $4 \cdot 5$ & $4 \cdot 5$ & 0.39 & 1.7 \\
\hline & $21 / 11$ & 0.50 & $3 \cdot 3$ & $6 \cdot 3$ & $6 \cdot 8$ & 18 & $10 \cdot 6$ & 29 & 38 & $4 \cdot 5$ & $4 \cdot 4$ & 0.48 & $1 \cdot 9$ \\
\hline & $22 / 11$ & 0.50 & $2 \cdot 6$ & $3 \cdot 4$ & $3 \cdot 4$ & 9 & $10 \cdot 0$ & 27 & 38 & $4 \cdot 5$ & $4 \cdot 4$ & 0.64 & $1 \cdot 8$ \\
\hline
\end{tabular}

At the final blood examination, four weeks after the lambs had returned to pasture, the red counts were still a little low in both groups, but no regenerative changes were apparent in smears. There was again a contrast between the two groups in that the average figures for haemoglobin in the treated grotap had risen from $7 \cdot 8$ to 9 gramme, while in the untreated group the average had fallen from 8.9 to 6.6 gramme. There were no abnormal figures for viscosity or fragility.

Indices.-It has already been pointed out that at the preliminary examination figures for the mean corpuscular volume in four of the lambs were in excess of the normal range. This increase in volume is to some extent confirmed by the fact that the figures for the mean corpuscular haemoglobin of these lambs were higher than in the remaining lambs. At the second examination, after the period on cabbages, this abnormality in size had disappeared and there was a slight increase in the mean corpuscular haemoglobin concentration. Owing to the wide variation in the figures considered normal for the erythrocyte counts and haemoglobin concentration in sheep, the establishment of a colour index is not considered practicable (Wirth, 1931), but, because the normal erythrocyte is considered to be saturated with haemoglobin, this increase in the M.C.H.C. demonstrated the existence of a previous hypochromic anaemia. Four weeks after the return to pasture the cells remained normocytic, but the average figure for the M.C.H.C. in the treated group had fallen from 41 per cent., at the second examination to 32 per cent., while in the untreated group it had fallen from 34 per cent. to as low as 24 per cent., demonstrating the presence of a marked hypochromic anaemia.

Price-fones Curves.-The principal data concerning these curves are included in Table No. III, but selected curves are shown in Fig. No. 2. The results from curves made at the preliminary examination were unexpected in that films made from lambs Nos. 5, 19,21 and 23 (in which the mean corpuscular volume was above normal) did not show a shift to the right, and further, in all ten lambs the mean corpuscular diameter was smaller at this preliminary examination 
than at either of the succeeding ones. Any increase in size in the preliminary examination would appear, therefore, to have been due to an increase in thickness, and this has been shown in Table No. III as the calculated mean average thickness.
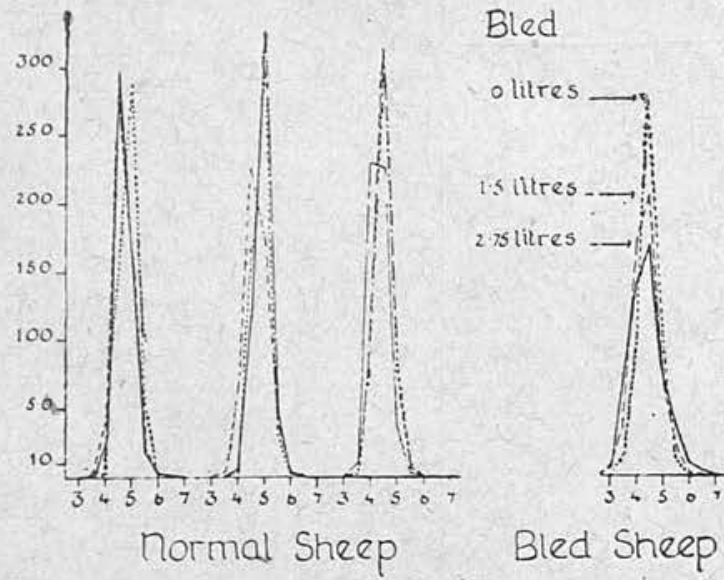

cetis

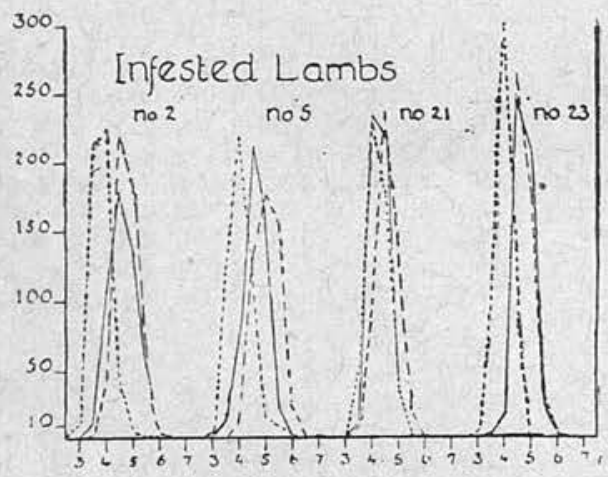

Fig. 2. - Price-Jones Curves for Infested Lambs. Curves for September 12th shown as dotted line, October 2nd as broken line, and November 2nd as a line. Curves for normals constructed for analogous dates.

At the preliminary examination no lamb showed an anisocytosis in any way comparable with that seen in lamb No. 615 suffering from a post-haemorrhagic anaemia (lamb No. 615, Table No. III, and Fig. No. 2). This statement includes the two severely affected lambs despite the fact that in one of these anisocytosis had been recorded among the anaemic changes present in the preliminary blood film. At the second examination, however, the higher figures for standard deviation for all lambs in the treated group suggested some slight anisocytosis in that group. At the final examination the figure for the standard deviation in lamb No. 2 was comparable to that of lamb No. 615 , but in the other lambs of the group the figure had fallen.

Anaemic Changes and their Correlation with Weight. - It has been pointed out that after the period during which the lambs were folded on cabbages, the severity of the anaemia in the group treated with phenothiazine had become more pronounced. This increased severity in anaemia appeared to correlate with an increase in weight. This correlation is demonstrated by means of a spot graph in Fig. No. 3.

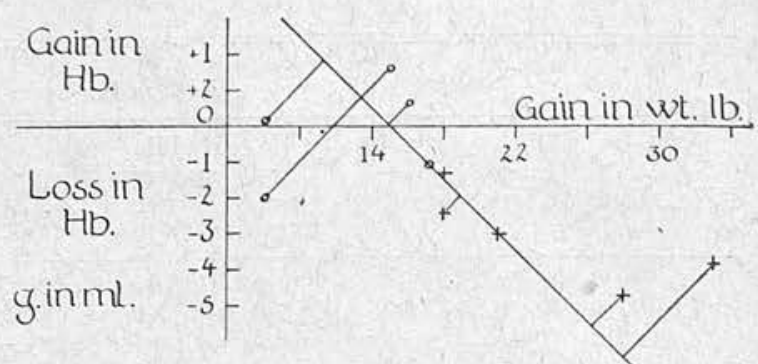

FIG. 3.-Correlation between loss in haemoglobin and gain in weight. $t=$ treated lambs, $0=$ untreated. Points are shown tagged to a line given by the equation $2 x-y+15=0$, where $x$ represents gain in haemoglobin and $y=$ the gain in weight.

It would thus appear that the presence of parasites interfered with factors concerned with growth, and that when these factors were removed by killing the parasites with phenothiazine, growth was inevitable, even though such growth necessitated an aggravation of the anaemia to a point in which regenerative changes appeared in blood films. This hypothesis is supported by the work of Greig et al. (1933) and Innes and Shearer (1940). Greig et al. working on "pine" in cattle, concluded that one type was due to an iron deficiency, an assumption supported by the low haemoglobin figures. An iron compound was fed in large quantities, but although nine animals showed a marked improvement in general health, three of the nine showed a fall instead of a rise in the haemoglobin concentration, while in four others the increase was negligible. Innes and Shearer found a most marked hypochromic anaemia combined with an oligocythaemia in pregnant ewes in Derbyshire. The ewes appeared to be in quite good health and the anaemia was suggested as being a physiological adjustment rather than a pathological manifestation. However, whether this phenomenon is regarded as physiological or pathological, it does support the hypothesis that when factors for growth, either of the individual or of the foetus within it, are active, the sheep is prepared to sacrifice its normal haemoglobin concentration in an effort to attain growth.

While the correlation between growth and anaemia is considered to exist in these lambs, and while work supporting the hypothesis that growth can cause anaemia has been quoted, it cannot be denied on our evidence that the growth and the anaemia may both be effects of the administration of phenothiazine. That the action of phenothiazine per se does produce an anaemia has been claimed by Errington and Westerfield (1940) following work carried out on horses. Their data, however, do not include figures for live weight increase and hence comparison is impossible.

\section{Discussion of Anaemic Changes}

The type of anaemia present in the infested lambs at the preliminary examination was a hypochromia combined with a reduction in red cell count, while in four cases out of ten there was also an excessive mean corpuscular volume. These findings are similar to those reported by Fraser and Fourie, for Fraser reports a chlorosis, but picks out one animal as having a high colour index due to the high proportion of megalocytes, while Fourie reports a hypochromic anaemia with an increase in cell volume, but 
includes tables that show that this increase in cell size was not constant.

In spite of the severity of the infestation in our experimental flock the various regenerative changes as reported by Fraser and Fourie were considered to be present in one lamb only, one of the two emaciated lambs kept aside from the main experiment, although in this case the presence of anisocytosis was not confirmed when a Price-Jones curve was drawn. This lamb also showed changes in the morphology of the platelets, as described by Chamberlin (1933). No observations on platelets were made by Fraser or Fourie.

Fourie postulated anaemia as the cause of death in experimental sheep dosed with Haemonchus contortus eggs. Our experimental flock was suffering from a severe mixed infestation, 13 animals out of a flock of 50 had died or had been sold in an emaciated condition, and three of the 17 lambs in the untreated group had lost weight during the three weeks they were folded on cabbages, yet despite this the anaemia seemed comparatively unimportant. The blood haemoglobin concentration was higher before treatment than at the final examination made when the lambs were active and thriving, while the lambs that showed most increase in weight did so in spite of the fact that this entailed a considerable increase in anaemia. That the anaemia present at the first examination was to some extent pathological and not entirely dependent on diet, was supported by two observations : firstly, the increase in cell size present at the preliminary examination and absent at the final examination despite the increase in hypochromic anaemia, and, secondly, at the final bleeding the hypochromic anaemia was much more pronounced in the untreated group.

Fourie recorded that the fatal anaemia in his experimental sheep was post-haemorrhagic in type, this conclusion being based on a comparison with a sheep showing a macrocytic hypochromic anaemia induced by repeated bleeding. However, his records show that of the five sheep that received a lethal dose of $H$. contortus eggs only two animals showed an increase in cell size, another showed a decrease and two showed no progressive change. Further, with regard to haemoglobin concentration in the cells, two showed a hypochromia, one showed little change, and the other two showed even an increase in concentration. It would appear likely, therefore, that Fourie was dealing with a variety of anaemias.

Fraser, seeking an hypothesis to explain the marked haemosiderosis present in infested sheep, postulated the presence of an haemolysin that attacked the circulating cells but did not affect the myeloid tissue. Chamberlin (1933) investigated one type of haemolytic anaemia in sheep, namely, enzootic toxaemic jaundice, and showed that the anaemia was not macrocytic but a true anisocytosis with a flattening of the Price-Jones curve. The regenerative changes also included the presence of normoblasts in blood films, in contrast to Fraser's findings that in the case of one infested sheep with a red cell count of only 2.5 millions per c.mm., the only indication of regeneration was the presence of polychromatic cells and an 8 per cent. reticulocyte count. Our own observations on the haemolytic anaemia following the administration of $\mathrm{Cl}$. welchii toxin, type $\mathrm{A}$, to sheep (Gordon et al.) showed that there was an increase in the fragility of the red cells, and that the clinical signs included haemoglobinuria, phenomena which were absent in cases of worm infestation.

The general blood picture of infested lambs in our investigation was that of hypochromic anaemia, with certain animals showing an increase in red cell size. An alimentary origin for this picture is suggested, based upon the presence of the parasites inhibiting the anabolism of iron to haemoglobin and, in certain cases, interrupting the formation of the haemopoietic principle and thus causing a macrocytic anaemia. A similar macrocytic anaemia is caused in man by the depredations of Diphyllobothrium latum, in which case it has been suggested that the worm either prevents absorption of the haemópoietic principle, or consumes it within its own body (Hadfield and Garrod, 1934). In view of this, we consider that in natural worm infestations causing parasitic gastritis the associated anaemia is due to disease of the alimentary tract, and that it is not a definite post-haemorrhagic anaemia. We do not, however, deny that haemorrhage may also be involved to a certain extent. Whitby and Britton (1937), speaking of alimentary types of anaemia, write as follows: "... one single clinical condition may give rise to anaemias which exhibit all possible haematological characters of cell size, cell count, haemoglobin deficiency, and other diagnostic features." In view of the variation shown in the results of Fourie using a pure $H$. contortus infestation, we feel that here, too, anaemia of an alimentary nature may have confused the picture of post-haemorrhagic anaemia.

After the flock had been penned on cabbages for three weeks, affording a different type of nutrition and a freedom from reinfestation, the macrocytic anaemia had disappeared and in most cases the hypochromic anaemia had decreased; these changes occurred in both groups. We have suggested that the anaemia present in the treated group was due to more rapid growth. It consisted of an oligocythaemia showing slight anisocytosis without increase in fragility, and was more normochromic than the anaemia present at the preliminary bleeding. This anaemia was similar to the post-haemorrhagic type, and therefore fits in with the theory that it was induced by growth, but does not so readily support the theory that it was an attribute of the toxic effect of phenothiazine, for such a toxic action would suggest the production of a haemolytic, an aplastic, or even a gastric anaemia.

At the final bleeding, four weeks after the return to pasture, a hypochromic anaemia was again apparent, severe in the untreated group, but less severe in the treated group. This simple hypochromic anaemia, while of little pathological importance in view of the general health of the flock at this time, is of interest in that it existed in a more severe degree in the untreated lambs despite the continued higher growth rate of the treated lambs, suggesting that the conditions ordered by the presence of the parasites still hindered the absorption of iron in the untreated lambs.

\section{Summary}

A flock of 35 lambs affected with parasitic gastritis was removed from pasture and folded on cabbages. Eighteen of the lambs were treated with phenothiazine and the remainder kept as controls. Three weeks later the average gain in weight was $9.5 \mathrm{lb}$. in the treated group and $3.2 \mathrm{lb}$, in the controls. This 
increase in weight was found to be statistically significant. Worm-egg counts were reduced to a greater extent in the treated group.

Preliminary blood samples from ten lambs showed the presence of a hypochromic anaemia, while in four of these cases an increase in red cell volume was apparent. Price-Jones curves were normal but in all cases showed a smaller average mean corpuscular diameter than at subsequent samples, indicating that increased cell volume was dependent on increased cell thickness. Fragility figures were normal while figures for blood viscosity were high. The anaemia is discussed, and it is suggested that it was neither post-haemorrhagic nor haemolytic, but fell within the wide classification of an anaemia of alimentary type. It is further suggested that the presence of anaemia was pathologically unimportant compared with other detrimental factors that inhibited growth.

After treatment with phenothiazine there was a fall in the red count and in the haemoglobin which correlated with the gain in weight-this correlation appeared to agree with the equation $2 x+y-15=0$, where $x=$ gain in haemoglobin and $y=$ gain in weight.

Leucocytic changes are recorded, and it is suggested that where an eosinophilia occurred it was connected with the process of recovery and was not due to the liberation of eosinotactic substances by the parasites. The high level of basophiles is commented upon.

Acknowledgments.-We wish to thank Dr. J. R. Greig for his continued helpfulness and encouragement, Dr W. S. Gordon for his help in arranging this experiment, and Dr. D. O. Morgan for advice and for his kindness in carrying out the final worm-egg counts.

The phenothiazine used in this experiment was supplied by the Agricultural Research Council.

\section{REFERENCES}

Chamberlin, W. E. (1933.) Australian Vet. F. 9. 2.

ERrington, B. J., and Westerfield, C. (1940.) Vet. Med. 35. 688. Abst. Vet. Rec. 53. 221.

FourIE, P. J. J. (1931.) 17th Rep. of the Director of Vet. Research, Department of Agriculture, Onderstepoort, South Africa, p. 493.

Fraser, A. C. (1930.) First Report, Institute of Animal Pathology, Univ. of Cambridge, p. 114.

GordoN, H. Mc.L., and WhITLOCK, H. V. (1939.) 7. Counc. Sci. Industr. Res. 12. 50.

Gordon, W. S., Stewart, J., Holman, H. H., and Taylor, A. W. (1940.). F. Path. and Bact. 50. 251.

Greig, J. R., Dryerre, H., Godden, W., Crichton, A., and OGG, W. G. (1933.) Vet. F. 89. 99.

HADFIELD, G., and Garrod, L. P. (1934.) "Recent Advances in Pathology," 2nd ed. (Churchill), London.

InNES, J. R. M., and Shearer, G. D. (1940.) F. comp. Path. 53. 1 .

JORPES, J. E. (1939.) "Heparin : Its Chemistry, Physiology and Application to Medicine." (Oxford Univ. Press), London. Review $\mathcal{F}$. Path. and Bact. 49.599.

Porter, D. A. (1937.) F. Parasitology. 23. 73.

StEWART, J. (1933.) Third Report, Institute of Animal Pathology, Univ. of Cambridge, p. 58.

TAYLOR, E. L. (1939.) Vet. Rec. 51. 895.

Weinberg, M., and Seguin, P. (1914.) Ann. Inst. Pasteur. 28. 470 .

. (1915.) Ibid. 29. 323.

Whitby, L. E. H., and Britton, C. J. C. (1937). " Disorders of the Blood," 2nd ed. (Churchill), London.

WIRTH, D. (1931.) "Grundlagen einer Klinischen Hämatologie der Haustiere." (Urban and Schwarzenberg), Berlin. 


\title{
ATTEMPTS TO REPRODUCE THE PYAEMIA ASSOCIATED WITH TICK-BITE
}

\author{
Part I.-The Nature of the Infections Produced. \\ Part II.-Comparison of the Blood Picture of the Different Infections.
}

\author{
A. WILSON TAYLOR, H. H. HOLMAN and W. S. GORDON \\ From the Animal Diseases Research Association, Moredun Institute, Gilmerton, Midlothian
}

On many of the tick-infested farms of Scotland and Northern England there occurs amongst lambs an illness characterised by debility, crippling lameness and in some cases paralysis, during the months of April and May each year. This is a period when ticks are very active and lambs become heavily infested with these parasites. As a result of this infestation the majority of lambs become infected with tick-borne fever and many also develop louping-ill. In addition to these two diseases it is common to find many lambs affected with abscesses at the site of tick-bites and in many cases a pyaemia develops resulting in the formation of abscesses in joints, muscles, tendon sheaths and even on the meninges of the brain and spinal cord. In the liver, kidney, spleen, lung and heart wall multiple abscess formation is also common. In the course of the routine examination of dead lambs received at this Institute, and also in extensive examination of lambs in the field, it has been found that under the flockmasters' diagnosis of "louping-ill" is included a number of diseases among which are those clinical conditions which result from infection with any combination of the tick-borne diseases and pyaemia. This pyaemic condition is that described by M'Fadyean (1894) and again by Stewart and Ponsford (1937). Both authors refer to the isolation of a slightly chromogenic Gram-positive micrococcus from the abscesses, and our own experience has been that an organism morphologically and culturally resembling Staphylococcus aureus can be isolated both from superficial and deeply seated abscesses. This pyaemia appears to be associated with tick-bite, because it occurs only in epizoötic form on tick-infested pastures and because the superficial abscesses, which contain the same organism as the deep abscesses, develop at the site of tick-bite. It has not been determined whether the ticks have a specific rôle in the perpetuation and spread of the staphylococcus or whether their part is merely that of mechanically assisting infection of the superficial tissues with a staphylococcus present on the surface of the skin of the lambs. Present evidence indicates, however, that the disease is specific in that it is rare to find any organism other than Staphylococcus aureus in the abscesses but, as might be expected, inoculation of lambs with this organism while it produces a local abscess fails to cause a pyaemic infection. There is therefore reason to suspect that, in some manner, infestation with ticks provides a factor favourable to the development of a pyaemia following superficial abscess formation resulting from infection with Staphylococcus aureus, and it was considered advisable to determine if the debilitating effect of louping-ill, with or without the association of tick-borne fever, which commonly accompanies this condition, might provide the necessary factor.

It is the purpose of this paper to record the result of a preliminary attempt to reproduce a generalised. pyaemic infection of lambs by superimposing a staphylococcal infection on an already existing infection with louping-ill, tick-borne fever or a combination of these two diseases. Although the experiments failed in their primary object, they provided an opportunity of making a comparison of the blood changes resulting from different types of infection. The paper is presented in two parts. Part I deals with the nature of the infections produced and Part II with the blood changes which occurred in the different infections.

\section{Part I.-The Nature of the Infections Produced}

\section{Evidence Regarding the Incidence of Pyaemia}

Evidence regarding the incidence of pyaemia in lambs as it occurs on tick-infested farms has been provided by M'Fadyean (1894), who estimated that approximately half of the lambs submitted to him as being affected with louping-ill were actually infected with pyaemia. Stewart and Ponsford (1937) record that " of 209 lambs examined after death on tickinfested pasture pyaemic infections were noted in 100 cases, and in all probability were the cause of death in 80 cases." In 1939 we examined 69 lambs from a group of tick-infested farms and found that 20 , or 
29 per cent., were affected with pyaemia, while in 1940 , of 193 lambs obtained from the same group of farms, 57 , or 29 per cent., were affected with pyaemia. There is therefore evidence of a high incidence of pyaemic infection in the lambs on tick-infested farms and on clinical grounds alone it is obvious that the abscesses resulting from this infection are the cause of much debility and crippling lameness in infected lambs. It is not yet clear, however, to what extent this infection per se can be regarded as responsible for death since the condition is so often complicated by the presence of other lamb diseases which are prevalent in the spring. Thus, although Stewart and Ponsford found a pyaemic infection in 100 lambs, they suggested that this infection was probably only responsible for death in 80 , while the remaining 20 died of infection with $\mathrm{Cl}$. welchii type D. Their methods of examination were adequate for the detection of an infection with $\mathrm{Cl}$. welchii, and wherever this infection was found then pyaemia was regarded as of secondary importance in the cause of death. It is possible also that had it been practicable for them to carry out examinations adequate for the diagnosis of louping-ill and tick-borne fever in all the lambs they examined, many, if not all, would have been found to be affected with tick-borne fever and possibly some with louping-ill. This view is expressed because in the course of the examination of lambs believed to have died of pyaemia we have frequently extended the investigation to include examination for the presence of louping-ill and tick-borne fever, and on numerous occasions have found that these infections may coexist with pyaemia. In this connection it should be noted that a negative diagnosis of tick-borne fever infection can be accepted only if blood from the animal under test fails to produce infection in a normal sheep. Similarly, in the case of louping-ill infection many animals die as a result of atypical infections in which the specific virus may be detected in the blood or spleen only and not in the central nervous system, and cases have also been encountered in which the virus was not detected in the tissues although definite lesions of encephalomyelitis have been observed in the brain and spinal cord. It is therefore becoming increasingly obvious that in the control of so-called louping-ill in lambs it is not only necessary to block infection with the virus of loupingill but consideration will have to be given also to the control of pyaemia, tick-borne fever and infections with $G l$. welchii since the mortality which results from any one or any combination of these infections on a tick-infested farm may be regarded by the flockmaster as resulting from louping-ill.

\section{Material and Methods Employed for Producing INFECTION}

The animals employed in this experiment were 21 Cheviot lambs, approximately four months' old. The various types of infection were produced by subcutaneous injection inside the thigh, and the infective material used was obtained from the following sources :

Tick-borne Fever. - Infective blood, collected in 3 per cent. potassium citrate, was obtained from a sheep infected with tick-borne fever. The strain was one which had been maintained at the Institute by passage through sheep in series. The dose employed was $15 \mathrm{c}, \mathrm{c}$.
Louping-ill infective material consisted of a 1 per cent. suspension in saline of the dried brain obtained from a sheep infected with louping-ill. The dose employed was 5.0 c.c.

Staphylococcus aureus.-The strain used was one isolated from an abscess in a naturally occurring case of pyaemia. It had been subcultivated three times and was grown on plain agar. The growth was washed off the agar with normal saline and its opacity standardised to match No. 2 on Brown's scale. The dose employed was 1 c.c.

The experimental animals were divided into seven groups, each of three individuals, and inoculated on the dates shown in Table I. Thus,

Group 1 received Staphylococcus aureus,

Group 2 tick-borne fever,

Group 3 louping-ill,

Group 4 tick-borne fever, and two days later, louping-ill, Group 5 tick-borne fever, and four days later, Staph. aureus, Group 6 louping-ill, and two days later, Staph. aureus, Group 7 tick-borne fever followed two days later by louping-ill, and after a further two days, by Staph. aureus.

\section{Procedure After Infection}

The temperature of each animal in the experiment was recorded daily from August 3rd to August 28th.

From August 8th to August 17th a blood sample from every surviving animal was obtained from the jugular vein and utilised in the following ways :-

(a) Inoculated into glucose broth and incubated at $37^{\circ} \mathrm{C}$. for the purpose of detecting infection of the blood with staphylococci.

(b) Inoculated intracerebrally into mice for the detection of the virus of louping-ill.

(c) For the preparation of blood films which were examined for the presence of the infective agent of tick-borne fever and for staphylococci.

(d) Used in the haematological investigation described in Part II of this paper.

At autopsy, cultures were made from the liver and heart blood in every instance. In the case of lambs infected with staphylococci agar slopes were inoculated with material obtained from the site of inoculation and from any lesion which might have harboured staphylococci. The cultures obtained were accepted as Staphylococcus aureus if they produced haemolysis on sheep blood agar, liquefied gelatin and formed a golden yellow pigment on Loeffler's serum at $22^{\circ} \mathrm{C}$. Following the death or destruction of lambs infected with louping-ill, sections of the medulla oblongata were examined for lesions of encephalitis and mice were inoculated intracerebrally with a 1 per cent. suspension of brain tissue in saline.

\section{Results}

The results of the experiment have been summarised and are presented in Table I, from which it will be seen that with the exception of lamb 116 the control-lambs, namely, Groups 2, 3 and 4, which were infected . respectively with tick-borne fever, louping-ill and these two diseases combined, all reacted satisfactorily. The inoculation of Staphylococcus aureus, was followed, except in Group 7, by the development of a local abscess which in the majority of cases matured and showed no tendency 


\section{TABLB I}

\begin{tabular}{|c|c|c|c|c|c|c|c|c|c|c|c|c|c|c|c|}
\hline \multirow{3}{*}{ Group. } & \multirow{3}{*}{ No. } & \multicolumn{3}{|c|}{ Inoculations. } & \multicolumn{3}{|c|}{ Clinical findings. } & \multicolumn{3}{|c|}{ Blood samples. } & \multirow{3}{*}{$\begin{array}{l}\text { Date of } \\
\text { death. }\end{array}$} & \multicolumn{4}{|c|}{ Autopsy. } \\
\hline & & \multirow[b]{2}{*}{ T.B.F. } & \multirow[b]{2}{*}{ L.I. } & \multirow[b]{2}{*}{ S.A. } & \multirow{2}{*}{$\begin{array}{l}\text { Temp. } \\
\text { exceeded } \\
106^{\circ} \mathrm{F} \text {. }\end{array}$} & \multirow{2}{*}{$\begin{array}{l}\text { Local } \\
\text { lesion. }\end{array}$} & \multirow[b]{2}{*}{ L.I.S. } & \multirow[b]{2}{*}{ T.B.F. } & \multirow[b]{2}{*}{ Culture. } & \multirow[b]{2}{*}{ L.I.V. } & & \multicolumn{2}{|c|}{ Cultures. } & \multirow{2}{*}{ 总 } & \multirow{2}{*}{ ث્ } \\
\hline & & & & & & & & & & & & $\begin{array}{l}\text { Liver an } \\
\text { H. blood }\end{array}$ & $\begin{array}{r}\text { Local } \\
\text { lesions. }\end{array}$ & & \\
\hline \multirow[t]{3}{*}{1} & 110 & - & - & 7.8 .39 & 8.8 .39 & + & - & - & - & - & K. 11.9 .39 & N.G. & N.G. & - & - \\
\hline & $\begin{array}{l}111 \\
112\end{array}$ & $\bar{z}$ & $\overline{-}$ & & 8.8 .39 & + & - & - & - & - & K. 11.9 .39 & N.G. & N.G. & - & - \\
\hline & & & & & 8.8 .39 & + & - & - & - & - & K. 11.9 .39 & N.G. & N.G. & - & - \\
\hline \multirow[t]{2}{*}{2} & 113 & $\begin{array}{l}3.8 .39 \\
3.8 .39\end{array}$ & 二 & 二 & 6.8 .39 & - & - & + & - & - & K. 11.9 .39 & N.G. & N.G. & - & - \\
\hline & 115 & 3.8 .39 & - & 二 & $\begin{array}{l}6.8 .39 \\
6.8 .39\end{array}$ & $\overline{-}$ & 二 & + & 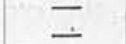 & 二 & 二 & $\bar{z}$ & $=$ & 二 & 二 \\
\hline \multirow[t]{3}{*}{3} & 116 & - & 5.8 .39 & - & - & - & - & - & - & - & K. 11.9 .39 & N.G. & - & - & - \\
\hline & 117 & - & 5.8.39 & - & 15.8 .39 & - & - & - & - & + & - & - & - & $=$ & - \\
\hline & 118 & - & 5.8 .39 & - & 14.8 .39 & - & & 一 & & + & - & - & - & - & - \\
\hline \multirow[t]{3}{*}{4} & 119 & 3.8 .39 & $\begin{array}{l}5.8 .39 \\
5\end{array}$ & - & 7.8 .39 & - & + & + & - & + & K. 14.8 .39 & N.G. & - & - & + \\
\hline & $\begin{array}{l}120 \\
121\end{array}$ & $\begin{array}{l}3.8 .39 \\
3.8 .39\end{array}$ & $\begin{array}{l}5.8 .39 \\
5.8 .39\end{array}$ & $\bar{z}$ & $\begin{array}{l}7.8 .39 \\
78.80\end{array}$ & - & \pm & + & - & + & D. 16.8 .39 & N.G. & - & - & + \\
\hline & & & 5.8 .39 & - & 7.8 .39 & - & & & & + & K. 11.9 .39 & N.G. & - & - & - \\
\hline \multirow[t]{2}{*}{5} & 122 & $\begin{array}{l}3.8 .39 \\
3.839\end{array}$ & $二$ & $\begin{array}{l}7.8 .39 \\
7.839\end{array}$ & $\begin{array}{l}6.8 .39 \\
6.82\end{array}$ & + & - & + & - & - & K. 11.9 .39 & N.G. & S.A. & - & - \\
\hline & $\begin{array}{l}123 \\
124\end{array}$ & $\begin{array}{l}3.8 .39 \\
3.8 .39\end{array}$ & I & $\begin{array}{l}7.8 .39 \\
7.8 .39\end{array}$ & $\begin{array}{l}6.8 .39 \\
6.8 .39\end{array}$ & $\stackrel{+}{+}$ & 二 & + & 二 & 二 & $\begin{array}{l}\text { K. } 11.9 .39 \\
\text { K. } 11.9 .39\end{array}$ & $\begin{array}{l}\text { N.G. } \\
\text { N.G. }\end{array}$ & $\begin{array}{l}\text { S.A. } \\
\text { S.A. }\end{array}$ & 三 & 二 \\
\hline \multirow[t]{3}{*}{6} & & - & 5.8 .39 & 7.8 .39 & & + & & - & & & & & & & - \\
\hline & 126 & - & 5.8 .39 & 7.8 .39 & 0.8 .39 & $t$ & 二 & 二 & $=$ & + & $\mathrm{K} .11 .9 .39$ & N.G. & N.G. & 二 & 二 \\
\hline & 127 & - & 5.8 .39 & 7.8 .39 & 8.8 .39 & + & & - & & + & K. 11.9 .39 & N.G. & S.A. & - & - \\
\hline \multirow[t]{3}{*}{7} & 128 & 3.8 .39 & 5.8 .39 & 7.8 .39 & 6.8 .39 & + & + & + & - & + & D. 15.8 .39 & N.G. & S.A. & - & + \\
\hline & 129 & 3.8 .39 & 5.8 .39 & 7.8.39 & & + & + & + & - & + & & N.G. & S.A. & - & + \\
\hline & 130 & 3.8 .39 & 5.8 .39 & .7 .8 .39 & 6.8 .39 & + & t & + & - & + & D. 12.8 .39 & N.G. & S.A. & - & + \\
\hline
\end{tabular}

T.B.F. = Tick-borne fever ; L.I., L.I.S., L.I.V., L.I.L. = Louping-ill, - symptoms, - virus, - lesions ; S.A. = Staph. aureus ; D. = Died ; K. = Killed ; N.G. $=$ No growth ; $+=$ Present.

to spread or to give rise to a generalised infection or serious constitutional disturbance. The lambs in Group 7, which received all three inocula, developed an extensive swelling which spread from the site of inoculation downwards to the hock joint and upwards along the abdominal wall to the umbilicus. At death the swelling was found to be due to a haemorrhagic oedema with marked thickening and necrosis of the subcutaneous tissue. The death of these animals apparently from louping-ill was probably accelerated by toxaemia.

\section{DISCUSSION}

In naturally occurring cases of pyaemia in lambs the widespread distribution of the lesions throughout the body is suggestive of infection by an organism possessing marked invasive characters, yet cultures of this organism when inoculated into lambs fail to show this invasive property. Among the reasons which could be put forward to explain this difference might be included the loss of invasive character as a result of cultivation outside the body, the presence of a factor associated with tick-bite which favours generalisation of a local infection, or a generalised infection might ensue because of a lowering of host resistance resulting from infection with tick-borne fever and/or louping-ill. This last possibility is that examined by the work described in this paper and within the limited scope of the experiment it has been shown that a pyaemic infection failed to develop when Staphylococcus aureus was inoculated subcutaneously into normal lambs and into lambs infected with louping-ill and tick-borne fever. The effect of variation either in the dose of organisms employed or in the route of infection was not included in the investigation.

Comparison of the mortality which occurred in Groups 3, 4 and 7 shows that none of the three animals in Group 3, which were infected with loupingill virus only, developed a fatal infection, whereas of the six animals in Groups 4 and 7, which were infected both with louping-ill and tick-borne fever, five died or had to be destroyed as a result of invasion of the brain and spinal cord with the virus of louping-ill. This confirms the observations of Gordon et al. (1932) and MacLeod and Gordon (1932) that tickborne fever aggravates the harmful effects of a loupingill infection.

\section{Summary}

Subcutaneous inoculation of lambs with Staphylococcus aureus freshly isolated from a natural case of pyaemia resulted in the formation of an abscess at the site of inoculation. This local infection showed no tendency to become a generalised infection either in normal lambs or in lambs infected with louping-ill and/or tick-borne fever. 


\section{Part II.-Comparison of the Blood Picture of the Different Infections.}

Advantage was taken of the foregoing experiment to compare the blood pictures in sheep resulting from three types of noxae: $(a)$ a bacterial organism, Staphylococcus aureus ; (b) a virus, namely, the virus of louping-ill; (c) a rickettsia-like organism, the cause of tick-borne fever. It was considered possible that this comparison might be of value with regard to the differential diagnosis of these infections.

The experiment involved the recording of the total and differential leucocyte counts and the estimation of the haemoglobin.

\section{TeChNIQUe}

Leucocytic counts were carried out according to the technique described by Schilling (1929), except that the lymphocytes were further classified into two groups, large lymphocytes and small or medium lymphocytes. The cells classified as large lymphocytes were cells of lymphocytic morphology but were equal to monocytes in size. This classification, therefore, was to some degree, subject to the personal factor.

The haemoglobin estimation was carried out by the use of a Zeiss Ikon haemometer, graduated in g. per 100 c.c. for human blood.

Observations were made at two-day intervals, the first observation being carried out a few minutes before the injection of the first noxa. The inocula and the methods of inoculation have been described in Part I of this paper.

The groups kept under observation for the purpose of determining the blood picture are tabulated below.

\begin{tabular}{ccccc} 
& \multirow{2}{*}{ Group. } & Sheep Nos. & \multicolumn{3}{c}{ Date of Injection. } \\
\cline { 3 - 5 } & & Aug. 3rd. & Aug. 5th. & Aug. 7th. \\
\hline 1 & $110,111,112$ & & Staph. \\
2 & $113,114,115$ & T.B.F. & L.I. & \\
3 & $116,117,118$ & T.B.F. & Staph. \\
5 & $122,123,124$ & L.I. & Staph. \\
6 & $125,126,127$ & & L. & \\
\hline \hline
\end{tabular}

\section{Results}

These are represented diagrammatically in Figs. 1,2 and 3 and the records for individual sheep are given in Table $I I$.

Staphylococcal Infection (Fig. 1).-Counts carried out two days after inoculation showed a definite absolute neutrophilia in each sheep. This occurred even when infection with louping-ill or tick-borne fever was already existent. This primary neutrophilia quickly regressed, and was followed about a fortnight later by a less transient neutrophilia, presumably connected with the process of recovery.

The lymphocytes showed a slight, but persistent decrease commencing four days after inoculation.

This decrease also occurred when the staphylococcal infection was secondary to either louping-ill or tick-borne fever. It might be presumed that this decrease in lymphocytes was followed at a later date by a " post-infective" lymphocytosis.

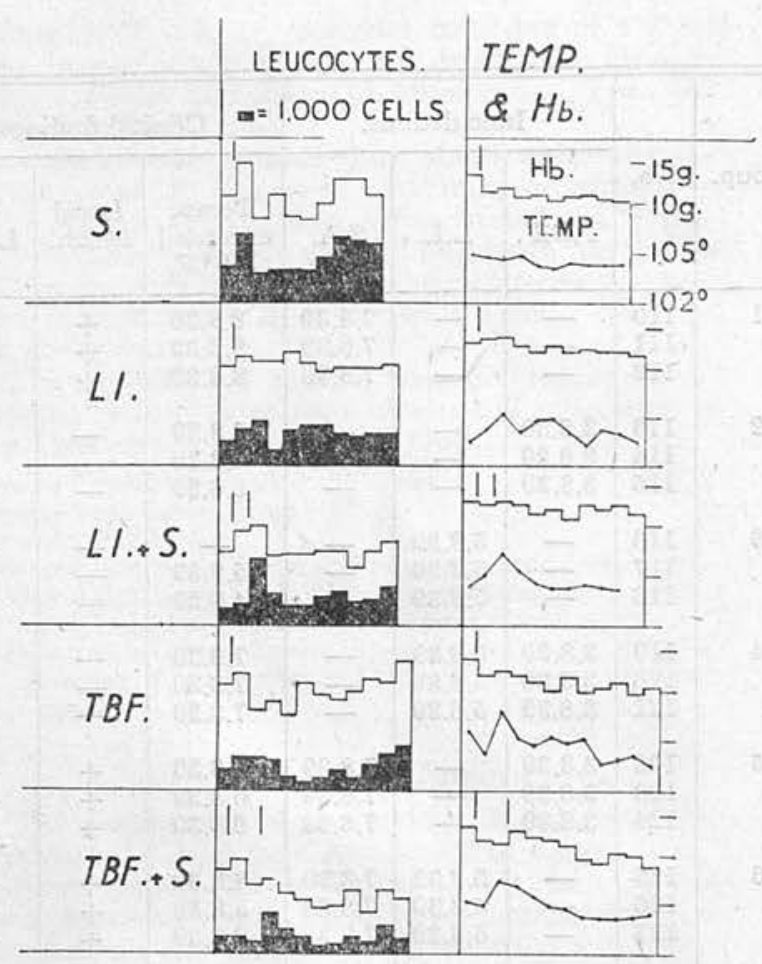

FIG. 1

FIG. 1.-Averaged readings taken at two-day intervals. Inoculation of noxae denoted by vertical lines, where two such lines are present the second line denotes the inoculation with Staph. aureus. Leucocytes: Upper line denotes average of the leucocytic counts, blacked-in area represents proportion of neutrophils present. Temperatures: The temperatures at two-day intervals are recorded as a curve. In the case of the sheep inoculated with Staph. aureus the only definite temperature reaction was present the day after inoculation and this has been indicated by a dot at the appropriate height.

Other changes occurring in these sheep are dealt with under the heading of "General Changes and Discussion."

Louping-ill (Fig. 1).-Following infection with louping-ill virus a slight neutrophilia was apparent on the second and fourth days after inoculation; on the sixth day, however, there was a decrease in numbers. This was followed by a second slight neutrophilia, and a return to normal. This neutrophilia following infection with louping-ill is apparently limited to the neurotropic viruses, the common finding with other viruses being a neutropenia (Whitby and Britton, 1937). In the case of sheep No. 116 that received an inoculation of live virus but did not show a febrile reaction (see Table I), the blood picture coincided with that of the other sheep of this group.

The lymphocytes in the case of louping-ill appear to play a passive part in the reaction, and alterations in their numbers do not appear to be significant.

Tick-borne Fever (Fig. 1).-The sheep infected with tick-borne fever alone showed a slight increase in neutrophil cells at the second and fourth day after inoculation. That such an increase does not always occur can be seen from the records of Group 5,

(Text continued on page 344.$)$ 


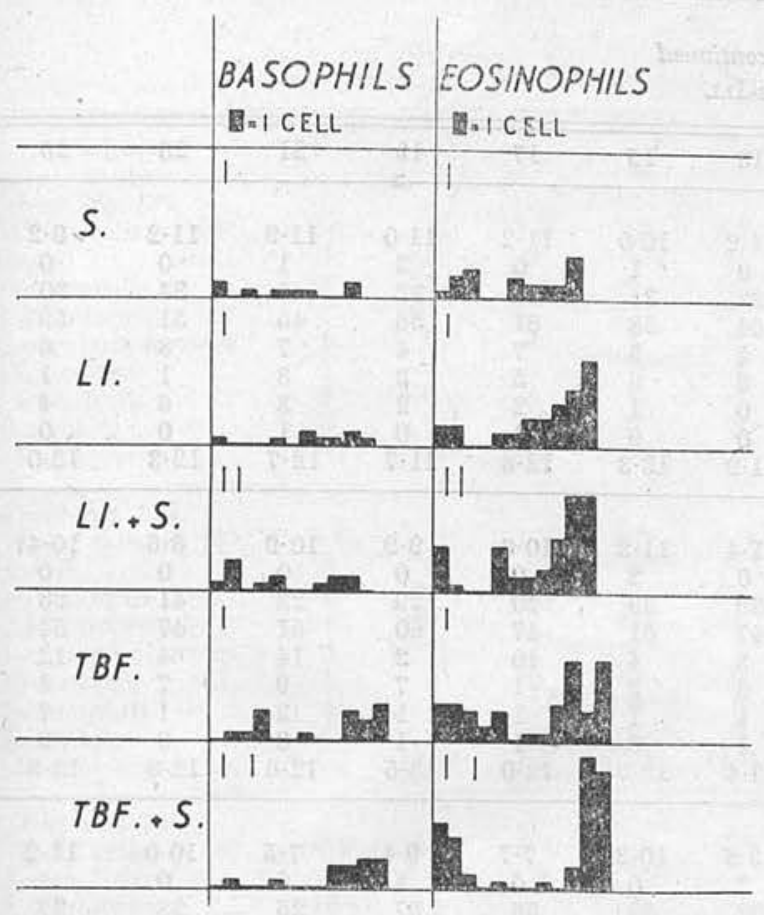

Fig. 2

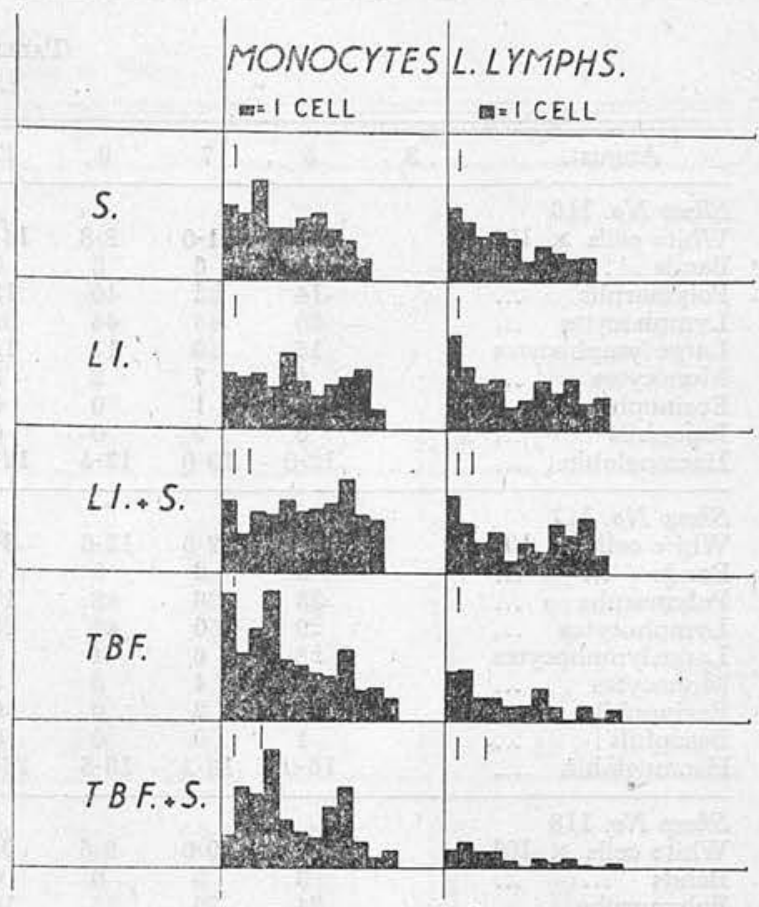

FIG. 3

FIGS. 2 and 3.-Averaged differential counts. Readings taken at two-day intervals. Inoculations of noxae denoted by vertical lines. Where two such lines are present the second denotes the inoculation of Staph. aureus.

TABLE II

STAPHYLOCOCCUS

\begin{tabular}{|c|c|c|c|c|c|c|c|c|c|c|c|c|}
\hline August. & 3 & 5 & 7 & 9 & 11 & 13 & 15 & 17 & 19 & 21 & 23 & 25 \\
\hline $\begin{array}{l}\text { Sheep No. } 110 \\
\text { White cells } \times 1 \\
\text { Bands ... } \\
\text { Polymorphs } \\
\text { Lymphocytes } \\
\text { Large lymphocyt } \\
\text { Monocytes } \\
\text { Eosinophils } \\
\text { Basophils } \\
\text { Haemoglobin }\end{array}$ & $\begin{array}{l}10^{3} \\
\ldots \\
\ldots \\
\ldots \\
\text { tes } \\
\ldots \\
\ldots \\
\ldots \\
\ldots\end{array}$ & 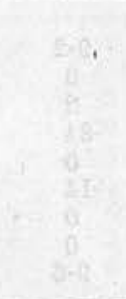 & $\begin{array}{c}9 \cdot 5 \\
2 \\
39 \\
33 \\
18 \\
7 \\
1 \\
0 \\
12 \cdot 8\end{array}$ & $\begin{array}{c}18 \cdot 1 \\
1 \\
55 \\
23 \\
15 \\
5 \\
1 \\
0 \\
12 \cdot 2\end{array}$ & $\begin{array}{c}8 \cdot 8 \\
2 \\
31 \\
42 \\
12 \\
10 \\
3 \\
0 \\
12 \cdot 0\end{array}$ & $\begin{array}{c}13 \cdot 0 \\
0 \\
41 \\
44 \\
11 \\
4 \\
0 \\
0 \\
11 \cdot 8\end{array}$ & $\begin{array}{c}9 \cdot 8 \\
0 \\
44 \\
40 \\
12 \\
3 \\
0 \\
1 \\
11 \cdot 1\end{array}$ & $\begin{array}{c}8 \cdot 0 \\
0 \\
58 \\
32 \\
2 \\
4 \\
3 \\
1 \\
10 \cdot 1\end{array}$ & $\begin{array}{c}7 \cdot 8 \\
0 \\
34 \\
49 \\
11 \\
4 \\
1 \\
1 \\
11 \cdot 4\end{array}$ & $\begin{array}{c}7 \cdot 4 \\
1 \\
33 \\
54 \\
5 \\
6 \\
1 \\
0 \\
11 \cdot 3\end{array}$ & $\begin{array}{c}11 \cdot 4 \\
0 \\
38 \\
52 \\
5 \\
4 \\
1 \\
0 \\
12 \cdot 0\end{array}$ & $\begin{array}{r}17 \cdot 6 \\
4 \\
48 \\
36 \\
5 \\
1 \\
4 \\
2 \\
12 \cdot 0\end{array}$ \\
\hline $\begin{array}{l}\text { Sheep No. } 111 \\
\text { White cells } \times 1 \\
\text { Bands ... } \\
\text { Polymorphs } \\
\text { Lymphocytes } \\
\text { Large lymphocyt } \\
\text { Monocytes } \\
\text { Eosinophils } \\
\text { Basophils } \\
\text { Haemoglobin }\end{array}$ & $\begin{array}{c}10^{3} \\
\ldots \\
\ldots \\
\ldots \\
\text { tes } \\
\ldots \\
\ldots \\
\ldots \\
\ldots\end{array}$ & 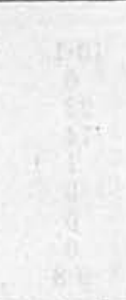 & $\begin{array}{c}14 \cdot 8 \\
3 \\
20 \\
52 \\
17 \\
7 \\
0 \\
1 \\
12 \cdot 7\end{array}$ & $\begin{array}{c}16 \cdot 8 \\
13 \\
29 \\
36 \\
17 \\
4 \\
1 \\
0 \\
9 \cdot 2\end{array}$ & $\begin{array}{c}9 \cdot 6 \\
7 \\
33 \\
50 \\
5 \\
5 \\
0 \\
0 \\
10 \cdot 6\end{array}$ & $\begin{array}{l}9 \cdot 2 \\
10 \\
20 \\
62 \\
5 \\
3 \\
0 \\
0 \\
9 \cdot 8\end{array}$ & $\begin{array}{c}9 \cdot 4 \\
13 \\
21 \\
56 \\
4 \\
6 \\
0 \\
0 \\
10 \cdot 0\end{array}$ & $\begin{array}{c}9 \cdot 5 \\
2 \\
35 \\
53 \\
5 \\
5 \\
0 \\
0 \\
9 \cdot 4\end{array}$ & $\begin{array}{c}10 \cdot 1 \\
1 \\
49 \\
35 \\
6 \\
8 \\
1 \\
0 \\
8 \cdot 8\end{array}$ & $\begin{array}{c}19 \cdot 3 \\
0 \\
59 \\
28 \\
8 \\
4 \\
1 \\
0 \\
9 \cdot 6\end{array}$ & $\begin{array}{c}19 \cdot 0 \\
0 \\
61 \\
30 \\
6 \\
3 \\
0 \\
0 \\
8 \cdot 7\end{array}$ & $\begin{array}{c}7 \cdot 9 \\
0 \\
56 \\
35 \\
7 \\
2 \\
0 \\
0 \\
8 \cdot 4\end{array}$ \\
\hline $\begin{array}{l}\text { Sheep No. } 112 \\
\text { White cells } \times 1 \\
\text { Bands ... } \\
\text { Polymorphs } \\
\text { Lymphocytes } \\
\text { Large lymphocyt } \\
\text { Monocytes } \\
\text { Eosinophils } \\
\text { Basophils } \\
\text { Haemoglobin }\end{array}$ & $\begin{array}{l}10^{3} \\
\ldots \\
\ldots \\
\ldots \\
\text { tes } \\
\ldots \\
\ldots \\
\ldots \\
\ldots\end{array}$ & the & $\begin{array}{c}8 \cdot 7 \\
0 \\
38 \\
41 \\
14 \\
6 \\
0 \\
1 \\
12 \cdot 7\end{array}$ & $\begin{array}{c}9 \cdot 2 \\
6 \\
37 \\
39 \\
8 \\
9 \\
1 \\
0 \\
12 \cdot 0\end{array}$ & $\begin{array}{c}7 \cdot 2 \\
5 \\
29 \\
39 \\
13 \\
12 \\
1 \\
1 \\
12 \cdot 0\end{array}$ & $\begin{array}{c}11 \cdot 2 \\
3 \\
10 \\
63 \\
17 \\
7 \\
0 \\
0 \\
10 \cdot 3\end{array}$ & $\begin{array}{c}6 \cdot 7 \\
0 \\
37 \\
45 \\
13 \\
5 \\
0 \\
0 \\
11 \cdot 5\end{array}$ & $\begin{array}{r}7 \cdot 4 \\
4 \\
25 \\
53 \\
6 \\
12 \\
0 \\
0 \\
11 \cdot 8\end{array}$ & $\begin{array}{r}11 \cdot 8 \\
0 \\
55 \\
28 \\
7 \\
10 \\
0 \\
0 \\
11 \cdot 8\end{array}$ & $\begin{array}{c}10 \cdot 3 \\
0 \\
58 \\
32 \\
6 \\
4 \\
0 \\
0 \\
12 \cdot 0\end{array}$ & $\begin{array}{c}6 \cdot 7 \\
0 \\
50 \\
40 \\
5 \\
4 \\
1 \\
0 \\
10.9\end{array}$ & $\begin{array}{c}7 \cdot 4 \\
0 \\
58 \\
32 \\
5 \\
3 \\
2 \\
0 \\
10 \cdot 5\end{array}$ \\
\hline
\end{tabular}


TABLB II-continued

LOUPING-ILI

\begin{tabular}{|c|c|c|c|c|c|c|c|c|c|c|c|c|c|}
\hline August. & & 3 & 5 & 7 & 9 & 11 & 13 & 15 & 37 & 19 & 21 & 23 & 25 \\
\hline $\begin{array}{l}\text { Sheep No. } 116 \\
\text { White cells } \times 1 \\
\text { Bands ... } \\
\text { Polymorphs } \\
\text { Lymphocytes } \\
\text { Large lymphocyt } \\
\text { Monocytes } \\
\text { Eosinophils } \\
\text { Basophils } \\
\text { Haemoglobin }\end{array}$ & $\begin{array}{c}10^{3} \\
\cdots \\
\cdots \\
\cdots \\
\text { ytes } \\
\cdots \\
\cdots \\
\cdots \\
\cdots\end{array}$ & . & $\begin{array}{c}11 \cdot 6 \\
4 \\
14 \\
60 \\
15 \\
6 \\
1 \\
0 \\
12 \cdot 0\end{array}$ & $\begin{array}{c}11 \cdot 0 \\
6 \\
22 \\
45 \\
19 \\
7 \\
1 \\
0 \\
13 \cdot 0\end{array}$ & $\begin{array}{c}8 \cdot 8 \\
3 \\
40 \\
44 \\
11 \\
2 \\
0 \\
0 \\
13 \cdot 4\end{array}$ & $\begin{array}{c}14 \cdot 4 \\
0 \\
13 \\
69 \\
15 \\
3 \\
0 \\
0 \\
12 \cdot 7\end{array}$ & $\begin{array}{c}14 \cdot 2 \\
0 \\
23 \\
64 \\
5 \\
8 \\
0 \\
0 \\
11 \cdot 9\end{array}$ & $\begin{array}{c}10 \cdot 0 \\
1 \\
31 \\
58 \\
3 \\
6 \\
1 \\
0 \\
13 \cdot 3\end{array}$ & $\begin{array}{c}11 \cdot 2 \\
0 \\
34 \\
51 \\
7 \\
5 \\
2 \\
1 \\
12 \cdot 4\end{array}$ & $\begin{array}{c}11 \cdot 0 \\
3 \\
32 \\
56 \\
4 \\
3 \\
2 \\
0 \\
11 \cdot 7\end{array}$ & $\begin{array}{c}11 \cdot 9 \\
1 \\
40 \\
45 \\
7 \\
3 \\
3 \\
1 \\
12 \cdot 7\end{array}$ & $\begin{array}{c}11 \cdot 2 \\
0 \\
34 \\
51 \\
8 \\
1 \\
6 \\
0 \\
12 \cdot 3\end{array}$ & $\begin{array}{c}9 \cdot 2 \\
0 \\
30 \\
59 \\
6 \\
1 \\
4 \\
0 \\
12 \cdot 0\end{array}$ \\
\hline $\begin{array}{l}\text { Sheep No. } 117 \\
\text { White cells } \times 1 \\
\text { Bands ... } \\
\text { Polymorphs } \\
\text { Lymphocytes } \\
\text { Large lymphocyt } \\
\text { Monocytes } \\
\text { Eosinophils } \\
\text { Basophils } \\
\text { Haemoglobin }\end{array}$ & $\begin{array}{c}10^{3} \\
\cdots \\
\cdots \\
\cdots \\
\cdots \\
\cdots \\
\cdots \\
\cdots \\
\cdots\end{array}$ & & $\begin{array}{c}9 \cdot 0 \\
3 \\
33 \\
29 \\
28 \\
5 \\
1 \\
1 \\
15 \cdot 0\end{array}$ & $\begin{array}{c}12 \cdot 6 \\
2 \\
36 \\
50 \\
6 \\
4 \\
2 \\
0 \\
13 \cdot 3\end{array}$ & $\begin{array}{c}13 \cdot 6 \\
0 \\
48 \\
42 \\
4 \\
6 \\
0 \\
0 \\
13 \cdot 5\end{array}$ & $\begin{array}{c}8 \cdot 2 \\
1 \\
17 \\
73 \\
4 \\
5 \\
0 \\
0 \\
12 \cdot 0\end{array}$ & $\begin{array}{c}11 \cdot 4 \\
0 \\
39 \\
47 \\
3 \\
9 \\
1 \\
1 \\
13 \cdot 4\end{array}$ & $\begin{array}{c}11 \cdot 2 \\
2 \\
29 \\
61 \\
4 \\
3 \\
1 \\
0 \\
12 \cdot 5\end{array}$ & $\begin{array}{c}10 \cdot 0 \\
0 \\
40 \\
47 \\
10 \\
1 \\
1 \\
1 \\
12 \cdot 0\end{array}$ & $\begin{array}{c}9 \cdot 9 \\
0 \\
29 \\
60 \\
2 \\
7 \\
1 \\
1 \\
13 \cdot 5\end{array}$ & $\begin{array}{c}10 \cdot 9 \\
0 \\
23 \\
51 \\
14 \\
9 \\
3 \\
0 \\
12 \cdot 6\end{array}$ & $\begin{array}{c}8 \cdot 6 \\
0 \\
41 \\
47 \\
4 \\
7 \\
1 \\
0 \\
12 \cdot 8\end{array}$ & $\begin{array}{c}10 \cdot 4 \\
0 \\
26 \\
54 \\
12 \\
1 \\
7 \\
0 \\
12 \cdot 8\end{array}$ \\
\hline $\begin{array}{l}\text { Sheep No. } 118 \\
\text { White cells } \times 1 \\
\text { Bands } \ldots \\
\text { Polymorphs } \\
\text { Lymphocytes } \\
\text { Large lymphocyt } \\
\text { Monocytes } \\
\text { Eosinophils } \\
\text { Basophils } \\
\text { Haemoglobin }\end{array}$ & $\begin{array}{c}10^{3} \\
\ldots \\
\ldots \\
\ldots \\
\ldots \\
\text { tes } \\
\ldots \\
\ldots \\
\ldots \\
\ldots\end{array}$ & & $\begin{array}{c}9 \cdot 8 \\
3 \\
24 \\
46 \\
22 \\
4 \\
1 \\
0 \\
11 \cdot 2\end{array}$ & $\begin{array}{c}10 \cdot 0 \\
3 \\
30 \\
44 \\
18 \\
5 \\
0 \\
0 \\
12 \cdot 5\end{array}$ & $\begin{array}{c}9 \cdot 5 \\
0 \\
35 \\
41 \\
17 \\
7 \\
0 \\
0 \\
11 \cdot 6\end{array}$ & $\begin{array}{c}9 \cdot 2 \\
0 \\
16 \\
65 \\
16 \\
3 \\
0 \\
0 \\
12 \cdot 1\end{array}$ & $\begin{array}{c}9 \cdot 6 \\
2 \\
32 \\
49 \\
8 \\
8 \\
1 \\
0 \\
9 \cdot 8\end{array}$ & $\begin{array}{c}10 \cdot 2 \\
0 \\
52 \\
31 \\
13 \\
4 \\
0 \\
0 \\
10 \cdot 9\end{array}$ & $\begin{array}{c}7 \cdot 7 \\
0 \\
56 \\
23 \\
17 \\
3 \\
1 \\
0 \\
10 \cdot 6\end{array}$ & $\begin{array}{c}9 \cdot 4 \\
1 \\
37 \\
38 \\
20 \\
2 \\
2 \\
0 \\
10 \cdot 4\end{array}$ & $\begin{array}{c}7 \cdot 5 \\
0 \\
25 \\
59 \\
14 \\
2 \\
0 \\
0 \\
10 \cdot 0\end{array}$ & $\begin{array}{c}10 \cdot 0 \\
0 \\
28 \\
53 \\
6 \\
8 \\
3 \\
2 \\
9 \cdot 8\end{array}$ & $\begin{array}{c}11 \cdot 2 \\
1 \\
37 \\
50 \\
5 \\
3 \\
3 \\
1 \\
9 \cdot 5\end{array}$ \\
\hline
\end{tabular}

TICK-BORNE FEVER

\begin{tabular}{|c|c|c|c|c|c|c|c|c|c|c|c|c|c|}
\hline August. & & 3 & 5 & 7 & 9 & 11 & 13 & 15 & 17 & 19 & 21 & 23 & 25 \\
\hline \multicolumn{14}{|c|}{ Sheep No. 113} \\
\hline White cells $\times 1$ & $10^{3}$ & $11 \cdot 6$ & $8 \cdot 3$ & $4 \cdot 4$ & $7 \cdot 6$ & $5 \cdot 8$ & $13 \cdot 1$ & $5 \cdot 4$ & $6 \cdot 8$ & $9 \cdot 2$ & $8 \cdot 7$ & $6 \cdot 5$ & $10 \cdot 8$ \\
\hline Bands $\quad \ldots$ & $\ldots$ & 0 & 0 & 0 & 0 & 0 & 0 & 0 & 0 & 0 & 0 & 0 & 2 \\
\hline Polymorphs & $\ldots$ & 23 & 30 & 39 & 33 & 26 & 5 & 10 & 24 & 2 & 25 & 37 & 42 \\
\hline Lymphocytes & ... & 52 & 16 & 44 & 51 & 65 & 88 & 69 & 71 & 84 & 70 & 52 & 41 \\
\hline Large lymphocyt & tes & 11 & 12 & 3 & 3 & 3 & 1 & 13 & 2 & 0 & 0 & 2 & 8 \\
\hline Monocytes & $\ldots$ & 13 & 10 & 12 & 11 . & 3 & 6 & 7 & 2 & 14 & 4 & 8 & 3 \\
\hline Eosinophils & $\ldots$ & 1 & 2 & 2 & 1 & 3 & 0 & 1 & $\overline{1}$ & 0 & 1 & 0 & 4 \\
\hline Basophils & $\cdots$ & 0 & 0 & 0 & 1 & 0 & 0 & 0 & 0 & 0 & 0 & 1 & 0 \\
\hline Haemoglobin & $\cdots$ & 13.0 & $11 \cdot 5$ & $12 \cdot 4$ & $11 \cdot 6$ & $10 \cdot 4$ & $10 \cdot 2$ & $11 \cdot 9$ & $10 \cdot 4$ & $9 \cdot 6$ & $11 \cdot 0$ & $9 \cdot 7$ & $9 \cdot 8$ \\
\hline \multicolumn{14}{|c|}{ Case No. 114} \\
\hline White cells $\times 1$ & $10^{3}$ & $9 \cdot 2$ & $15 \cdot 2$ & $11 \cdot 4$ & $10 \cdot 1$ & $8 \cdot 4$ & $8 \cdot 8$ & $11 \cdot 6$ & $9 \cdot 0$ & $10 \cdot 1$ & $11 \cdot 5$ & $13 \cdot 3$ & $14 \cdot 2$ \\
\hline Bands $\quad \ldots$ & $\cdots$ & 0 & 2 & 0 & 0 & 0 & 0 & 0 & 0 & 0 & 0 & 0 & 0 \\
\hline Polymorphs & $\ldots$ & 21 & 25 & 39 & 40 & 18 & 19 & 20 & 25 & 22 & 26 & 32 & 32 \\
\hline Lymphocytes & $\ldots$ & 50 & 64 & 48 & 44 & 72 & 71 & 70 & 68 & 74 & 73 & 68 & 62 \\
\hline Large lymphocyt & tes & 14 & 4 & 7 & 7 & 5 & 4 & 6 & 2 & 1 & 0 & 0 & 0 \\
\hline Monocytes & ... & 15 & 4 & 5 & 5 & 4 & 6 & 3 & 5 & 3 & 0 & 0 & 0 \\
\hline Eosinophils & $\ldots$ & 0 & 1 & 1 & 1 & 1 & 0 & 0 & 0 & 0 & 1 & 0 & 6 \\
\hline Basophils & $\ldots$ & 0 & 0 & 0 & 3 & 0 & 0 & 1 & 0 & 0 & 0 & 0 & 0 \\
\hline Haemoglobin & $\cdots$ & $13 \cdot 4$ & $11 \cdot 6$ & $11 \cdot 6$ & $11 \cdot 1$ & $11 \cdot 9$ & $9 \cdot 8$ & $11 \cdot 0$ & $9 \cdot 0$ & $9 \cdot 8$ & $9 \cdot 8$ & $8 \cdot 5$ & 8.9 \\
\hline \multicolumn{14}{|c|}{ Sheep No. 115} \\
\hline White cells $\times 1$ & $10^{3}$ & $11 \cdot 0$ & $12 \cdot 1$ & $8 \cdot 8$ & $9 \cdot 2$ & $8 \cdot 8$ & $11 \cdot 4$ & $8 \cdot 4$ & $9 \cdot 6$ & $12 \cdot 1$ & $15 \cdot 1$ & $13 \cdot 3$ & $14 \cdot 3$ \\
\hline Bands $\quad \ldots$. & ... & 1 & 0 & 0 & 0 & 1 & 0 & 0 & 0 & 0 & 0 & 1 & 0 \\
\hline Polymorphs & $\ldots$ & 16 & 30 & 41 & 25 & 10 & 10 & 6 & 26 & 16 & 20 & 31 & 30 \\
\hline Lymphocytes & $\ldots$ & 65 & 45 & 43 & 52 & 79 & 82 & 88 & 63 & 77 & 53 & 61 & 61 \\
\hline Large lymphocyt & tes & 8 & 18 & 6 & 6 & 1 & 5 & 3 & 6 & 0 & 10 & .0 & 0 \\
\hline Monocytes & ... & 6 & 4 & 8 & 17 & ] & 3 & 3 & 5 & 2 & 4 & 1 & 3 \\
\hline Eosinophils & $\ldots$ & 4 & 2 & 1 & 0 & 0 & 0 & 0 & 0 & 5 & 9 & 4 & 1 \\
\hline Basophils & ... & 0 & 1 & 1 & 0 & 0 & 0 & 0 & 0 & 0 & 4 & 2 & 5 \\
\hline Haemoglobin & ... & $13 \cdot 4$ & $11 \cdot 6$ & $12 \cdot 3$ & $12 \cdot 2$ & $10 \cdot 6$ & $30 \cdot 6$ & $11 \cdot 7$ & $10 \cdot 6$ & $11 \cdot 5$ & $12 \cdot 0$ & $11 \cdot 0$ & $12 \cdot 0$ \\
\hline
\end{tabular}


TABLE II-continued

Staphylococcus. Tick-Borne Fever

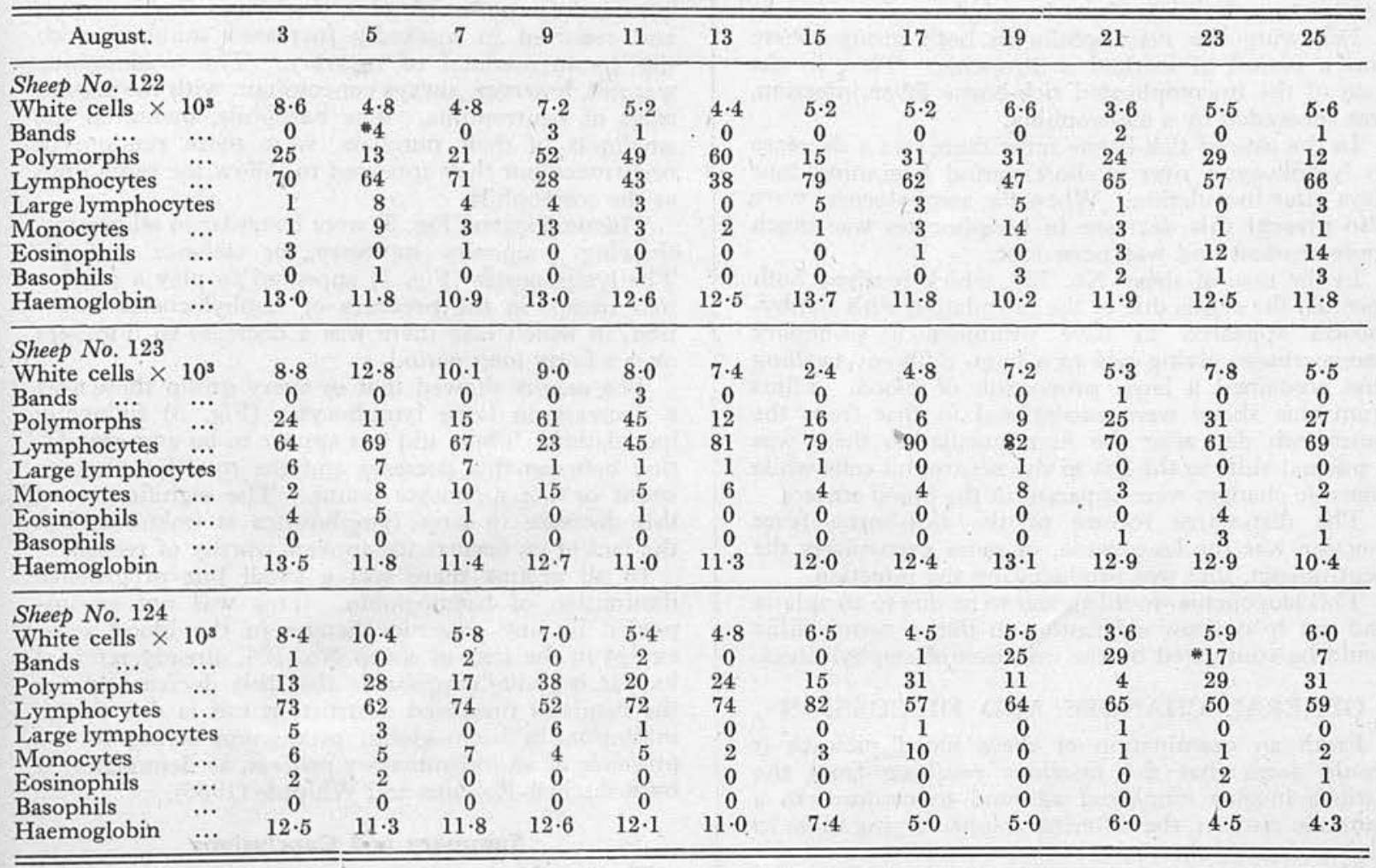

* = One young form

STAPHYLOCOCCUS. LOUPING-ILL

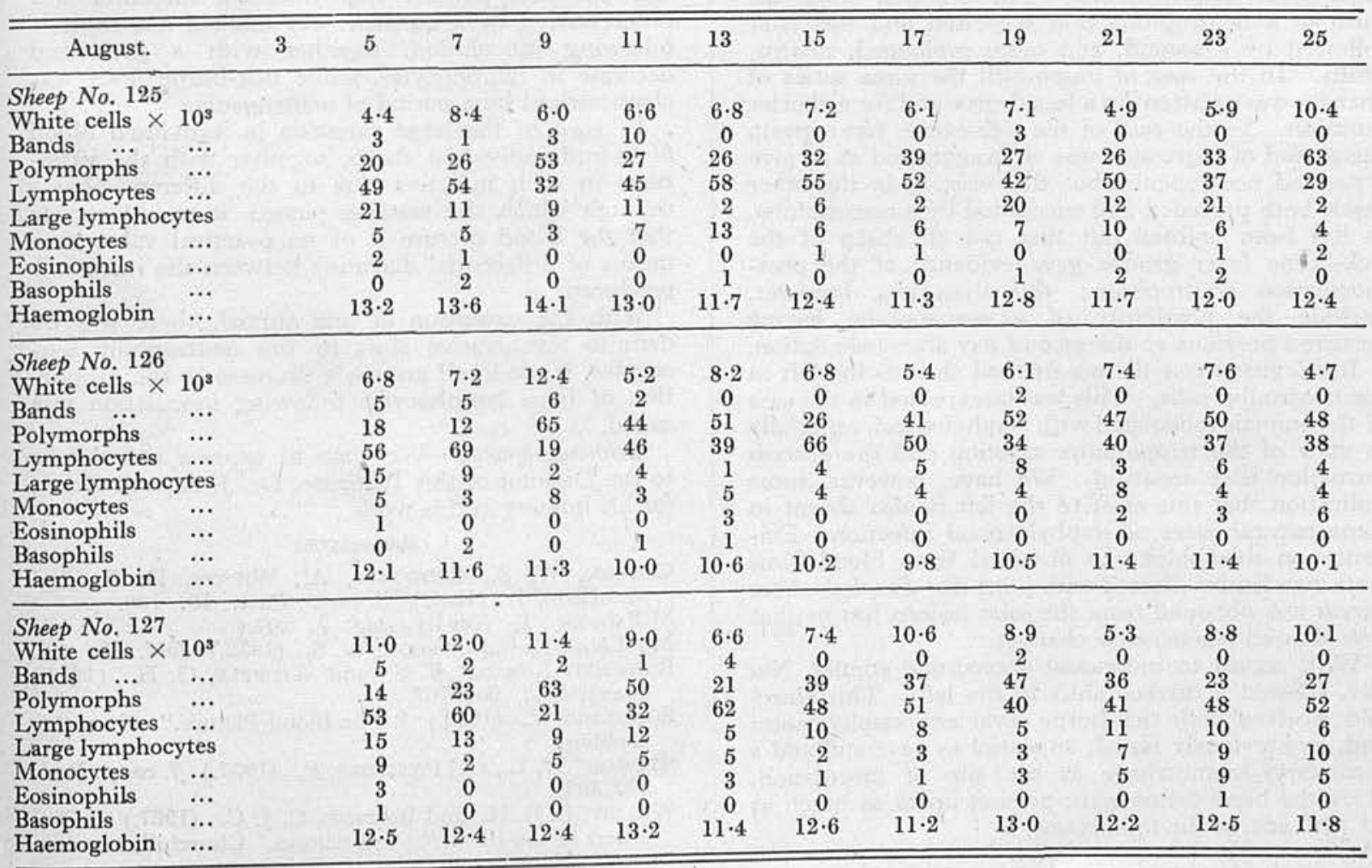


previous to the inoculation of staphylococci. In this group a transient neutrophilia was, however, caused by the secondary injection of staphylococci.

Following the neutrophilia in both groups there was a period of marked neutropenia. This, in the case of the uncomplicated tick-borne fever infection, was succeeded by a neutrophilia.

In the case of tick-borne fever there was a decrease in lymphocytes over a short period beginning four days after inoculation. When the staphylococci were also present this decrease in lymphocytes was much more marked and was persistent.

In the case of sheep No. 124, which received both inocula, the sepsis due to the inoculation with staphylococci appeared to have produced a secondary haemorrhage, giving rise to a large diffluent swelling that contained a large proportion of blood. Films from this sheep were exceptional in that from the fourteenth day after the first inoculation there was a marked shift to the left in the neutrophil cells while anaemic changes were apparent in the blood smears.

The distinctive feature of the tick-borne fever reaction was the leucopenia, or more particularly the neutropenia, that was produced by the infection.

This leucopenia would appear to be due to an aplasia and not to marrow exhaustion in that a neutrophilia could be stimulated by the injection of staphylococci.

\section{GENERAL CHANGES AND DISCUSSION}

From an examination of these blood pictures it would seem that the reactions resulting from the various inocula employed all tend to conform to a common pattern, the differing results varying more in degree than in character.

The changes in the absolute numbers of neutrophils were most apparent in the case of sheep inoculated with staphylococci. The reaction took the form of a neutrophilia that regressed and was later followed by a second, and more prolonged, neutrophilia. In the case of louping-ill the same series of changes was apparent in a less degree and for a shorter duration. In the case of the tick-borne fever group the period of regression was so exaggerated as to give a marked neutropenia, but this was, as in the other cases, both preceded and succeeded by a neutrophilia. It has been pointed out that not all sheep of the tick-borne fever groups gave evidence of the postinoculation neutrophilia; this does not, however, exclude the possibility of a neutrophilia having occurred previous to the second day after inoculation.

In no group was there a marked shift to the left in the neutrophil cells. This was unexpected in the case of the animals inoculated with staphylococci, especially in view of the temperature reaction and the abscess formation that occurred. We have, however, some indication that this shift to the left is also absent in some natural cases of staphylococcal infection. Evidence on this point was obtained from blood films from two lambs affected with joint-ill. Staphylococcus aureus was obtained from the joint lesions but neither case showed regenerative changes.

With regard to individual sheep, one animal, No. 124 , showed a marked shift to the left. This sheep had received both tick-borne fever and staphylococci and, as previously noted, appeared to have suffered a secondary haemorrhage at the site of inoculation. Here the band forms were present up to as much as 29 per cent. of the total count.
The reaction of the eosinophil cells (Fig. 2) was essentially the same in all groups. These cells disappeared from the blood a few days after infection and recurred in markedly increased numbers with the commencement of recovery. This eosinophilia was not, however, always concomitant with the second stage of neutrophilia. The basophils, owing to the smallness of their numbers, were more random in occurrence but they appeared to follow the same lines as the eosinophils.

The monocytes (Fig. 3) were irregular in all groups, showing temporary increases, or defence periods. The lymphocytes (Fig. 1) appeared to play a passive part except in the presence of staphylococcal infection, in which case there was a decrease in numbers over a fairly long period.

The results showed that in every group there was a decrease in large lymphocytes (Fig. 3) following inoculation. There did not appear to be any correlation between this decrease and the total lymphocyte count or the monocyte count. The significance of this decrease in large lymphocytes is unknown but the fact of its occurrence appears worthy of record.

In all groups there was a small but progressive diminution of haemoglobin. This was not accompanied by any anaemic changes in the blood cells, except in the case of sheep No. 124, already referred to. It is thought probable that this decrease is not the result of increased destruction but is due to the inhibition in haemoglobin production owing to the presence of an inflammatory process, as demonstrated by Robscheit-Robbins and Whipple (1936).

\section{Summary and Conclusions}

The results showed that each infection produced a similar series of changes in the blood picture. From this common pattern staphylococcal infection was differentiated by a transient but marked neutrophilia following inoculation, together with a prolonged decrease in lymphocytes, while tick-borne fever was characterised by a period of neutropenia.

In view of the large variation in individual blood films and individual sheep, together with the variations in each infection due to the different phases through which the reaction passed, it would appear that the blood picture is of no practical value as a means of differential diagnosis between the infections produced.

With the exception of one animal, there was no definite regenerative shift in the neutrophilic leucocytes, while in all groups a decrease in the proportion of large lymphocytes following inoculation was noted.

Acknowledgment.-We wish to express our thanks to the Director of this Institute, Dr. J. Russell Greig, for his interest in this work.

\section{REFERENCES}

Gordon, W. S., Brownlee, A., Wilson, D. R., and MacLeod, J. .'(1932.) f. comp. Path. 45. 106.

M'Fadyean, J. (1894.) Ibid. 7. 207.

MacLeOd, J., and Gordon, W. S. (1932.) Ibid. 45. 240.

RobscheIt-Robins, F. S., and Whipple, G. H. (1936.) f. $\exp$. Med. 63. 767 .

Schilling, V. (1929.) "The Blood Picture." Kimpton, London.

Stewart, W. L., and Ponsford, P. (1937.) F. comp. Path. 50. 395.

WhitBy, L. E. H., and Britron, C. J. C. (1937.) "Disorders of the Blood." 2nd edition. Churchill, London. 